Arnaldo Oliveira Lima

MÉTODO NUMÉRICO PARA DETERMINAÇÃO DO COEFICIENTE DE ATRITO AO LONGO DA SUPERFÍCIE EM CONTATO LUBRIFICADO

São Paulo

2019 
Arnaldo Oliveira Lima

MÉTODO NUMÉRICO PARA DETERMINAÇÃO DO COEFICIENTE DE ATRITO AO LONGO DA SUPERFÍCIE EM CONTATO LUBRIFICADO

Dissertação apresentada à Escola Politécnica da Universidade de São Paulo para obtenção do título de Mestre em Ciências

São Paulo

2019 
Arnaldo Oliveira Lima

\section{MÉTODO NUMÉRICO PARA DETERMINAÇÃO DO COEFICIENTE DE ATRITO AO LONGO DA SUPERFÍCIE EM CONTATO LUBRIFICADO}

Dissertação apresentada à Escola Politécnica da Universidade de São Paulo para obtenção do título de Mestre em Ciências

Área de Concentração: Engenharia Mecânica de Projeto e Fabricação

Orientadora: Prof ${ }^{\mathrm{a}}$. Dra. Izabel Fernanda Machado

Coorientador: Prof. Dr. Newton Kiyoshi Fukumasu

São Paulo 2019 
Autorizo a reprodução e divulgação total ou parcial deste trabalho, por qualquer meio convencional ou eletrônico, para fins de estudo e pesquisa, desde que citada a fonte

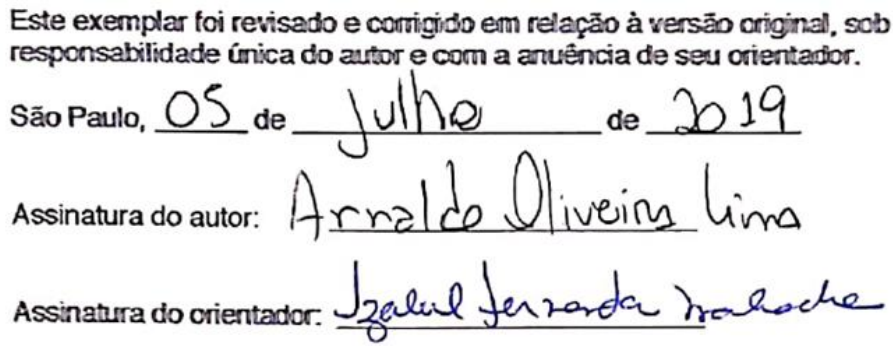

\section{Lima, Arnaldo Oliveira}

Método numérico para determinação do coeficiente de atrito ao longo da superfície de contato lubrificado / A. O. Lima - versão corr. -- São Paulo, 2019. $93 \mathrm{p}$.

Dissertação (Mestrado) - Escola Politécnica da Universidade de São Paulo. Departamento de Engenharia Mecatrônica e de Sistemas Mecânicos.

1.Coeficiente de atrito 2.Eficiência 3.Método de Elementos Finitos 4.Engrenagem helicoidal 5.Curva de Stribeck I.Universidade de São Paulo. Escola Politécnica. Departamento de Engenharia Mecatrônica e de Sistemas Mecânicos II.t. 
DEDICATÓRIA

Dedico este trabalho à Deus e a minha família, que sempre ajudaram em meus sonhos. 


\section{AGRADECIMENTOS}

A Deus por todas as bênçãos eternas e pela oportunidade de aprendizado nesta Terra.

Aos meus pais, Alberto e Ivelisa, pelo incentivo ao estudo desde criança, pela educação que veio do lar e pelo amor que levo em meu coração. Aos meus irmãos, Alberto e Caroline, pelo apoio incondicional, pelas aventuras marcantes e pela honra de fazer parte desta família.

A uma pessoa muito especial Marcionila Neli pelo apoio e incentivo. Por sempre acreditar que eu posso ir além e dar o meu melhor. Sou grato por sua sinceridade, amizade e companheirismo que me ajudaram a alcançar objetivos e sonhos.

A professora Dr. a Izabel Fernanda Machado pela orientação, dedicação, paciência, oportunidade, amizade e pelos conselhos que vou levar pra toda vida. Sou imensamente grato pelo suporte no meu desenvolvimento profissional e principalmente pessoal.

Ao professor Dr. Newton Kiyoshi Fukumasu por mostrar uma visão diferenciada para cada problema encontrado no mundo da ciência e pela paciência com os programas de simulação. Sou grato pela sua amizade e inspiração.

Ao Programa de Residência Tecnológica para Engenheiros da Fiat Chrysler Automobiles (FCA) e a Fundação Christiano Ottoni da Universidade Federal de Minas Gerais (UFMG) pelo apoio financeiro e em especial aos amigos da FCA, Dr. Guilherme Antônio Assis Machado e Thiago Petermann Figueiredo, e ao professor Dr. Alexandre Queiroz Bracarense da UFMG.

Ao Laboratório de Fenômenos de Superfície (LFS) da Escola Politécnica da Universidade de São Paulo (EPUSP) pela estrutura, licença dos programas e pela oportunidade que tive de conhecer e discutir este trabalho com os amigos Vanessa Seriacopi, Iramar Tertuliano, Ana Julia Tertuliano, Guido Boidi, Eleir Bortoleto, Karolina Tonello, Roberto Balarini, Pâmella Esteves, Pedro Tayer, Gustavo Tressia, Gustavo Siebert, Francisco Briones, Luiz Franco, Michael Cano, Juan Ignacio, Juan Acero, Marcos Ara, Deiso Zuleta, Rafael Obara, Luiz Lima, Felipe Carneiro, Carlos Ramires, Rodnei Santos, Cássio Junqueira, Rafael Melchior, Raphael Ferreira e Ricardo Manoel. 
Aos professores Dr. Roberto Martins Souza e Dr. Francisco José Profito pelas discussões e sugestões ao longo deste trabalho. Sou grato pelo exemplo de gentileza e cavalheirismo.

Ao Laboratório de Engenharia Térmica e Ambiental (LETE) da EPUSP pela licença com o programa da AVL e em especial ao professor Dr. Guenther Carlos Krieger Filho.

A AVL List Gmbh pela licença do seu programa Excite Power Unit, em especial a Renata Zava e Fillipe Santos. Ao Brett Sheets pelo suporte no uso do programa.

Aos amigos que incentivaram a prosseguir neste objetivo de vida professora Giseli Aparecida, professora Marcia Varella, Alex Trevisan, Giulia Tesser, Talytha Lima, Paulo Rogério Renk, Valdir Feijóo, Antônio Castro, Carlos Premazzi, Vagner Pierri, Antonio Carlos Rissan, Everton Reis, Daniel Takao, Thiago Lira, Carina dos Santos, Eduardo Nishimoto, Michele Rufino, André e Karina Yudi, Caio e Debora Zara, Fabio e Maria Fukuda, Leonardo Hamamoto, Salomão Elias Kim e aos demais amigos (as) que possuo um carinho especial.

E por fim, mas não o menos importante, quero deixar meu agradecimento especial ao Cassiano Ferreira Bernardes que sempre esteve próximo em momentos muito importantes durante estes últimos 10 anos e aceitou comigo esta jornada marcante. Sou grato pelos seus conselhos, broncas, risadas e por auxiliar nas Escrituras. Segundo João 15:13 "Ninguém tem maior amor do que este: de dar alguém a sua vida pelos seus amigos". 
Provérbios 22:1 "Mais digno de ser escolhido é o bom nome do que as muitas riquezas; e a graça é melhor do que a riqueza e o ouro." 


\section{RESUMO}

A eficiência dos sistemas mecânicos é influenciada diretamente pelo coeficiente de atrito local, sendo este relacionado com os regimes de lubrificação. O coeficiente de atrito pode ser estudado usando o método de elementos finitos (MEF) com a finalidade de substituir ensaios experimentais e reduzir tempo de análise. Esta dissertação teve como objetivo desenvolver uma metodologia para avaliar o coeficiente de atrito em um par tribológico e seu efeito na eficiência por simulação numérica. Para esta modelagem foi definido um sistema composto por um par de engrenagens helicoidais. Em uma primeira análise, foi empregado o programa AVL Excite Power Unit, que utiliza a ferramenta MBD (MultiBody Dynamic - Dinâmica de Multi-Corpos), possibilitando a simulação da transmissão com seus principais elementos em um modelo $1 \mathrm{D}$, que leva em consideração a teoria da lubrificação elastohidrodinâmica (EHL). Também foi utilizado o programa Abaqus®, da Dassault Systèmes, para a criação de um modelo 3D, que considera o par engrenado e sendo necessário o desenvolvimento de uma subrotina para a aplicação do modelo de lubrificação da literatura. Em todas as simulações foram considerados condições de operação de um banco de provas e três diferentes acabamentos superficiais dos dentes das engrenagens em função do processo de fabricação: fresamento, retificação e polimento. Além da rugosidade, avaliou-se o efeito da velocidade angular nas perdas do sistema. $\mathrm{O}$ modelo 3D foi comparado com o modelo 1D e com resultados de eficiência de ensaios de banco de prova. O modelo 3D permitiu avaliar o coeficiente de atrito local na linha de contato do dente engrenado. Maiores velocidades angulares aumentaram a espessura de específica de filme, diminuindo assim o coeficiente de atrito e promovendo uma melhoria na eficiência do sistema. Os menores valores de coeficiente de atrito estão na região do diâmetro primitivo, onde o SRR é nulo. A velocidade angular influenciou mais do que a rugosidade. As análises dos modelos 1D e 3D indicaram que o modelo 1D superestima a eficiência da transmissão, enquanto que o modelo 3D apresentou resultados compatíveis com o banco de provas. 


\begin{abstract}
The efficiency of mechanical systems is influenced directly by the local friction coefficient, which is related to the lubrication regimes. The coefficient of friction can be studied using the finite element method (FEM) to replace experimental tests and reduce analysis time. This dissertation had the objective to develop a methodology to evaluate the coefficient of friction in a tribological pair and the effect on the efficiency by numerical simulation. In this model, a system composed of a pair of helical gears was defined. In a first analysis, the AVL Excite Power Unit software was used, which uses the tool MBD (Multi-Body Dynamic), enabling the simulation of the transmission with the main elements in a 1D model, which takes into account the theory of elastohydrodynamic lubrication (EHL). The Abaqus ${ }^{\circledR}$ software was used to create a 3D model, which considers the pair of helical gear and a developed subroutine for application of the literature lubrication model. In all simulations, the conditions of operation of a rig tests and three different surface finishes of the gear teeth were considered, depending on the manufacturing process: milling, grinding and polishing. Besides the roughness, the effect of angular velocity on the losses of the system was evaluated. The 3D model was compared with the 1D model and with the results of rig tests efficiency. The 3D model allowed to evaluate the coefficient of local friction in the contact line of the tooth. Higher angular velocities increased the film specific thickness, thus reducing the coefficient of friction and promoting an improvement in the efficiency of the system. The lowest values of coefficient of friction are in the region of the primitive diameter, there the SRR is zero. The angular velocity influenced more than the roughness. The analyzes of the $1 \mathrm{D}$ and $3 \mathrm{D}$ models indicated that the 1D model overestimates the transmission efficiency, while the 3D model presented results compatible with the rig tests.
\end{abstract}




\section{LISTA DE FIGURAS}

Figura 1 - Esquema da distribuição de tensão em contato de Hertz. (a) apresenta uma distribuição em forma de elipse e em (b), tem-se uma distribuição de tensão em forma retangular (Norton, 2013). 25

Figura 2 - Esquema de contato (a) conforme e (b) não-conforme. Adaptado de (ASM HANDBOOK, 1992). 26

Figura 3 - Esquema da curva de Stribeck, $\mu$ (coeficiente de atrito) em função de $\lambda$ (espessura específica de filme) com os regimes de lubrificação (Limítrofe, misto, EHL lubrificação elastohidrodinâmica e HL - lubrificação hidrodinâmica) e exemplos de sistemas tribológicos (rolamentos, contato de engrenagens e sistemas de anel/camisa) onde podem variar os regimes conforme as condições de funcionamento. Adaptado de (BJÖRLING, 2014; SEABRA, 2005; TERTULIANO, 2017). 28

Figura 4 - Esquema da seção transversal de um contato não-conforme com lubrificação elastohidrodinâmica. A região de entrada, onde começa a formação do filme, possui pressão praticamente nula. Na região central do contato a pressão sob e o filme diminui a espessura, também é observado a diferença de velocidades (velocidade de deslizamento) das superfícies. A pressão no contato alcança o seu valor de pico com a restrição na saída. Por fim, região de saída tem o rompimento do filme e a pressão volta a valores nulos. Adaptado de (PIRRO; WEBSTER; DASCHNER, 2016). 30 Figura 5 - a-) Esquema da configuração do ensaio em MPR. b-) Equipamento MPR. É possível observar a posição dos discos e a direção de rotação de cada um, o lubrificante e a refrigeração do mesmo e o termopar para a medição da temperatura próxima a região de contato. Adaptado de (LIN, 2013).

Figura 6 - Gráfico do coeficiente de atrito pelo número de ciclos em superfícies com diferentes Rz. Ensaio em MPR com pressão de 1,7 GPa, velocidade de 3,15 m/s, SRR de $52 \%$, temperatura de $70{ }^{\circ} \mathrm{C}$ e contato lubrificado. Adaptado de (LIN, 2013). 32 Figura 7 - Variação do coeficiente de atrito ao longo da linha de contato do engrenamento. A região A' até A representa o início do contato do engrenamento, o ponto C corresponde ao diâmetro primitivo e a região do E até E', o fim do contato do engrenamento. Adaptado de (BEILICKE; BOBACH; BARTEL, 2016) 36 Figura 8 - Malha de elementos finitos no engrenamento e detalhe do refinamento da malha no contato entre os dentes das engrenagens (PARKER; VIJAYAKAR; IMAJO, 2000). 
Figura 9 - Malha simplificada de engrenagem helicoidal apresentada por Sanchez et al. (2013) 38

Figura 10 - a-) Resultado da distribuição de tensões de Von Mises nos dentes. b-) Malha de elementos finitos usada na simulação. c-) Detalhe do refinamento da malha na região de contato dos dentes. d-) Resultado da variação das tensões de Von Mises em relação a profundidade na região de contato entre os dentes das engrenagens. Adaptado de (QIN; GUAN, 2014) 39

Figura 11 - a-) Região de contato dos pares dos dentes em vermelho. b-) Distribuição das tensões de Von Mises ao longo do perfil do dente e na região central da sua largura em um instante do engrenamento. Adaptado de (FUKUMASU et al., 2016) 40 Figura 12 - Esquematização da transmissão automotiva manual com os seus principais componentes, como eixos, engrenagens e rolamentos. A distribuição de força normal, no par de engrenagens helicoidais, está representada no detalhe. 41 Figura 13 - Modelagem do virabrequim automotivo. a- Modelagem 2D no programa da AVL Excite Power Unit. b- Modelagem 3D e malha aplicada e desenvolvida por Villalva (2014).

Figura 14 - Esquema da distribuição das perdas de energia de um veículo, popular de passeio à gasolina, viajando a $64 \mathrm{~km} / \mathrm{h}$. Adaptado de (PIRRO; WEBSTER; DASCHNER, 2016)

Figura 15 - Gráfico da variação da pressão máxima de contato, da taxa de deslizamento por rolamento e da espessura especifica do filme lubrificante ao longo do perfil do dente, para engrenagens de dente reto (AMARO, 2001). 44 Figura 16 - a- Comportamento da linha de contato em dente helicoidal. (Adaptado de Pirro, et al. (2016)); b e c-Variação da linha de contato, em destaque, dividida em dois para três dentes durante o engrenamento (Adaptado de Jabbour e Asmar 2015) 45 Figura 17 - Esquema das regiões de rolamento e deslizamento dos dentes das engrenagens adaptado com um esquema de movimento entre duas superfícies. (a) Rolamento puro, (b) combinação deslizamento e rolamento. Adaptado de Al-Tubi et al (2015) e (Matos, 2004).

Figura 18 - Esquematização da velocidade de deslizamento e rolamento ao longo do contato. Adaptado de (KLUBER, 1998).

Figura 19 - Variação do SRR em dentes helicoidais. Adaptado de (FIGUEIREDO, 2017). 
Figura 20 - Esquema dos regimes de lubrificação encontrados na superfície do dente de engrenagem. a) Para velocidade tangencial de até $5 \mathrm{~m} / \mathrm{s}$. b) Para velocidade tangencial acima de $5 \mathrm{~m} / \mathrm{s}$. Adaptado de (NAUNHEIMER et al., 2011)

Figura 21 - Variação da viscosidade em função da temperatura para o óleo SAE75W-90. Adaptado de (XLROTOR, 2016).

Figura 22 - Lubrificação na área frontal do contato. Adaptado de (PIRRO; WEBSTER; DASCHNER, 2016). 50

Figura 23 - Comportamento do coeficiente de atrito em função do SRR. Na região 1 e 3 maiores valores de $\mu$ devido ao deslizamento. Na região 2 , indicado pelo deslizamento nulo, mínimos valores de $\mu$. Adaptado de (PIRRO; WEBSTER; DASCHNER, 2016). 51 Figura 24 - Modelo do engrenamento utilizado no programa AVL Excite Power Unit. Em azul o pinhão e em vermelho a engrenagem. 55

Figura 25 - Esquema das áreas selecionadas para avaliação topográfica, em cinza, da superfície do dente 57

Figura 26 - Modelo 1D da transmissão utilizada nas simulações com o programa AVL Excite Power Unit. Em destaque os principais elementos da transmissão, como, os eixos e o par de engrenagens..... 58

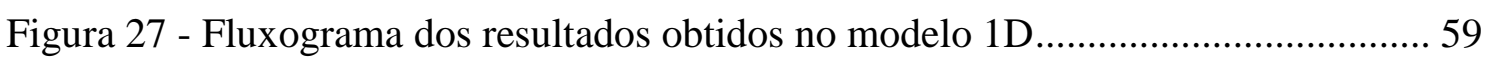

Figura 28 - Modelo 3D do par engrenado e a malha aplicada.

Figura 29 - Gráfico da variação do coeficiente de atrito pela largura do elemento. Análise realizada para verificação da convergência da malha aplicada no modelo 3D. 61 Figura 30 - Fluxograma do fluxo de processo usado na simulação com Abaqus ${ }^{\circledR}$ e subrotina.

Figura 31 - Fluxograma da metodologia utilizada neste trabalho, levando em consideração os principais fatores que foram levados em consideração nas simulações.

Figura 32 - Imagem topográfica da coroa antes do ensaio da transmissão 65 Figura 33 - a-) Imagem da topografia da coroa depois do ensaio da transmissão. A primeira imagem está a 2,5 mm da borda e as demais estão com espaçamento entre si de 2,1 mm, as áreas analisadas vão do pé do dente até o topo. b-) Esquema da face do dente da coroa onde foram analisadas as áreas das imagens.

Figura 34 - Linha de contato (linha vermelha) e linha de análise (linha amarela) dos resultados no centro do dente helicoidal.

Figura 35 - Variação da pressão de contato ao longo do engrenamento para as simulações com modelo 1D. 68 
Figura 36 - Gráfico das velocidades tangenciais do pinhão e engrenagem

Figura 37 - Gráfico das velocidades de deslizamento e rolamento ao longo da porcentagem do contato.

Figura 38 - Taxa de deslizamento para o rolamento pela porcentagem de perfil de dente engrenado.

Figura 39 - Gráfico da espessura específica de filme ao longo da porcentagem do perfil do dente

Figura 40 - Gráfico do coeficiente de atrito ao longo da porcentagem de engrenamento

Figura 41 - Gráfico da variação do coeficiente pela taxa de deslizamento pelo rolamento.

Figura 42 - Eficiência do par engrenado ao longo do perfil do dente em porcentagem para o modelo 1D. 74

Figura 43 - Gráfico de perda de torque em relação ao coeficiente de atrito. 75

Figura 44 - Variação do coeficiente de atrito na linha de contato do pinhão para $4000 \mathrm{rpm}$ e Rz de $0,5 \mu \mathrm{m}$. 76

Figura 45 - Variação do coeficiente de atrito na linha de contato do pinhão para $1000 \mathrm{rpm}$ e Rz de $0,5 \mu \mathrm{m}$.

Figura 46 - Variação do coeficiente de atrito na linha de contato do pinhão para $4000 \mathrm{rpm}$ e Rz de $7 \mu \mathrm{m}$

Figura 47 - Comparação do comportamento do coeficiente de atrito para a simulação no modelo $1 \mathrm{D}$ e modelo 3D.

Figura 48 - Comparação da eficiência obtida nos modelos 1D, 3D e de banco de prova para $1000 \mathrm{rpm}$. 80

Figura 49 - Variação do coeficiente de atrito na linha de contato do pinhão para $1000 \mathrm{rpm}$ e Rz de $0,5 \mu \mathrm{m} ; 4000 \mathrm{rpm}$ e $\mathrm{Rz}$ de $0,5 \mu \mathrm{m}$ e $7 \mu \mathrm{m}$ 82 


\section{LISTA DE TABELAS}

Tabela 1 -Tipos e exemplos de contatos conforme e não conforme. As engrenagens têm contato não-conforme linear. Adaptação de (PIRRO; WEBSTER; DASCHNER, 2016).

Tabela 2 - Dados geométricos do par engrenado ........................................................... 55

Tabela 3 - Propriedades mecânicas do par de engrenagens........................................... 55

Tabela 4 - Propriedades do óleo de transmissão comercial SAE 75W-90 (XLROTOR,

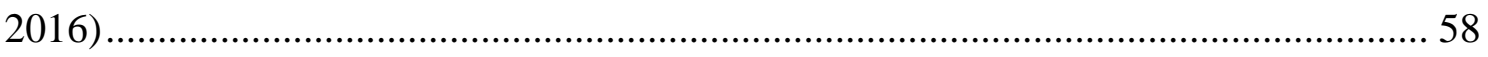

Tabela 5 - Resumo dos resultados do modelo 1D obtidos com a pressão de contato, velocidade de deslizamento e rolamento, taxa de deslizamento pelo rolamento, espessura específica de filme lubrificante, coeficiente de atrito e eficiência em relação a variação da velocidade e rugosidade................................................................................... 81 Tabela 6 - Resumo do efeito da velocidade angular e a rugosidade na variação do coeficiente de atrito para o modelo 3D. 82 


\section{ABREVIAÇÕES}

- $\quad$ RPM - Rotação por minuto

- FCA - Fiat Chrysler Automobiles

- LFS - Laboratório de Fenômenos de Superfícies

- EHL - Elastohydrodynamic Lubrication - Lubrificação elastohidrodinâmica

- EHD / HL - Hydrodynamic Lubrication - Lubrificação hidrodinâmica

- $\quad$ MPR - Micro Pitting Rig - Ensaio de micro-pitting

- $\quad \mathrm{FZG} \mathrm{-} \mathrm{Forschungsstelle} \mathrm{für} \mathrm{Zahnräder} \mathrm{und} \mathrm{Getriebebau} \mathrm{-} \mathrm{Central} \mathrm{para} \mathrm{Pesquisas}$ de Engrenagens

- $\mathrm{MEF}$ - Método de Elementos Finitos

- MBD - Multi-Body Dynamic - Dinâmica de Multi-Corpos

- ACYG - Advanced Cylindrical Gear Joint - Conector de Engrenagem Cilíndrica Avançado 


\section{LISTA DE SIMBOLOS}

- E modulo de elasticidade

- E' modulo de elasticidade reduzida

- $v \quad$ coeficiente de Poisson

- $v_{1} \quad$ coeficiente de Poisson do pinhão

- $v_{1} \quad$ coeficiente de Poisson da coroa

- G parâmetro adimensional do material

- H número de Hersey

- $\mathrm{h}_{0} \quad$ espessura de filme

- $\omega_{1}$ rotação angular do pinhão

- $\omega_{2}$ rotação angular da coroa

- U parâmetro adimensional de velocidade

- $\mathrm{U}_{1} \quad$ velocidade do pinhão

- $\mathrm{U}_{2} \quad$ velocidade da coroa

- Us velocidade de deslizamento

- $\mathrm{U}_{\mathrm{R}}$ velocidade de rolamento

- SRR razão de deslizamento e rolamento

- $V_{\Sigma \text { vert }}$ soma das velocidades perpendiculares à linha de contato

- $\eta \quad$ eficiência

- $\eta_{0} \quad$ viscosidade do lubrificante,

- $\bar{u} \quad$ velocidade média

- W parâmetro adimensional de carga

- F força normal.

- $\alpha \quad$ coeficiente de pressão-viscosidade

- $\mu \quad$ coeficiente de atrito

- $\mu_{\text {local coeficiente de atrito local }}$

- $p_{H} \quad$ pressão de contato

- $\rho_{1}$ raio de curvatura do pinhão

- $\rho_{2} \quad$ raio de curvatura da coroa

- $p_{\text {ers }}$ raio de curvatura

- $\lambda$ espessura específica de filme

- $\lambda_{z} \quad$ espessura de específica de filme relativa ao $\mathrm{Rz}$ 
- $R \quad$ rugosidade

- $R a$ média quadrática do perfil de rugosidade

- $\mathrm{Rq}$ desvio médio quadrático do perfil de rugosidade

- $\mathrm{Rz} \quad$ soma dos valores absolutos dos pontos de maiores afastamentos

- Zn altura de pico da rugosidade

- Pe potência de entrada

- Ps potência de saída

- b largura da face do dente

- $\quad \beta \quad$ ângulo de hélice do dente da engrenagem

- $l$ comprimento da linha de contato na região de avaliação 


\section{SUMÁRIO}

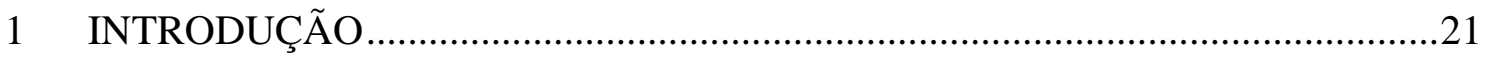

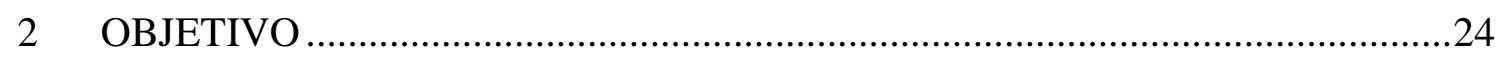

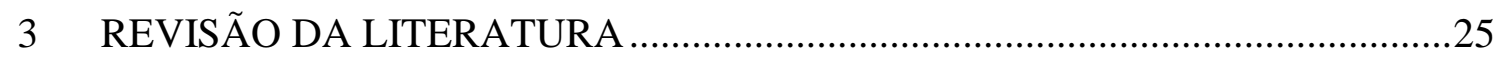

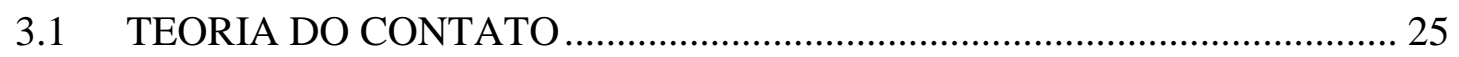

3.2 CARACTERÍSTICAS DO CONTATO LUBRIFICADO ............................ 27

3.2.1 Efeito da rugosidade nas condições de lubrificação ................................ 30

3.3 MODELOS DE LUBRIFICAÇÃO …..................................................... 32

3.3.1 Modelo desenvolvido por Heingartner e Mba (2003) ............................ 33

3.3.2 Modelo desenvolvido por Klein (2012)............................................ 33

3.3.3 Modelo desenvolvido por Fernandes; Martins; Seabra (2016) ................ 34

3.3.4 Modelo desenvolvido por Beilicke; Bobach; Bartel (2016) .................... 35

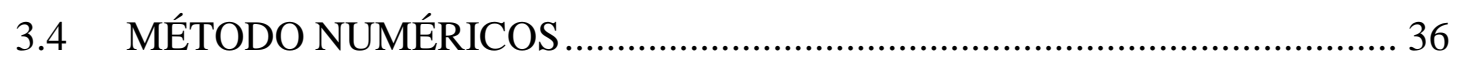

3.4.1 Método de Elementos Finitos ............................................................... 36

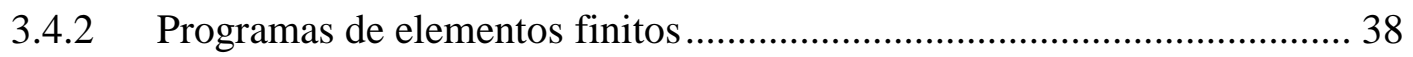

3.4.3 AVL Excite Power Unit ...................................................................... 40

3.5 EFICIÊNCIA: AVALIAÇÃO DE UMA TRANSMISSÃO MANUAL

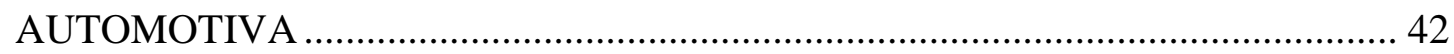

3.5.1 Contato em engrenagens helicoidais ................................................... 44

3.5.2 Cinemática da engrenagem helicoidal .................................................. 46

3.5.3 Regimes de lubrificação em engrenamento........................................... 48

3.5.4 Eficiência mecânica de engrenagem helicoidal ...................................... 51

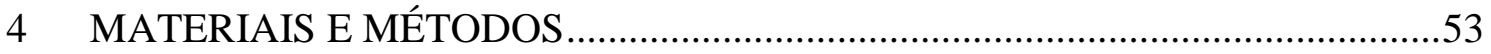

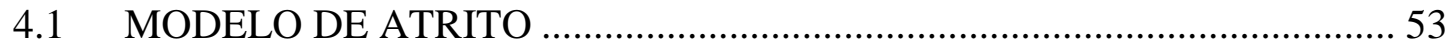

4.2 GEOMETRIA E MATERIAL DO ENGRENAMENTO ............................... 54

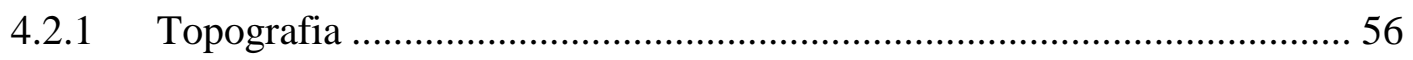

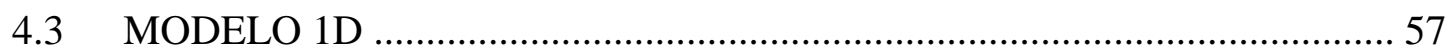




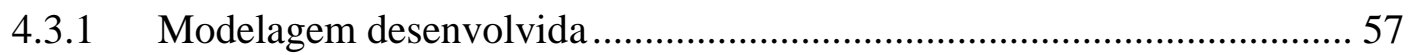

4.3.2 Fluxograma dos resultados obtidos no modelo 1D …........................... 58

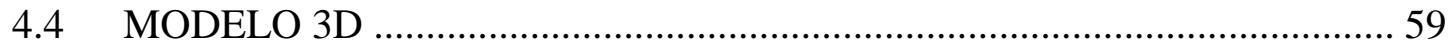

4.4.1 Modelagem desenvolvida ............................................................ 59

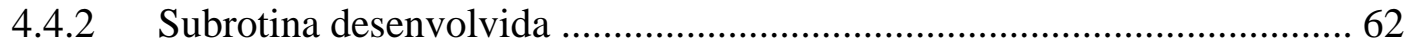

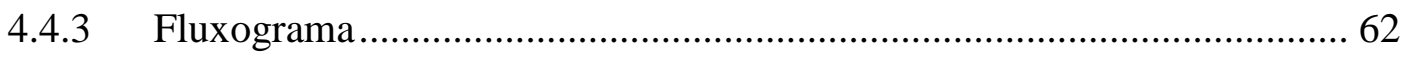

4.5 FLUXOGRAMA DA METODOLOGIA APLICADA .................................... 62

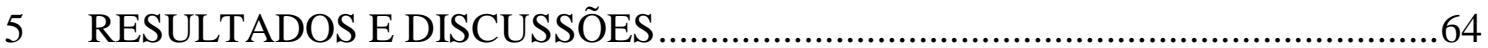

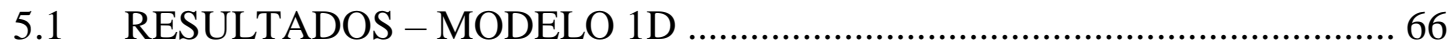

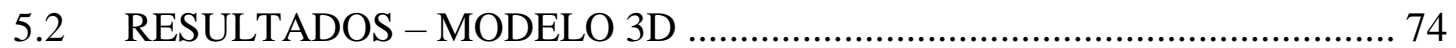

5.2.1 Simulação com coeficiente de atrito constante....................................... 74

5.2.2 Simulação com aplicação da subrotina..................................................... 75

5.3 COMPARAÇÃO ENTRE OS MODELOS 1D E 3D.................................... 78

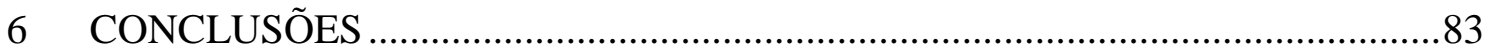

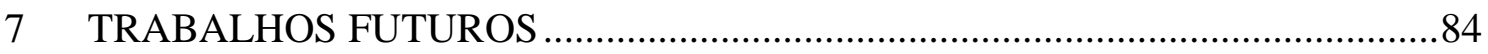

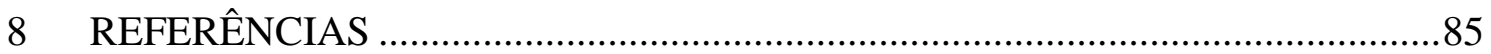

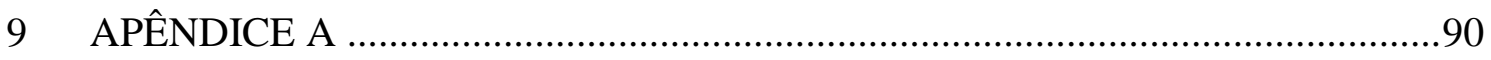

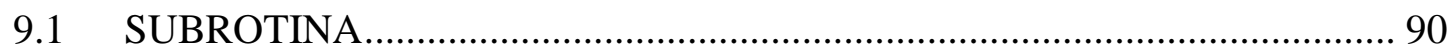




\section{INTRODUÇÃO}

Em 2012, o governo brasileiro criou o Programa de Incentivo à Inovação Tecnológica e Adensamento da Cadeia Produtiva de Veículos Automotores, conhecido como Inovar-Auto. Este programa teve como objetivo incentivar o setor automotivo nacional, por meio de benefícios tributários, a produzir veículos mais econômicos e seguros, investindo em pesquisas, desenvolvimento e capacitação dos fornecedores nacionais (FERREIRA FILHO et al., 2013; INOVAR-AUTO, 2012). O programa InovarAuto impulsionou a interação entre universidades e empresas, criando o Programa de Residência Tecnológica para Engenheiros dentro das empresas. Este programa resumese na criação de bolsas de estudo para alunos de pós-graduação de mestrado, com dedicação exclusiva para solução de questões de engenharia dentro da Fiat Chrysler Automobiles (FCA) (SOUZA; BRACARENSE; MASSARANI, 2016).

Dentro deste programa existiram várias propostas, incluindo as desenvolvidas em conjunto com o Laboratório de Fenômenos de Superfície (LFS) da Escola Politécnica da Universidade de São Paulo. O projeto conjunto entre a FCA e o LFS versou sobre o aumento de eficiência em uma transmissão automotiva, com o desenvolvimento de lubrificantes e materiais avançados na busca por menores perdas por atrito e maiores ganhos de eficiência. Este tema tem sido recorrente, pois o aumento de eficiência está diretamente ligado a redução de emissões de $\mathrm{CO}$ e $\mathrm{CO}_{2}$. No trabalho de Holmberg; Andersson; Erdemir (2012), que é um exemplo importante de avaliação de eficiência, foi apresentado um mapeamento das principais perdas de energia para movimentar um veículo de passeio. Do total de perdas do sistema, 33\% são gastos somente devido ao atrito. Holmberg; Andersson; Erdemir (2012) também fizeram um levantamento mundial e mostraram que em 2009, 208 mil milhões de litros de combustível foram gastos devido às perdas por atrito nos veículos. Desse total, $5 \%$ é perdido apenas no sistema de transmissão. Dessa forma, uma melhoria de $1 \%$ na eficiência da transmissão seria possível economizar mais de 2 mil milhões de litros de combustível e obter uma redução na emissão de $\mathrm{CO}_{2}$ de 290 milhões de toneladas na atmosfera no prazo de 5 a 10 anos (HOLMBERG; ANDERSSON; ERDEMIR, 2012).

A transmissão por engrenagens é o principal mecanismo de ajuste de movimento e torque utilizado em automóveis, se apresentando como um importante candidato ao processo de desenvolvimento e inovação para a redução das perdas por atrito no 
engrenamento, pois estas representam 55\% das perdas na transmissão. Este sistema apresenta desafios no contexto tribológico e mecânico, pois seus componentes, como engrenagens, eixos, elementos de vedação, mancais de rolamento, anéis e outros, apresentam geometrias complexas e operam em regimes variados de velocidades, esforços, condições de lubrificação e temperaturas (PARKER; VIJAYAKAR; IMAJO, 2000).

Na transmissão por engrenagens, estas são responsáveis pela transmissão da potência e podem ser fabricadas com diversos tipos de configurações geométricas. No sistema automotivo, o formato mais comum de engrenagens é a de dentes helicoidais, pois estes levam a uma menor vibração e ruído devido a uma mudança gradual e progressiva na troca do contato entre os dentes (NORTON, 2013). Outra vantagem desta configuração, é que a carga é dividida entre mais do que um único dente. Segundo a literatura (CASTRO, 2005; FRANÇOSO, 2009; LI et al., 2009), de modo geral, a engrenagem helicoidal pode chegar a ter eficiência mecânica de aproximadamente 96 \% . No entanto, o estudo da eficiência no par engrenado apresenta diversas dificuldades, tais como: os custos de ensaios em banco de provas, a dificuldade de determinação do coeficiente de atrito no contato do par engrenado e o controle das condições e parâmetros de ensaio para reproduzir as condições reais de uso.

A literatura apresenta modelos analíticos e numéricos, como uma alternativa para avaliar os fenômenos envolvidos durante o engrenamento, sendo que Weisbach e Gordon, em 1848, foram os pioneiros no estudo da eficiência de engrenagens. No entanto, só 100 anos depois, Earl Buckingham, em 1949, apresentou modelos analíticos para analisar as perdas devido ao atrito em engrenagens (FERNANDES; MARTINS; SEABRA, 2016). Nestes modelos, as engrenagens de dentes helicoidais apresentam uma dificuldade em questão de modelamento por causa dos movimentos de deslizamento e de rolamento no ângulo de hélice (ALI et al., 2015; WEI; ZHANG; GAO, 2016).

Nesta dissertação são apresentados e discutidos modelos de lubrificação, com o intuito de avaliar a variação e a influência do coeficiente de atrito na eficiência de um sistema lubrificado. É feita a verificação em uma condição específica, que está direcionada para o engrenamento de uma engrenagem helicoidal em uma transmissão automotiva. Em função do apresentado, esta dissertação foi dividida da seguinte forma: 
- Capítulo 2: principais objetivos deste trabalho, dentro do contexto apresentado como motivação na Introdução.

- Capítulo 3: é apresentada uma revisão na literatura da teoria do contato e da lubrificação com foco em aplicação para engrenamento de transmissão automotivo. Também são apresentados modelos de lubrificação e o método de elementos finitos para a aplicação proposta (sistema mecânico).

- Capítulo 4: é apresentada a metodologia desenvolvida e aplicada nesta dissertação e também a geometria e as propriedades do contato de um par engrenado.

- Capítulo 5: são apresentados os principais resultados obtidos nas simulações com aplicação do modelo selecionado. A subrotina desenvolvida e utilizada no programa de elementos finitos para a solução discreta do acoplamento entre as engrenagens e comparação com os resultados de um programa comercial e banco de prova.

- Capítulo 6: são apresentadas as conclusões para o caso estudado.

- Capítulo 7: são apresentadas propostas para trabalhos futuros.

- Capítulo 8: são apresentadas as referências utilizadas nesta dissertação

- Finalmente são apresentados anexos, contendo a subrotina desenvolvida. 


\section{OBJETIVO}

Esta dissertação tem como principal objetivo apresentar uma metodologia, usando análise numérica, para reproduzir e estudar os fenômenos mecânicos em um contato lubrificado não conforme. Esta metodologia permitirá estudar a variação do coeficiente de atrito e sua relação com a eficiência de um sistema mecânico. Um exemplo de sistema mecânico é o par de engrenagens cilíndricas helicoidais, que será a condição de contato selecionada para o presente estudo. São objetivos específicos desta dissertação:

- Desenvolvimento de um modelo unidimensional (1D), que represente uma transmissão automotiva com os seus principais componentes, como eixos, rolamentos, par engrenado e diferencial, para determinação do coeficiente de atrito na linha de contato do par engrenado.

- Avaliação de um modelo 3D a partir do desenvolvimento de uma subrotina, para a inclusão dos efeitos de contato lubrificado sobre o coeficiente de atrito, em uma simulação tridimensional (3D) de componentes sólidos (engrenagens helicoidais), utilizando a método de elementos finitos.

- Comparação dos resultados entre os modelos 1D, 3D e resultados de eficiência obtidos em banco de prova de transmissões de trabalho anterior (MACHADO, 2018).

- Avaliação do efeito de um parâmetro de rugosidade da superfície do dente da engrenagem, ao longo do contato não conforme durante o engrenamento, no coeficiente de atrito e na eficiência do par engrenado. 


\section{REVISÃO DA LITERATURA}

Neste capítulo serão abordados aspectos associados ao coeficiente de atrito e lubrificação, que ocorrem na interação do contato entre as superfícies e, são a base para a modelagem de avaliação do coeficiente de atrito. Serão abordadas a teoria do contato, a teoria da lubrificação elastohidrodinâmica e a modelagem em elementos finitos.

\subsection{TEORIA DO CONTATO}

A mecânica do contato está presente em diferentes sistemas tribológicos, como no caso do rolamento do pneu de um carro no asfalto e em deslizamento de um conjunto cilindro-pistão de motores a combustão. A importância da mecânica do contato está no entendimento da distribuição da pressão de contato entre duas superfícies e como esta distribuição afeta o sistema tribológico. O contato pode ser avaliado experimentalmente ou modelado numericamente. A avaliação experimental requer infraestrutura de equipamentos e instalações que têm custos e períodos de avaliação mais elevados que a numérica (SAMPAIO, 2009). Embora a modelagem requeira validação, as simulações do modelo podem ser usadas de forma exploratória, podendo diminuir o número de ensaios e testes a serem conduzidos.

$\mathrm{Na}$ teoria do contato, quando duas superfícies entram em contato, ocorre uma deformação elástica desta região finita e são geradas tensões, conhecidas como tensões de contato ou de Hertz (NORTON, 2013). Dependendo da geometria das superfícies é possível obter uma distribuição elipsoidal, para um contato pontual (Figura 1a), ou retangular, para um contato linear (Figura 1b) (NORTON, 2013). Esta última distribuição ocorre no contato em engrenagens.
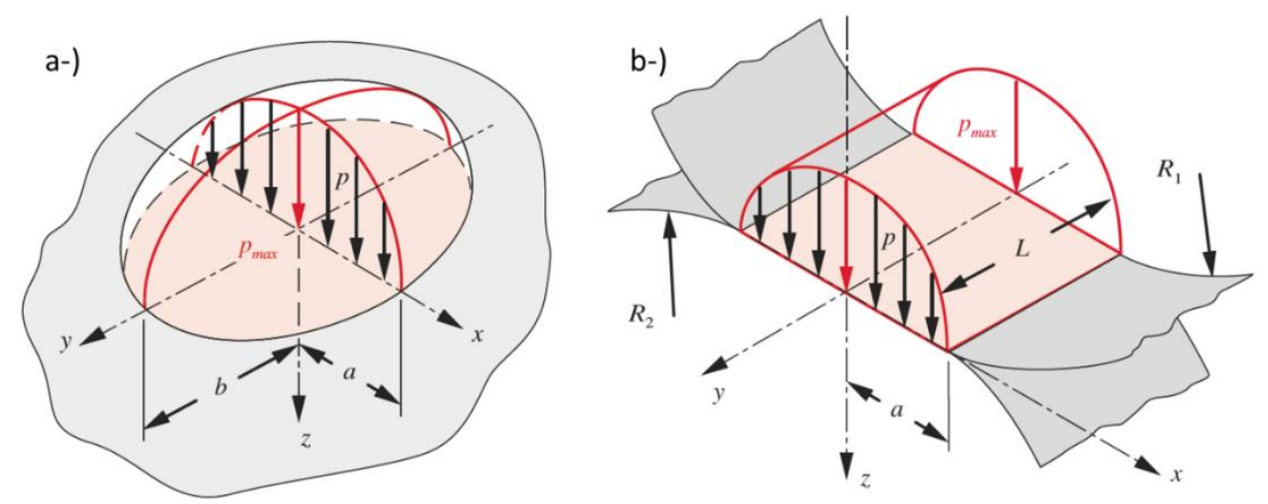

Figura 1 - Esquema da distribuição de tensão em contato de Hertz. (a) apresenta uma distribuição em forma de elipse e em (b), tem-se uma distribuição de tensão em forma retangular (Norton, 2013). 
O contato entre duas superfícies é dividido também pela sua forma geométrica: conforme e não-conforme (Figura 2). No contato conforme, as superfícies têm forma e tamanhos proporcionalmente similares (Figura 2a). Já no não-conforme, ou também chamado concentrado, as superfícies não possuem geometrias similares (Figura 2b), como é o caso do contato em engrenagens (ASM HANDBOOK, 1992).
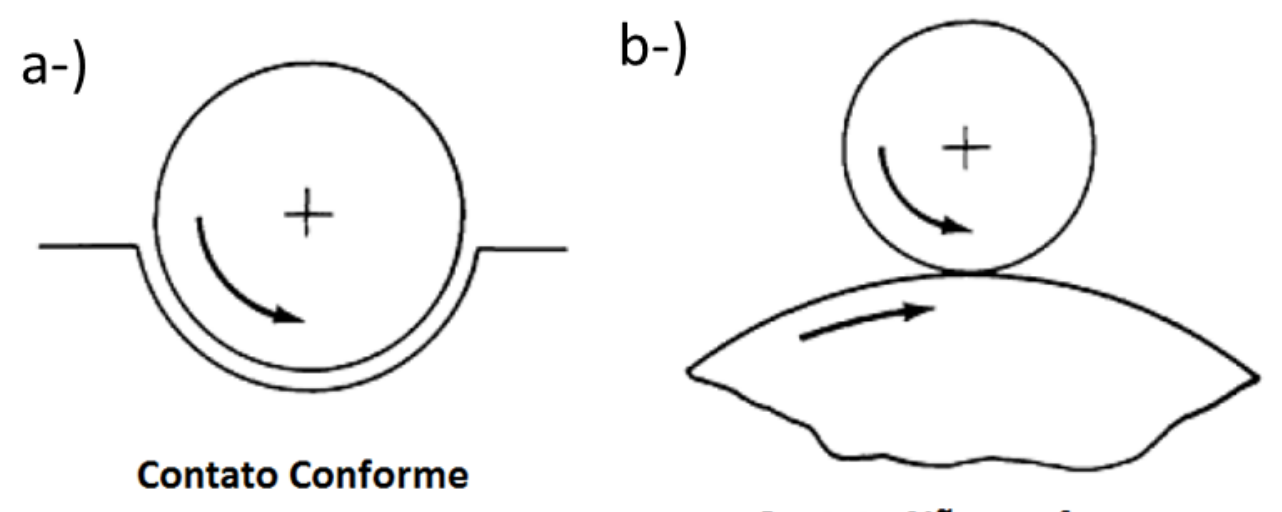

\section{Contato Não-conforme}

Figura 2 - Esquema de contato (a) conforme e (b) não-conforme. Adaptado de (ASM HANDBOOK, 1992).

O contato entre duas superfícies pode ser classificado de acordo com o apresentado na Tabela 1. Os exemplos mostram que em mancais de apoio ou deslizamento é encontrado o tipo de contato conforme e para rolamentos e cames o contato é não-conforme. Em contato não-conforme, pode-se chegar a pressões de contato maiores que $1 \mathrm{GPa}$, tanto para casos de distribuição de tensões de Hertz pontual como linear (PIRRO; WEBSTER; DASCHNER, 2016).

Tabela 1 -Tipos e exemplos de contatos conforme e não conforme. As engrenagens têm contato nãoconforme linear. Adaptação de (PIRRO; WEBSTER; DASCHNER, 2016).

\begin{tabular}{|c|c|c|}
\hline $\begin{array}{c}\text { Tipo de Contato } \\
\text { Geometria }\end{array}$ & Conforme & Não-conforme \\
\hline $\begin{array}{c}\text { Característica } \\
\text { Tensões de contato }\end{array}$ & Material macio & Dissilar \\
\hline $\begin{array}{c}\text { Esquema e exemplos de } \\
\text { sistemas mecânicos } \\
\text { lubrificados }\end{array}$ & $0-100 \mathrm{MPa}$
\end{tabular}


Um exemplo importante de contato não-conforme é o contato entre as engrenagens, que possuem contato linear e uma distribuição retangular da carga, conforme a teoria de Hertz. Com isso, dependendo da aplicação de carregamentos e geometrias, as engrenagens podem apresentar elevadas tensões de contato. Uma engrenagem helicoidal de primeira marcha de câmbios automotivos, descrita no trabalho de Figueiredo (2017), são indicadas pressões de contato de $3 \mathrm{GPa}$, aproximadamente.

\subsection{CARACTERÍSTICAS DO CONTATO LUBRIFICADO}

As duas principais funções do lubrificante, no contato entre duas superfícies, indicadas por Abraham (2014) são: a) promover uma camada de lubrificante entre as asperezas das superfícies em contato e, b) promover a remoção do calor gerado no contato. A espessura da camada de lubrificante está relacionada com o regime de lubrificação. Os regimes de lubrificação podem ser descritos utilizando a curva de Stribeck (Figura 3). Na Figura 3 é possível identificar os regimes: limítrofe, misto, elastohidrodinâmico (EHL) e hidrodinâmico (HL), os quais serão descritos ao longo deste capítulo.

A curva de Stribeck foi aplicada originalmente para rolamentos (STRIBECK, 1902 apud JACOBSON, 2003), mas também pode ser usada para outros sistemas tribológicos, como é o caso das transmissões automotivas (PIRRO; WEBSTER; DASCHNER, 2016). O formato dessa curva é influenciado pela geometria das superfícies, condições de operação (temperatura, carga e velocidade) e pelas propriedades dos materiais em contato e do lubrificante (PIRRO; WEBSTER; DASCHNER, 2016).

Na Figura 3 é apresentado um esquema da curva de Stribeck. No eixo das ordenadas temos o coeficiente de atrito, já o eixo das abscissas pode ser representado por diferentes variáveis, como o Número de Hersey $(H)$, que é definido na equação (1), porém neste caso é definida em função da espessura específica de filme lubrificante (ACERO, 2015; DOWSON, 1993; SEABRA, 2005).

$$
H=\frac{\eta_{0} U s}{F}
$$

Sendo $\eta_{0}$ a viscosidade dinâmica do lubrificante, Us a velocidade de deslizamento e F a força normal no contato. A Figura 3 também mostra exemplos de sistemas tribológicos, como em rolamentos, em engrenamentos e contato do sistema anel/camisa, 
onde estes últimos apresentam todos os regimes de lubrificação ao longo do movimento do engrenamento e do motor, respectivamente (TERTULIANO, 2017). Tertuliano (2017) indica também o uso de aditivos (Figura 3) aditivos, como extrema pressão (EP), antidesgaste (AW), modificador de atrito (FM) e índice de viscosidade (VII). Estes aditivos podem atuar e diferentes condições de lubrificação que são indicadas na curva de Stribeck.

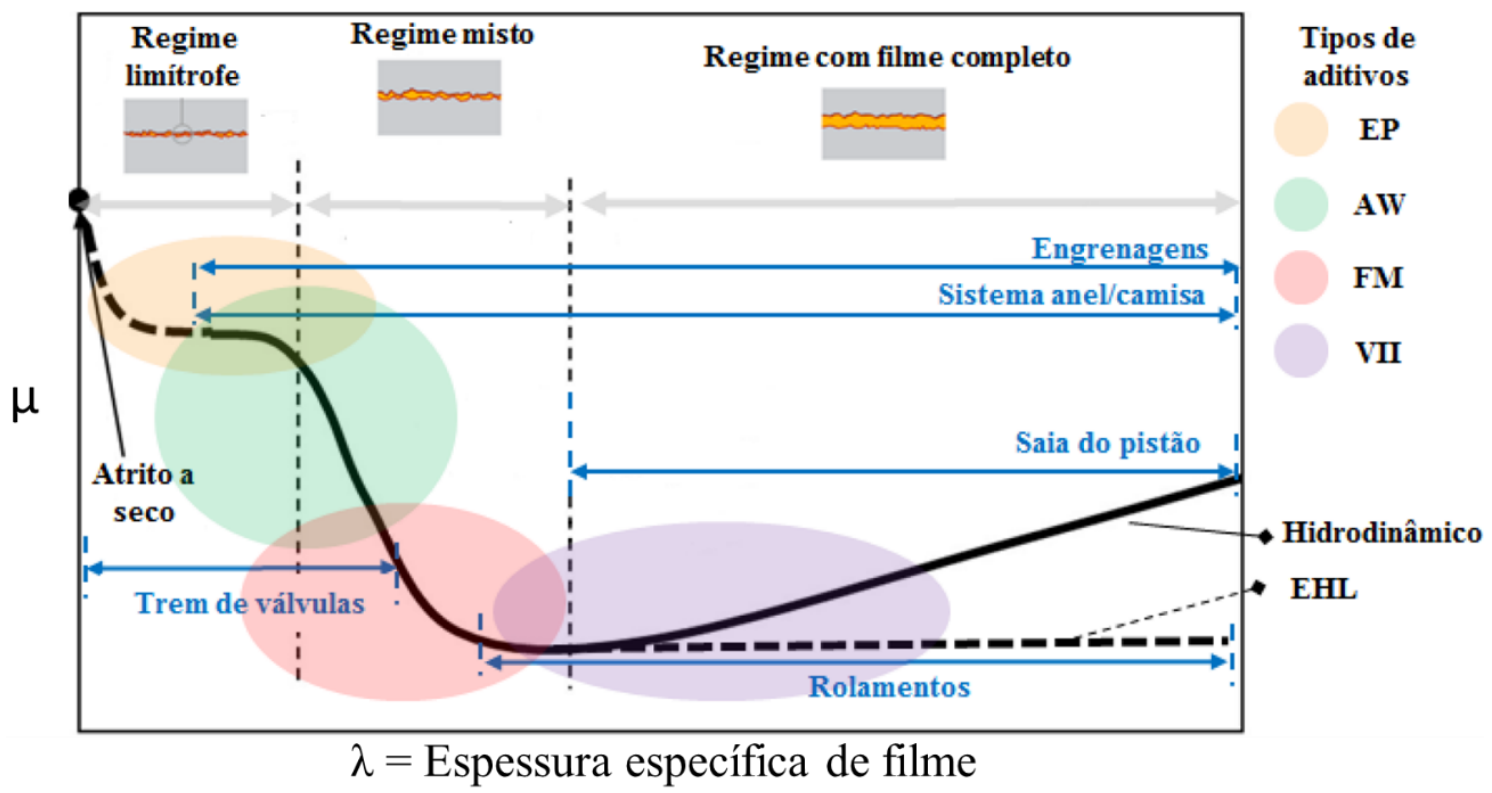

Figura 3 - Esquema da curva de Stribeck, $\mu$ (coeficiente de atrito) em função de $\lambda$ (espessura específica de filme) com os regimes de lubrificação (Limítrofe, misto, EHL - lubrificação elastohidrodinâmica e HL - lubrificação hidrodinâmica) e exemplos de sistemas tribológicos (rolamentos, contato de engrenagens e sistemas de anel/camisa) onde podem variar os regimes conforme as condições de funcionamento.

Adaptado de (BJÖRLING, 2014; SEABRA, 2005; TERTULIANO, 2017)

Um aspecto importante na análise a ser feitas está no cálculo da espessura específica de filme é feito pela razão entre a espessura de filme lubrificante $\left(h_{0}\right)$ e um parâmetro de rugosidade (R), como mostra a equação (2):

$$
\lambda=\frac{h_{0}}{R}
$$

Na literatura (HAMROCK, 1991) existem modelos para o cálculo do ho e a rugosidade pode ser representada por diferentes parâmetros, como por exemplo o Rq, que é definido como a raiz quadrada da média dos valores das ordenadas de afastamento $\left(Z_{N}\right)$, dentro de um comprimento de amostragem (equação (3)) (NBR ISO 4287, 2002). O valor de $\mathrm{Rq}$ é considerado, estatisticamente, mais representativo que o Ra, porém não tem uma 
distinção entre picos e vales (KREIL, 2008). O Ra é a média aritmética dos valores absolutos das ordenadas no comprimento da amostragem (NBR ISO 4287, 2002).

$$
R q=\sqrt{\frac{1}{l} \int_{0}^{l} Z^{2}(x) d x}
$$

Usando o parâmetro de rugosidade Rq, para o cálculo da espessura específica de filme, onde para valores de $\lambda$ menor que 0,7 indicam condições de regime limítrofe, para valores maiores que 2 é considerado filme completo com regime elastohidrodinâmico ou hidrodinâmico. Entre 0,7 a 2, o regime de lubrificação é considerado misto (SEABRA, 2005).

Na lubrificação limítrofe $(\lambda<0,7)$, ocorre o contato entre as asperezas, produzindo um alto coeficiente de atrito. A literatura indica que neste regime de lubrificação pode ocorrer a diminuição da vida útil do sistema (ALI et al., 2015; HUTCHINGS, 1992).

Na lubrificação mista $(0,7 \leq \lambda<2)$ a espessura do filme lubrificante aumenta, levando a uma queda no coeficiente de atrito. Nessa condição, ainda podem ocorrer regiões com contato entre as asperezas (SEABRA, 2005).

Já a lubrificação elastohidrodinâmica (EHL) e hidrodinâmica (HL), em que o $\lambda$ é maior que 2,0, não ocorre o contato entre as asperezas das superfícies. A diferença entre EHL e HL está no tipo de contato, que vai afetar o filme lubrificante e as superfícies. No EHL, o contato é não-conforme e apresenta elevada pressão de contato que pode deformar elasticamente as superfícies. Já no HL, o comportamento é oposto, e não é comum ocorrer em engrenagens ou rolamentos (SEABRA, 2005).

Na teoria da lubrificação elastohidrodinâmica, o contato se dá em uma pequena área, devido à deformação elástica, representada no esquema da Figura 4, que mostra a seção transversal de um contato não-conforme lubrificado. Esta área finita de contato é referida e aproximada de uma região de contato Hertziana (PIRRO; WEBSTER; DASCHNER, 2016). Portanto, o regime de lubrificação elastohidrodinâmico é gerado com o aumento da pressão de contato e o movimento relativo, a velocidade de rolamento, que permite a geração de uma película de fluido entre as superfícies. Na região de entrada, com o aumento da pressão, ocorre o aumento da viscosidade do fluido, avaliado pelo seu coeficiente de pressão-viscosidade ( $\alpha$ ) (ASM HANDBOOK, 1992). 
O coeficiente pressão-viscosidade tem relação com a estrutura molecular do lubrificante e pode ser modificado com o uso de aditivos. Os fluidos com baixa resistência ao cisalhamento, normalmente possuem coeficiente de pressão-viscosidade mais baixo, podendo resultar em filmes EHL mais finos, comparados com outros fluidos de resistência ao cisalhamento maiores, sob as mesmas condições (PIRRO; WEBSTER; DASCHNER, 2016).

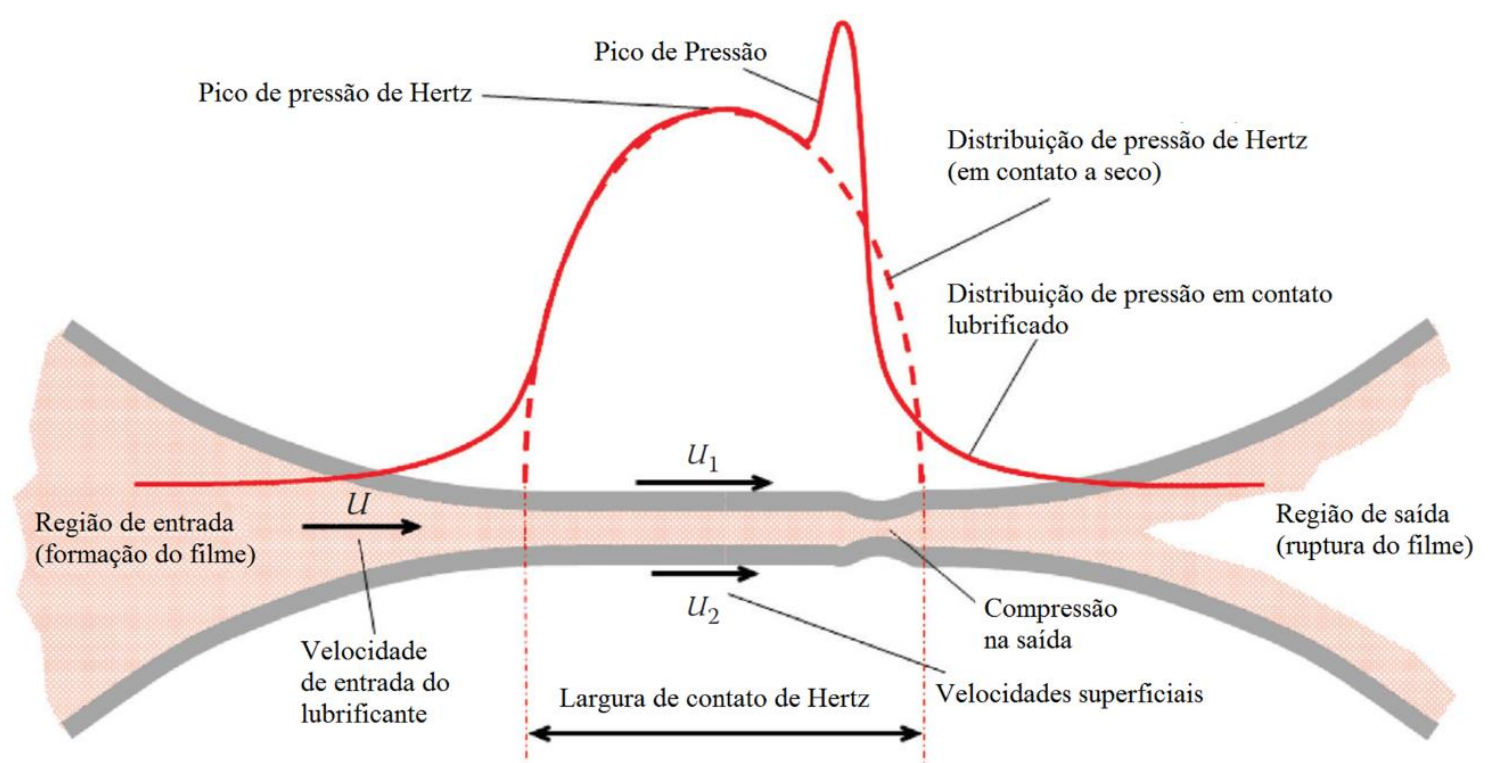

Figura 4 - Esquema da seção transversal de um contato não-conforme com lubrificação elastohidrodinâmica. A região de entrada, onde começa a formação do filme, possui pressão praticamente nula. Na região central do contato a pressão sob e o filme diminui a espessura, também é observado a diferença de velocidades (velocidade de deslizamento) das superfícies. A pressão no contato alcança o seu valor de pico com a restrição na saída. Por fim, região de saída tem o rompimento do filme e a pressão volta a valores nulos. Adaptado de (PIRRO; WEBSTER; DASCHNER, 2016).

Pirro; Webster; Daschner (2016) descrevem que a viscosidade do lubrificante deve ser alta o suficiente para gerar um filme completo e eficiente, mas não tão elevada, a ponto de ser influenciado pela resistência elevada ao cisalhamento do fluido. Sendo assim, a viscosidade afeta tanto a capacidade de carga, como o fluxo do filme no contato. Pirro; Webster; Daschner (2016) citam que a viscosidade também afeta na diminuição de ruído e vibração das engrenagens devido ao contato entre as superfícies.

\subsubsection{Efeito da rugosidade nas condições de lubrificação}

Como descrito anteriormente na equação (2), a espessura específica do filme lubrificante também é influenciada pela rugosidade, tendo um papel muito importante no 
estudo do efeito das características e comportamento tribológico da engrenagem. Superfícies com rugosidade mais alta exigem maiores espessuras de filme e maiores valores de viscosidade do lubrificante, para evitar contato entre as asperezas (KRUPKA; SPERKA; HARTL, 2016).

Wang; Lin (1991), que estudaram o efeito da rugosidade superficial na lubrificação elastohidrodinâmica aplicada em um contato não-conforme linear, indicaram que com o aumento da rugosidade há um aumento dos valores de pico de pressão, diminuição da espessura de filme e aumento do resistência ao cisalhamento do fluido. Hohn; Michaelis; Kreil (2006) também estudaram a influência da rugosidade na distribuição de pressão e espessura de filme em contato elastohidrodinâmico. Eles mostraram que picos e vales no perfil da rugosidade superficial resultam em picos e vales na pressão de contato.

Lin (2013) também estudou o efeito do parâmetro de rugosidade $\mathrm{Rz}$ e da viscosidade do óleo no coeficiente de atrito sobre condições de rolamento-deslizamento. Lin utilizou em seus ensaios contato não-conforme linear (MPR - Micropitting Rig), com discos com parâmetro de rugosidade Rz diferentes. A Figura 5 mostra o esquema do ensaio. Neste equipamento é possível medir o coeficiente de atrito sob condições controladas de temperatura, carga, e velocidade de deslizamento. Dessa forma, ele analisou o efeito da rugosidade no coeficiente de atrito, conforme mostra a Figura 6. Nesta figura, maiores rugosidades levam a maiores coeficientes de atrito. É possível notar também, que com o aumento do número de ciclos, o coeficiente de atrito tende a diminuir para a superfície mais rugosa, possivelmente devido à ocorrência de desgaste e também diminuição na altura das asperezas das superfícies, alterando assim a rugosidade.
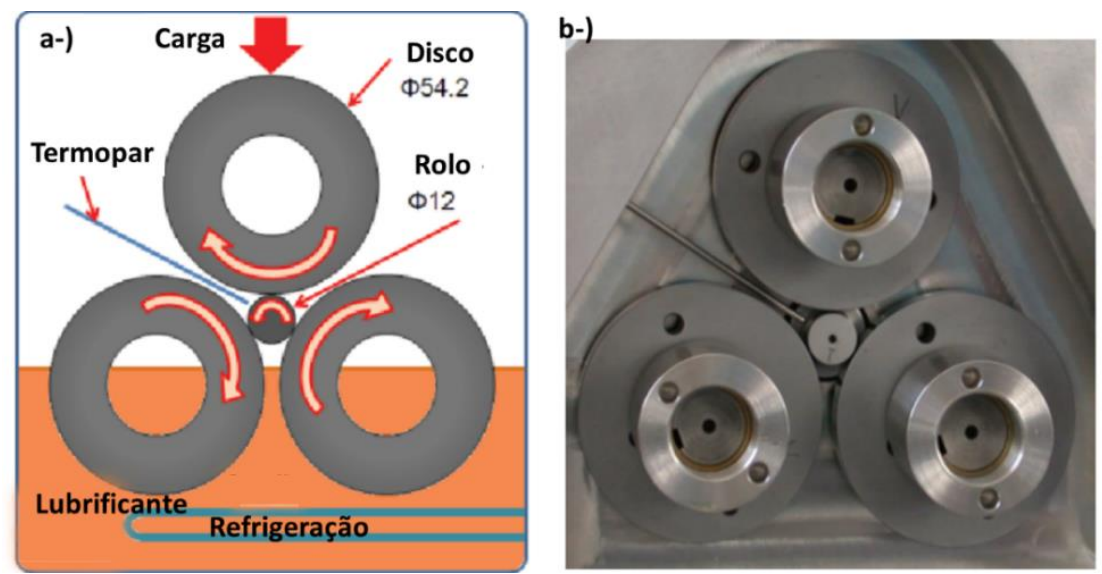

Figura 5 - a-) Esquema da configuração do ensaio em MPR. b-) Equipamento MPR. É possível observar a posição dos discos e a direção de rotação de cada um, o lubrificante e a refrigeração do mesmo e o termopar para a medição da temperatura próxima a região de contato. Adaptado de (LIN, 2013). 


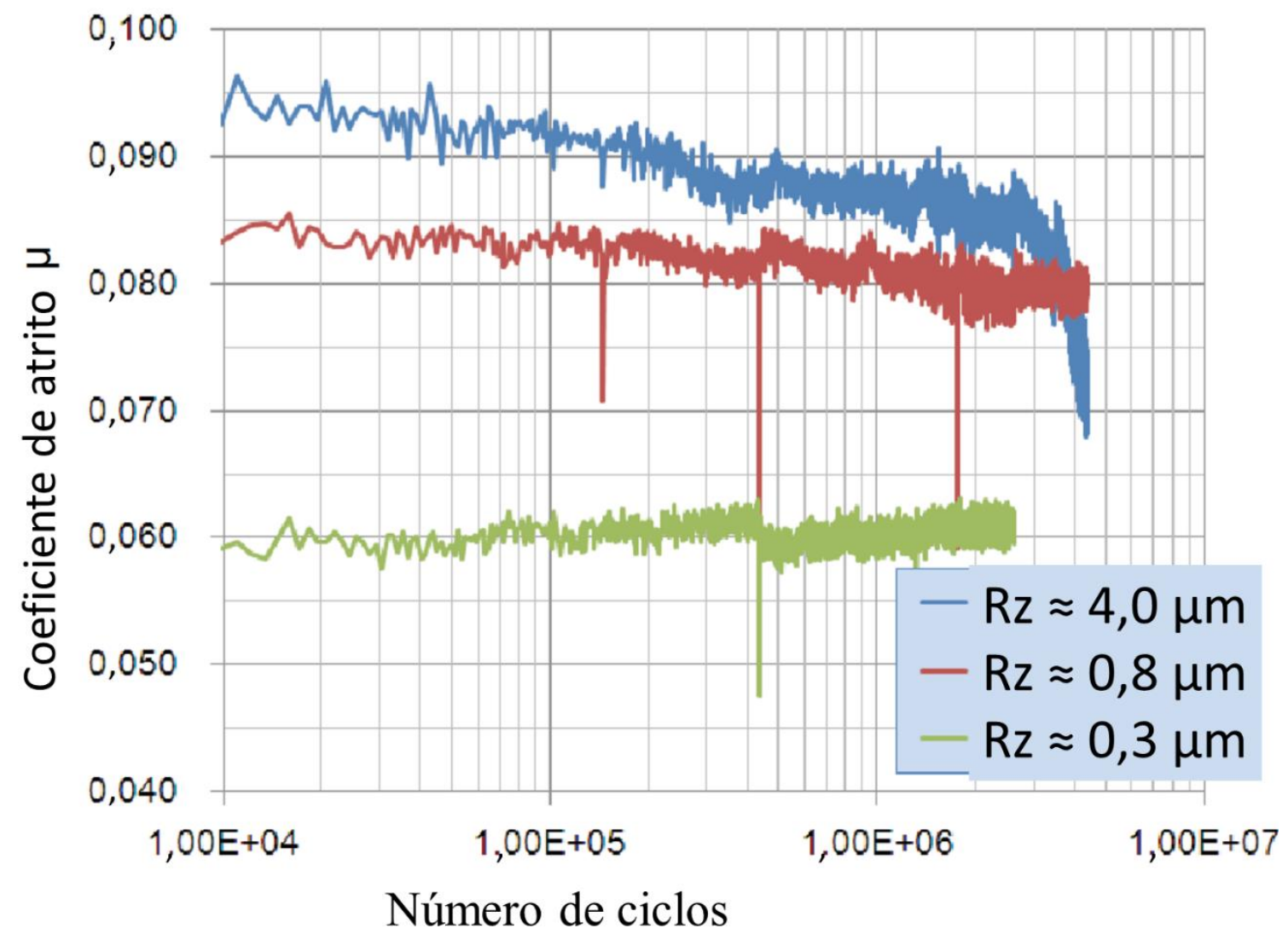

Figura 6 - Gráfico do coeficiente de atrito pelo número de ciclos em superfícies com diferentes Rz. Ensaio em MPR com pressão de $1,7 \mathrm{GPa}$, velocidade de $3,15 \mathrm{~m} / \mathrm{s}$, SRR de $52 \%$, temperatura de $70{ }^{\circ} \mathrm{C}$ e contato lubrificado. Adaptado de (LIN, 2013).

Abraham (2014) também concluiu que superfícies superpolidas, com Rq de $0,23 \mu \mathrm{m}$, aumentam a capacidade de carga em comparação as superfícies sem qualquer tipo de polimento. Logo a rugosidade é relevante nas análises de eficiência, pois tem relação direta com o coeficiente de atrito no contato em condições de rolamentodeslizamento.

Além disso, as velocidades de rolamento e deslizamento são importantes no comportamento tribológico em regime EHL, já que a velocidade de rolamento também influencia diretamente a espessura do filme e a velocidade de deslizamento no comportamento do coeficiente de atrito ( $\mu$ ) (ASM HANDBOOK, 1992).

\subsection{MODELOS DE LUBRIFICAÇÃO}

Para prever e estudar o coeficiente de atrito em contato lubrificado foram desenvolvidos na literatura modelos analíticos, numéricos e experimentais que levam em consideração, principalmente, a influência da temperatura, carga aplicada, velocidade de deslizamento, tamanho e forma da região do contato e as propriedades mecânicas e 
térmicas do material e do lubrificante. Esses modelos são apresentados neste capítulo e serão importantes na avaliação de eficiência.

\subsubsection{Modelo desenvolvido por Heingartner e Mba (2003)}

Heingartner e Mba (2003) desenvolveram um modelo de eficiência de engrenagem helicoidal e validaram com ensaios experimentais. Para a modelagem analítica, os autores levaram em consideração as perdas devido ao atrito, fluxo de ar e do lubrificante. Para as perdas devido ao atrito, os autores adaptaram o modelo de coeficiente de atrito desenvolvido por Anderson e Loewenthal (1980) e apresentaram a equação (5). Heingartner e Mba (2003) também comentam que as velocidades de rolamento e deslizamento e a força normal variam em função da posição do engrenamento.

$$
\mu_{\text {local }}=0,0127 * \log \left(\frac{29,66 \frac{F}{L}}{\eta_{0} * U_{S} * U_{R}^{2}}\right)
$$

Onde, $\mu_{\text {local }}$ é o coeficiente de atrito, $F$ é a força normal, $L$ é o comprimento da linha de contato, $\eta$ é a viscosidade dinâmica do lubrificante, $U_{S}$ é a velocidade de deslizamento e $U_{R}$ é a velocidade de rolamento. A eficiência das engrenagens foi medida em um equipamento produzido pela FZG (Forschungsstelle für Zahnräder und Getriebebau - Centro para Pesquisas de Engrenagens) ou também conhecido como backto-back test rig, o qual utiliza duas engrenagens reais para avaliar a eficiência do sistema. Os resultados indicaram uma correlação do modelo analítico com os dados experimentais obtidos pelo ensaio das engrenagens.

\subsubsection{Modelo desenvolvido por Klein (2012)}

Um dos trabalhos apresentados na literatura e mais utilizados, tanto na indústria automotiva como em laboratórios de pesquisa, é o modelo proposto por Klein (2012). Klein propôs um modelo analítico com base na teoria da lubrificação elastohidrodinâmica. Este modelo leva em consideração no seu desenvolvimento, o deslocamento axial e o ângulo de hélice, importantes parâmetro em uma engrenagem com dentes helicoidais. Klein, também correlacionou o seu modelo com ensaios experimentais. Na equação (6) é apresentado o modelo de Klein para o cálculo do

coeficiente de atrito local $\left(\mu_{\text {local }}\right)$ em termos de: $p_{H}$ a pressão de contato pontual $\left[\mathrm{N} / \mathrm{mm}^{2}\right]$, 
$U_{S}$ a velocidade de deslizamento [m/s], $S R R$ a taxa de deslizamento pelo rolamento na zona de contato [-] e $\lambda_{z}$ a espessura específica de filme [-].

$$
\mu_{\text {local }}=0.032\left(p_{H}\right)^{0.1}\left(U_{S}\right)^{-0.2}(S R R)^{0.05}\left(\lambda_{z}\right)^{-0.1}
$$

$\lambda_{z}$ é calculado com a espessura específica de filme de óleo real $h_{0}[\mu \mathrm{m}] \mathrm{e}$ a rugosidade $R_{z}[\mu \mathrm{m}]$, dada pela equação (7), diferente da apresentada na equação (2), onde é utilizado o Rq. Sendo Rz definido como a soma dos valores absolutos das ordenadas dos pontos de maior afastamento, acima e abaixo da linha média (NBR ISO 4287, 2002). Este parâmetro é indicado para quantificar superfícies de apoio e de deslizamento, contudo tem uma característica extrema, leva em consideração a influência do valor de pico sob a máxima pressão e mínima espessura de filme lubrificante (Kreil, 2008) (Klein, 2012).

$$
\lambda_{z}=\frac{h_{0}}{R_{z}}
$$

\subsubsection{Modelo desenvolvido por Fernandes; Martins; Seabra (2016)}

Fernandes; Martins; Seabra (2016) propuseram um modelo para o cálculo do coeficiente de atrito em engrenagens com modificações nos parâmetros de Hersey. Neste modelo foi encontrada uma correlação entre o coeficiente de atrito e a modificação proposta pelos autores do parâmetro de Hersey, onde foi levado em consideração principalmente o parâmetro de pressão-viscosidade. Neste modelo também foi levado em consideração os efeitos da carga, velocidade, viscosidade e pressão-viscosidade. O modelo foi desenvolvido experimentalmente conforme equação (8) e foi validado com ensaios experimentais e comparado com outros modelos da literatura (FERNANDES; MARTINS; SEABRA, 2014):

$$
\mu_{m Z}^{E X P}=\frac{P_{V Z P}^{E X P}}{P_{i n} \cdot H_{V L}}
$$

Sendo, $\mu_{m Z}^{E X P}$ o atrito médio calculado experimentalmente, $P_{V Z P}^{E X P}$ é a perda de potência média obtida no ensaio, $P_{i n}$ é a potência de entrada no sistema e $H_{V L}$ é o fator de perda local do engrenamento, levando em consideração apenas a influência da geometria do dente. 
O modelo para o cálculo do coeficiente de atrito desenvolvido por Fernandes; Martins; Seabra (2016) está resumido na equação (9), na equação (10) e na equação (11):

$$
\begin{gathered}
S_{g}=\frac{R_{a}}{\left(\rho_{\text {ers }} \cdot \epsilon_{\alpha} \cdot b \cos \beta_{b}\right)^{1 / 2}} \\
S_{p}=\frac{U_{S} \cdot \eta_{0} \cdot \alpha^{1 / 2}}{F^{1 / 2}} \\
\mu_{m Z}=0,014 \cdot\left(\frac{1}{S_{p}}\right)^{1 / 4} \cdot S_{g}^{1 / 4} \cdot X_{L}
\end{gathered}
$$

Sendo $R_{a}$ a rugosidade média da superfície, $\rho_{\text {ers }}$ o raio de curvatura equivalente no diâmetro primitivo, $b$ a largura da face do dente da engrenagem, $\beta_{b} \mathrm{o}$ ângulo de hélice da base, $\eta_{0}$ a viscosidade dinâmica, $\alpha$ o coeficiente pressão-viscosidade e $F$ a força normal. $S_{p}$ é a modificação no parâmetro de Hersey, $S_{g}$ é o parâmetro geométrico da engrenagem e $X_{L}$ é o fator do lubrificante distinto para diferentes óleos conforme o trabalho de Schlenk (SCHLENK, 1994 apud; FERNANDES; MARTINS; SEABRA, 2016; HAMMAMI, 2017). Diferente do modelo apresentado por Klein (2012), Fernandes; Martins; Seabra (2016) não usam a espessura específica de filme no seu modelo.

\subsubsection{Modelo desenvolvido por Beilicke; Bobach; Bartel (2016)}

Beilicke; Bobach; Bartel (2016), desenvolveram um modelo analítico para regimes EHL e aplicaram no estudo de engrenagens helicoidais. Os resultados permitem verificar a variação do coeficiente de atrito ao longo da linha de ação do contato (Figura 7). As regiões de A' a A e de E até E' são, respectivamente, o início e o fim do engrenamento. $\mathrm{O}$ ponto $\mathrm{C}$ representa o diâmetro primitivo, e neste ponto, o coeficiente de atrito está próximo de zero, pois a velocidade de deslizamento é nula nesta região. 


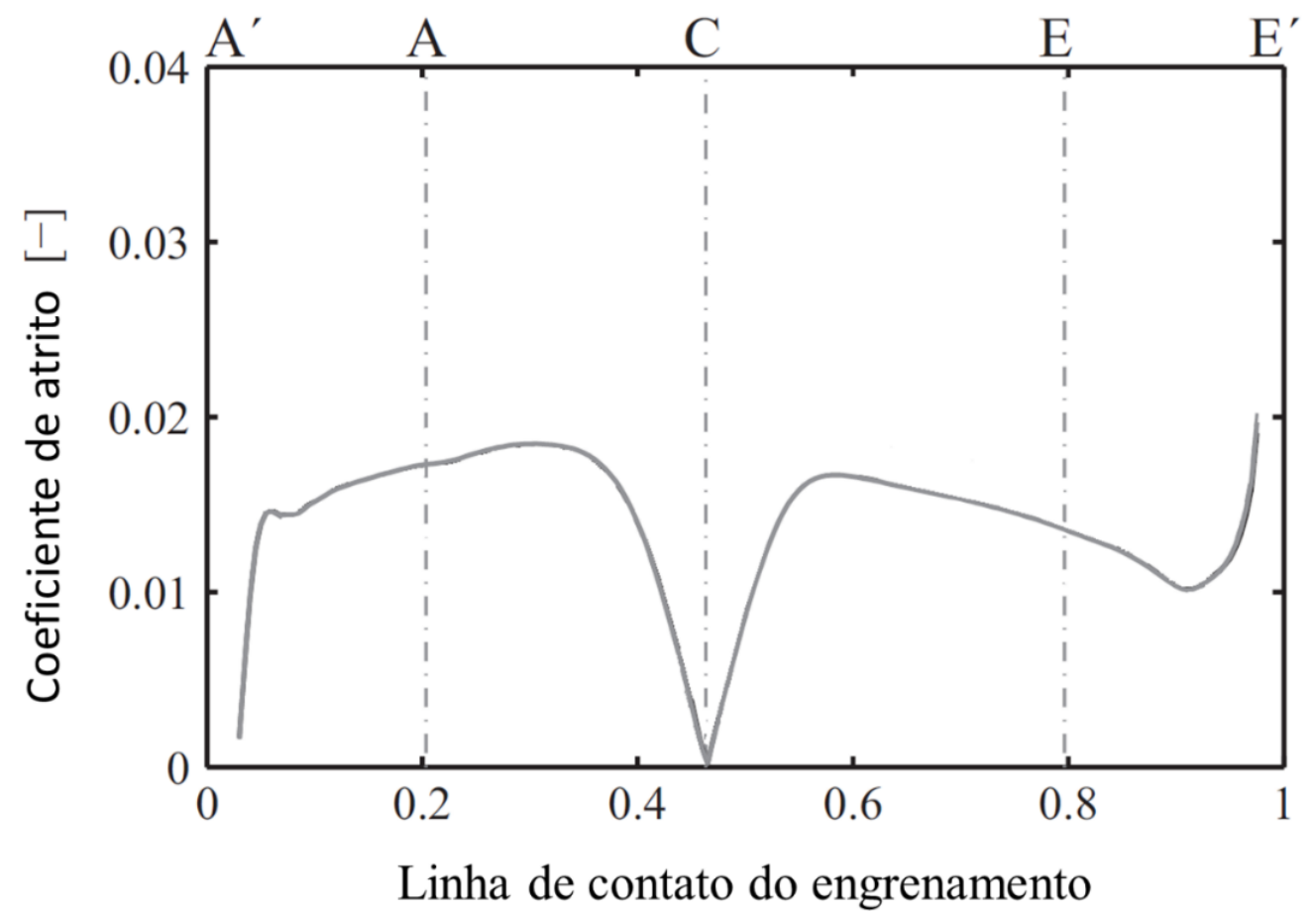

Figura 7 - Variação do coeficiente de atrito ao longo da linha de contato do engrenamento. A região A' até $\mathrm{A}$ representa o início do contato do engrenamento, o ponto $\mathrm{C}$ corresponde ao diâmetro primitivo e a região do E até E', o fim do contato do engrenamento. Adaptado de (BEILICKE; BOBACH; BARTEL, 2016)

\subsection{MÉTODO NUMÉRICOS}

\subsubsection{Método de Elementos Finitos}

Segundo a literatura (APONTE, 2011; DUNNE; PETRINIC, 2005; LOTTI et al., 2006), o Método de Elementos Finitos (MEF) pode ser definido como um método numérico para a solução de equações matemáticas que descrevem um problema ou um comportamento genérico. Para isso, um meio contínuo (domínio) é discretizado em elementos com formato de geometrias já existente, como triângulos, quadriláteros, tetraedros, e estudado o seu comportamento em relação a tensões ou deformações (SOUSA, 2007).

O MEF é recomendado em casos que tenham uma dificuldade de reprodução, valor elevado de ensaios e casos complexos, sendo possível analisar e controlar apenas as variáveis desejadas no estudo (DUNNE; PETRINIC, 2005). Exemplo de aplicação do MEF foi apresentado por Parker; Vijayakar; Imajo (2000) em seus estudos sobre dinâmica de engrenamento. A Figura 8 mostra a malha de elementos finitos utilizada pelos autores na simulação e em detalhe um refinamento da malha, ou seja, um aumento do número de 
elementos da malha nos dentes das engrenagens. Segundo Turner et al. (1956), o refinamento da malha melhora a correlação dos resultados numéricos com os valores reais (TURNER, 1956 apud SERIACOPI, 2013). Na Figura 8 é possível observar também as formas geométricas dos elementos e o contato entre os dentes. Os autores (PARKER; VIJAYAKAR; IMAJO, 2000) obtiveram uma boa correlação, dos seus resultados, da frequência do erro da transmissão, do modelo numérico com o experimental .

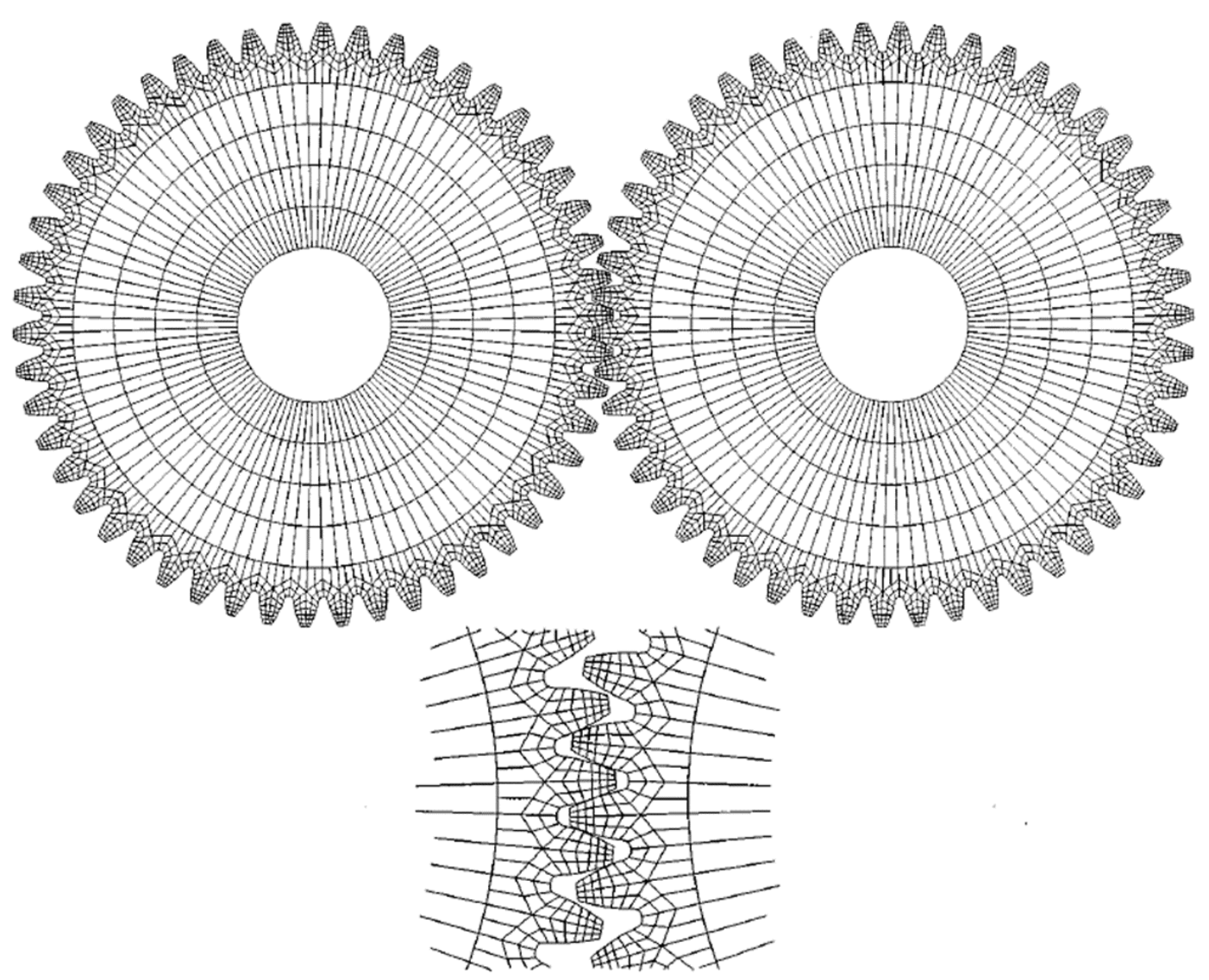

Figura 8 - Malha de elementos finitos no engrenamento e detalhe do refinamento da malha no contato entre os dentes das engrenagens (PARKER; VIJAYAKAR; IMAJO, 2000).

Outro exemplo de aplicação de MEF é apresentada no trabalho de Sanchez, Pedrero, Pleguezuelos (2013), onde usaram o MEF para estudar as tensões e condições de carga críticas na flexão de engrenagens helicoidais. A Figura 9 apresenta a malha de elementos finitos aplicada pelos autores em seu modelo, onde é possível observar um refinamento da malha nos dentes da engrenagem, também visto no trabalho de Parker; Vijayakar; Imajo (2000). 


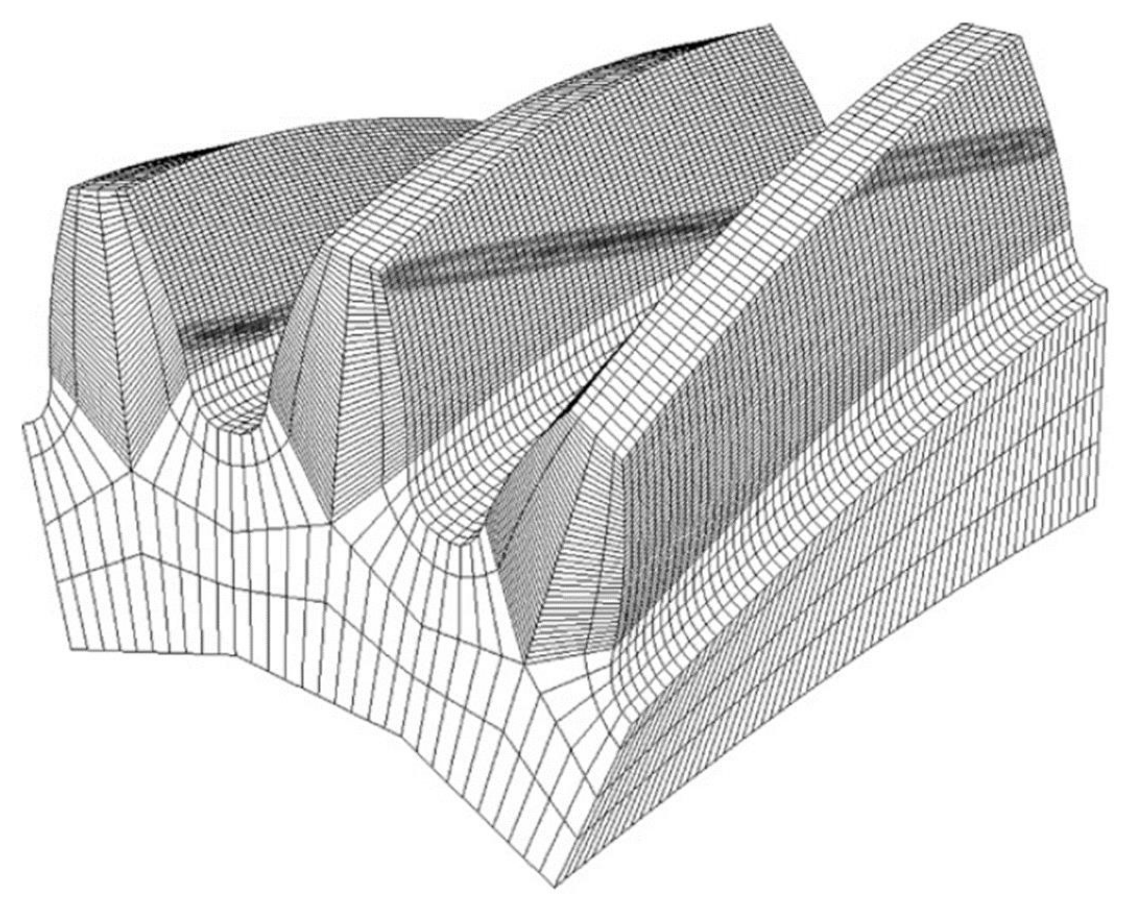

Figura 9 - Malha simplificada de engrenagem helicoidal apresentada por Sanchez et al. (2013)

Sendo de grande interesse para esta dissertação, o MEF permite implementação de equacionamentos da literatura ou criação de novos modelos matemáticos (APONTE, 2011). Nos próximos subcapítulos serão apresentados uma breve revisão sobre dois programas que aplicam o MEF, sendo ambos usados na literatura e neste trabalho.

\subsubsection{Programas de elementos finitos}

Existem diferentes programas de elementos finitos. Neste trabalho foi utilizado o programa Abaqus ${ }^{\circledR}$ é uma ferramenta de análise numérica e possui uma extensa biblioteca de elementos geométricos e leis constitutivas, podendo assim resolver de maneira generalizada diferentes problemas (APONTE, 2011). Este programa foi utilizado em análises anteriores e alguns dos resultados obtidos são apresentados para ilustrar o potencial de aplicação em sistemas lubrificados.

Qin; Guan (2014) e Fukumasu et al. (2016) aplicaram o programa Abaqus® para estudar as tensões na linha de contato de um engrenamento e possíveis causas que contribuem para as falhas dos dentes das engrenagens. Qin e Guan usaram engrenagem de dentes retos em seus estudos (Figura 10b). A Figura 10a mostra o resultado da distribuição de tensões de Von Mises na seção transversal dos dentes. É possível observar que o raio do pé do dente funciona como um concentrador de tensões e que os maiores valores de tensões de Von Mises estão na subsuperfície da região de contato, como 
mostrado graficamente na Figura 10d. A Figura 10b mostra a malha de elementos finitos no engrenamento e um refinamento na malha no dente e na região de contato e de interesse para o estudo na Figura 10c.

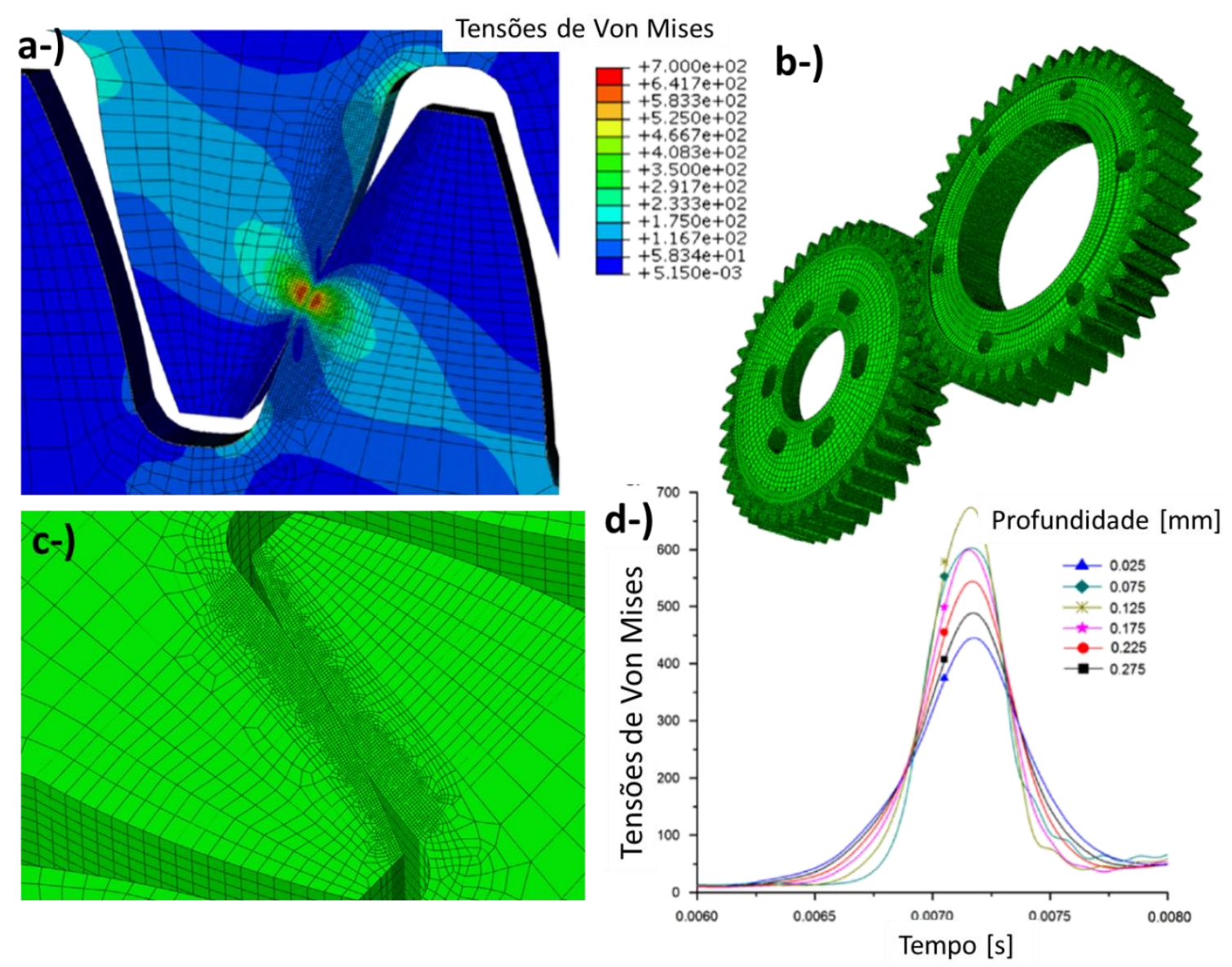

Figura 10 - a-) Resultado da distribuição de tensões de Von Mises nos dentes. b-) Malha de elementos finitos usada na simulação. c-) Detalhe do refinamento da malha na região de contato dos dentes. d-) Resultado da variação das tensões de Von Mises em relação a profundidade na região de contato entre os dentes das engrenagens. Adaptado de (QIN; GUAN, 2014)

Já no estudo apresentado por Fukumasu et al. (2016), em seu modelo numérico, foram utilizadas engrenagens de dentes helicoidais. A Figura 11a mostra a região de contato em vermelho distribuída em três pares de dentes. Na Figura 11b é apresentado os resultados obtidos em relação a distribuição de tensões de Von Mises ao longo do perfil do dente na região central de sua largura. As curvas representam diferentes tensões residuais na superfície e a faixa em cinza, mostra a região de contato do dente em um instante do engrenamento. 

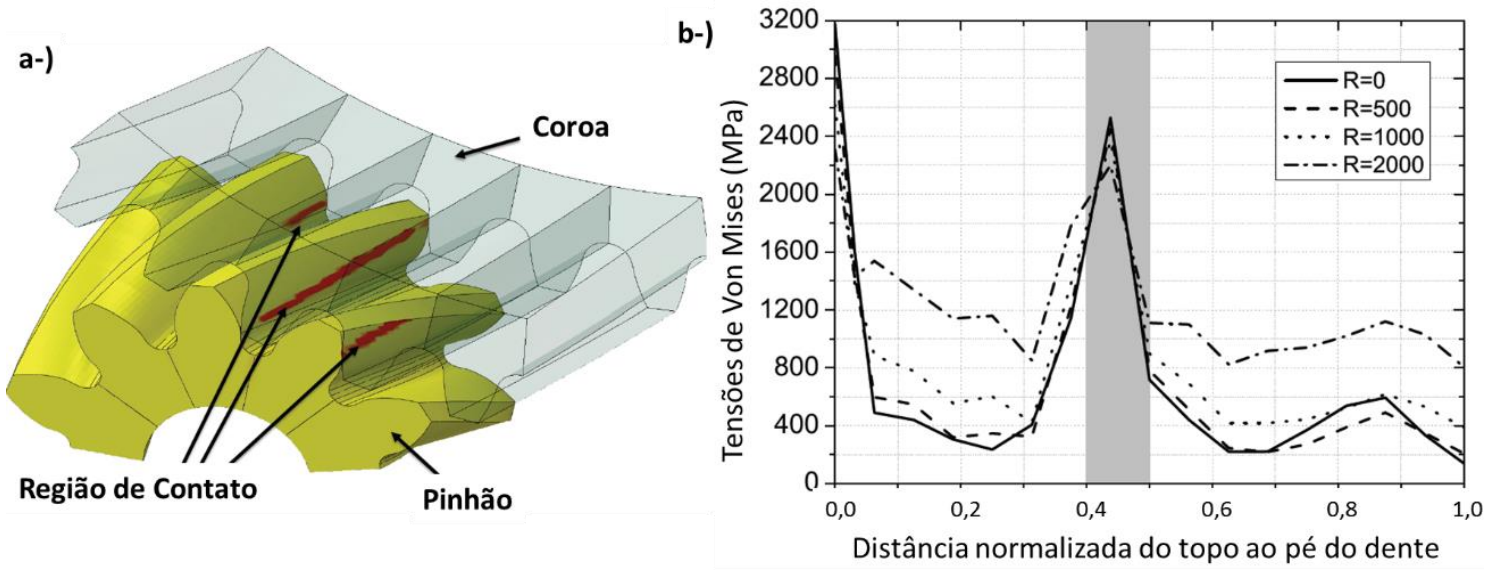

Figura 11 - a-) Região de contato dos pares dos dentes em vermelho. b-) Distribuição das tensões de Von Mises ao longo do perfil do dente e na região central da sua largura em um instante do engrenamento.

Adaptado de (FUKUMASU et al., 2016)

\subsubsection{AVL Excite Power Unit}

O AVL Excite Power Unit é um programa para projetar, analisar e otimizar sistemas de motores e transmissões. Sendo a análise dinâmica de multi-corpos flexíveis (MBD - Multi-Body Dynamic), a principal característica deste programa é que ele leva em consideração na simulação de sistemas complexos, vários corpos e a interação não linear entre eles. Cada corpo utiliza modelos para representar o contato, a influência de vibração, rotação e oscilações, que ocorrem durante o engrenamento. Os modelos utilizados neste programa já foram comparados e analisados com veículos e banco de provas reais (AVL LIST GMBH, 2016).

O ACYG (Advanced Cylindrical Gear Joint - Conector de Engrenagem Cilíndrica Avançado) é o principal conector deste programa em análise de engrenagens cilíndricas helicoidais para eixos paralelos, por possibilitar a inserção de uma quantidade maior de características do engrenamento. Neste conector, algumas restrições são consideradas: superfície do flanco ideal e o modelo de contato, o qual é utilizado somente para a interação entre os flancos (AVL LIST GMBH, 2016). Com esta interação, a pressão de contato é calculada com base na ISO 6336 (2006) pela equação (12).

$$
p_{H}=\sqrt{\frac{F * E^{\prime}}{2 \pi * \rho_{\text {ers }} * l *\left(1-v^{2}\right)}}
$$


Onde $p_{H}$ é a pressão de contato, $F$ é a força normal no contato, $E^{\prime}$ é o modulo de elasticidade reduzido, $\rho_{\text {ers }}$ é o raio de curvatura equivalente, $l$ é o comprimento da linha de contato na região de avaliação e $v$ é o coeficiente de Poisson. O cálculo de pressão de contato pelo programa, não leva em consideração a influência da rugosidade.

Uma aplicação com o programa da AVL Excite Power Unit foi desenvolvida por Sopouch; Resch; Herster (2016), onde estudaram a emissão acústica de uma transmissão automotiva manual. A Figura 12 esquematiza o modelo desenvolvido pelos autores com os principais itens da transmissão, como eixos, rolamentos e engrenagens, e em detalhe, a distribuição da força normal na linha de contato do par de engrenagens helicoidais. Os autores validaram os seus resultados com ensaios de banco. Sopouch; Resch; Herster (2016) escolheram o uso deste programa, para aplicação em engrenagem, devido a análise dinâmica de multi-corpos flexíveis (MBD) e por permitir um melhor detalhamento da geometria das engrenagens.

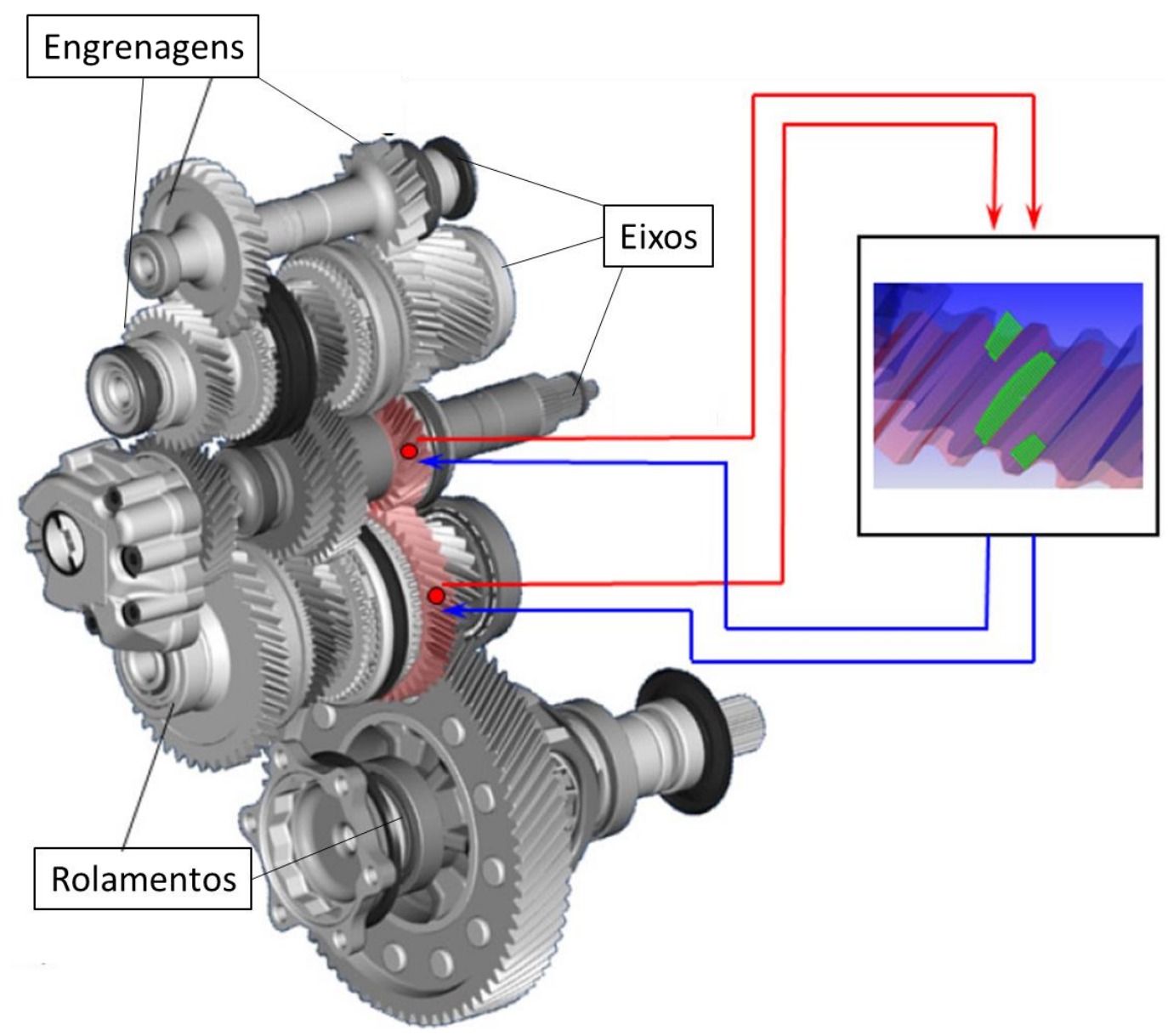

Figura 12 - Esquematização da transmissão automotiva manual com os seus principais componentes, como eixos, engrenagens e rolamentos. A distribuição de força normal, no par de engrenagens helicoidais, está representada no detalhe. 
Outra aplicação do programa AVL Excite Power Unit foi abordada por Villalva (2014), onde foi desenvolvido um novo programa computacional, que utilizou um método analítico e flexível para analisar as tensões e a fadiga de virabrequim em motores a diesel. Este trabalho validou seus resultados utilizando o programa AVL Excite Power Unit e ensaios experimentais. A Figura 13 mostra a modelagem utilizada no AVL e a malha construída no programa desenvolvido por Villalva. $\mathrm{O}$ autor conseguiu ter resultados com apenas $5 \%$ de erro comparando os resultados experimentais com os numéricos, mostrando assim uma correlação entre o banco de prova e o programa AVL Excite Power Unit.

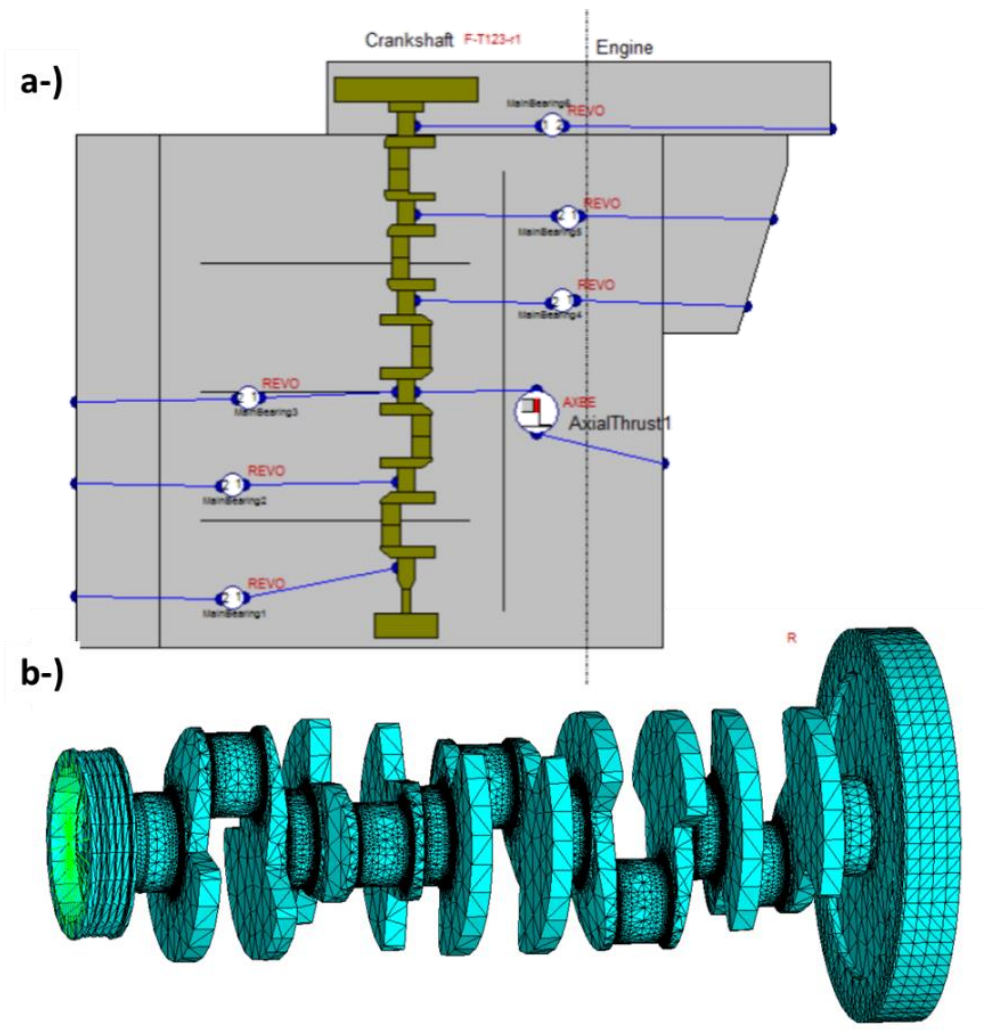

Figura 13 - Modelagem do virabrequim automotivo. a- Modelagem 2D no programa da AVL Excite Power Unit. b- Modelagem 3D e malha aplicada e desenvolvida por Villalva (2014).

\subsection{EFICIÊNCIA: AVALIAÇÃO DE UMA TRANSMISSÃO MANUAL AUTOMOTIVA}

Pirro; Webster; Daschner (2016) mostram que utilizando um veículo popular de passeio, em uma velocidade aproximada de $64 \mathrm{~km} / \mathrm{h}$ e usando gasolina como combustível, foi possível mapear as perdas conforme mostra a Figura 14. Do total de perdas mecânicas, a transmissão manual responde por $8 \%$. Vale a pena ressaltar que esta estimativa varia para cada veículo e condições ambientes. Porém, as principais fontes de 
perdas apresentadas são semelhantes às publicadas em outros trabalhos, como o de Holmberg; Andersson; Erdemir, (2012).

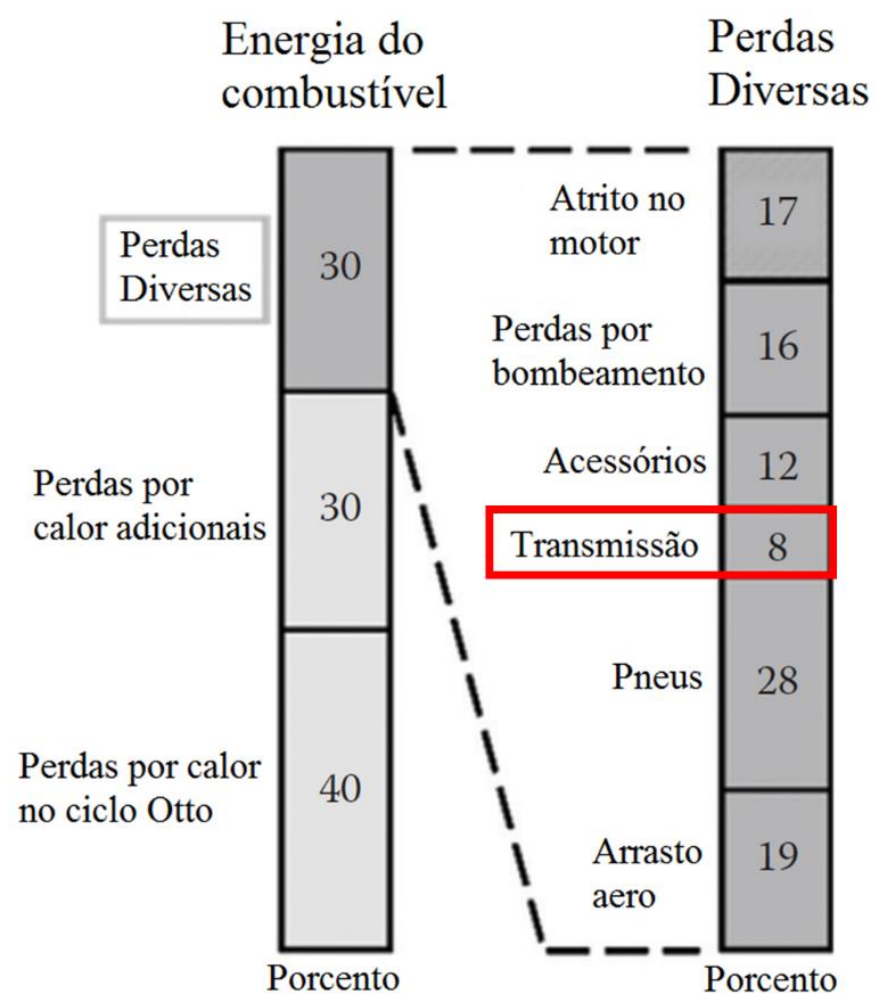

Figura 14 - Esquema da distribuição das perdas de energia de um veículo, popular de passeio à gasolina, viajando a 64km/h. Adaptado de (PIRRO; WEBSTER; DASCHNER, 2016).

Melhorias na eficiência da transmissão podem ser alcançadas de diversas maneiras, de acordo com Holmberg, na redução do coeficiente de atrito. Um aperfeiçoamento na geometria e no processo de fabricação da engrenagem, uso de revestimento e desenvolvimento de lubrificante que diminua o atrito são alternativas (HOLMBERG; ANDERSSON; ERDEMIR, 2012).

Amaro (2001) estudou o comportamento tribológico de revestimentos para engrenagens utilizando um banco de ensaios da FZG. O autor construiu um gráfico (Figura 15), que correlaciona a variação do $\lambda$, do SRR (que será abordado no capítulo 3.5.2) e da pressão de contato $\left(\mathrm{p}_{\mathrm{H}}\right)$, ao longo do perfil do dente da engrenagem. Sendo que no diâmetro primitivo (Ponto I), ocorre a maior espessura específica de filme lubrificante. Entre os pontos $\mathrm{A}$ e $\mathrm{C}$, na área do dedendo, existe uma região mais crítica para iniciar e propagar defeitos, principalmente para o pinhão, por causa do número maior de rotações em relação à coroa para um mesmo ensaio. 


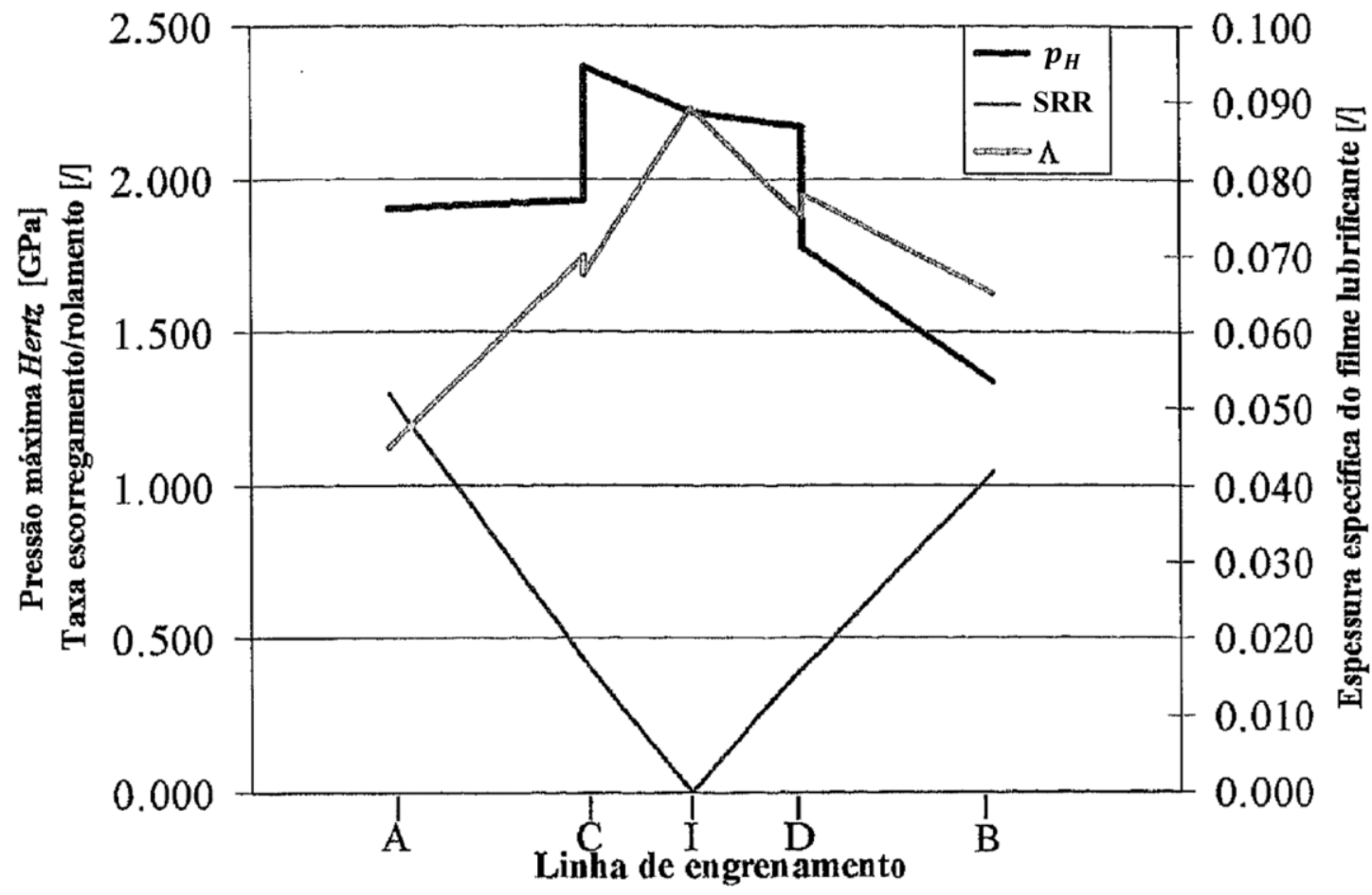

Figura 15 - Gráfico da variação da pressão máxima de contato, da taxa de deslizamento por rolamento e da espessura especifica do filme lubrificante ao longo do perfil do dente, para engrenagens de dente reto (AMARO, 2001).

Além do trabalho de Amaro, (2001), existem outras propostas na literatura com o intuito de melhorar a eficiência global da transmissão automotiva (HOLMBERG; ANDERSSON; ERDEMIR, 2012), que já foram mencionadas anteriormente. Esta dissertação irá utilizar um conjunto de análises numéricas para avaliar uma melhoria na eficiência a partir da variação da rugosidade superficial com o modelo de lubrificação nos dentes do engrenamento. Os próximos subcapítulos apresentaram uma revisão voltada para os fenômenos que ocorrem no engrenamento.

\subsubsection{Contato em engrenagens helicoidais}

O contato não-conforme das engrenagens é formado por uma linha ao longo da largura do dente, chamada de linha de contato. A Figura 16a mostra o comportamento desta linha para dente helicoidal. Na engrenagem de dente helicoidal, a linha de contato cruza a linha de diâmetro primitivo, em vários momentos diferentes do engrenamento, pois se desloca na diagonal do dente, influenciando na distribuição de carga e pressão na face do dente. 


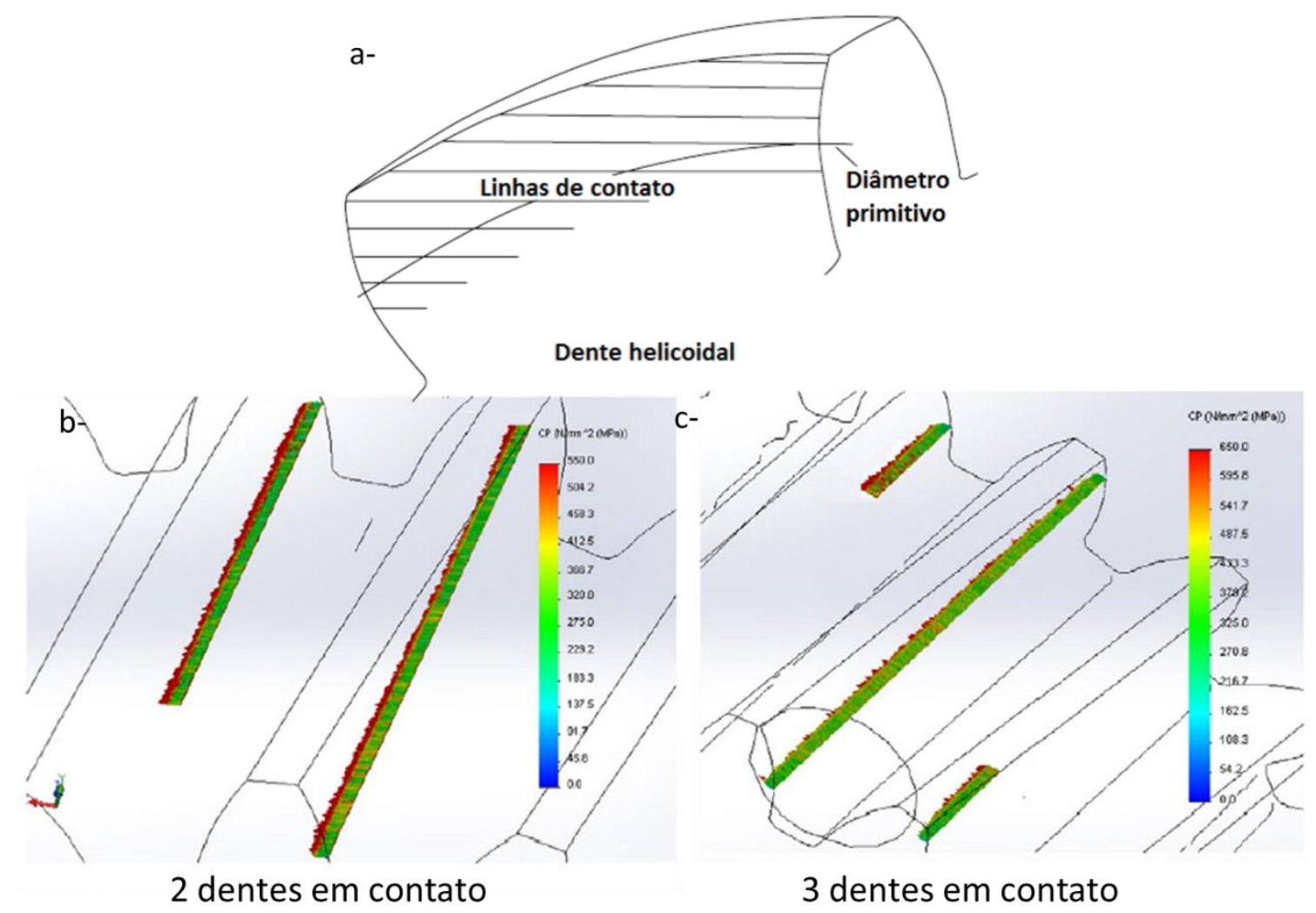

Figura 16 - a- Comportamento da linha de contato em dente helicoidal. (Adaptado de Pirro, et al. (2016)); b e c-Variação da linha de contato, em destaque, dividida em dois para três dentes durante o engrenamento (Adaptado de Jabbour e Asmar 2015).

A geometria das engrenagens helicoidais permite que ocorra mais do que um único dente em contato, como mostra a Figura 16(b e c), que mostra a variação de dois para três dentes, onde a distribuição de pressão de contato pode aumentar ou diminuir por este efeito.

Vaidyanathan (2009), em seus ensaios experimentais, utilizou engrenagens com configurações geométricas diferentes sendo possível avaliar o efeito do módulo, ângulo de pressão e hélice, rotação e torque na perda de potência e comparar com modelos analíticos da literatura. As condições de rotações estudadas pelo autor foram de $2000 \mathrm{rpm}$, $4000 \mathrm{rpm}$ e $6000 \mathrm{rpm}$. Em seus ensaios foi possível observar que quanto maior o torque, menor é a eficiência e, quanto menor a rotação, a eficiência também é menor. Este comportamento não é linear, dependendo assim das condições de operação. $\mathrm{O}$ autor também concluiu que o módulo e o ângulo de pressão têm maiores influências do que o ângulo de hélice. 


\subsubsection{Cinemática da engrenagem helicoidal}

Em função da geometria e do contato, durante o engrenamento, o dente da engrenagem sofre uma complexa combinação de rolamento e deslizamento das superfícies em contato, a qual varia ao longo do perfil do dente (AL-TUBI et al., 2015), conforme mostra a Figura 17. As setas em vermelho indicam a direção da velocidade de deslizamento e as setas em verdes a direção da velocidade de rolamento. Quando as direções das velocidades de rolamento e deslizamento estiverem alinhadas, a relação das velocidades será positiva, porém, em sentidos opostos, essa relação é negativa.

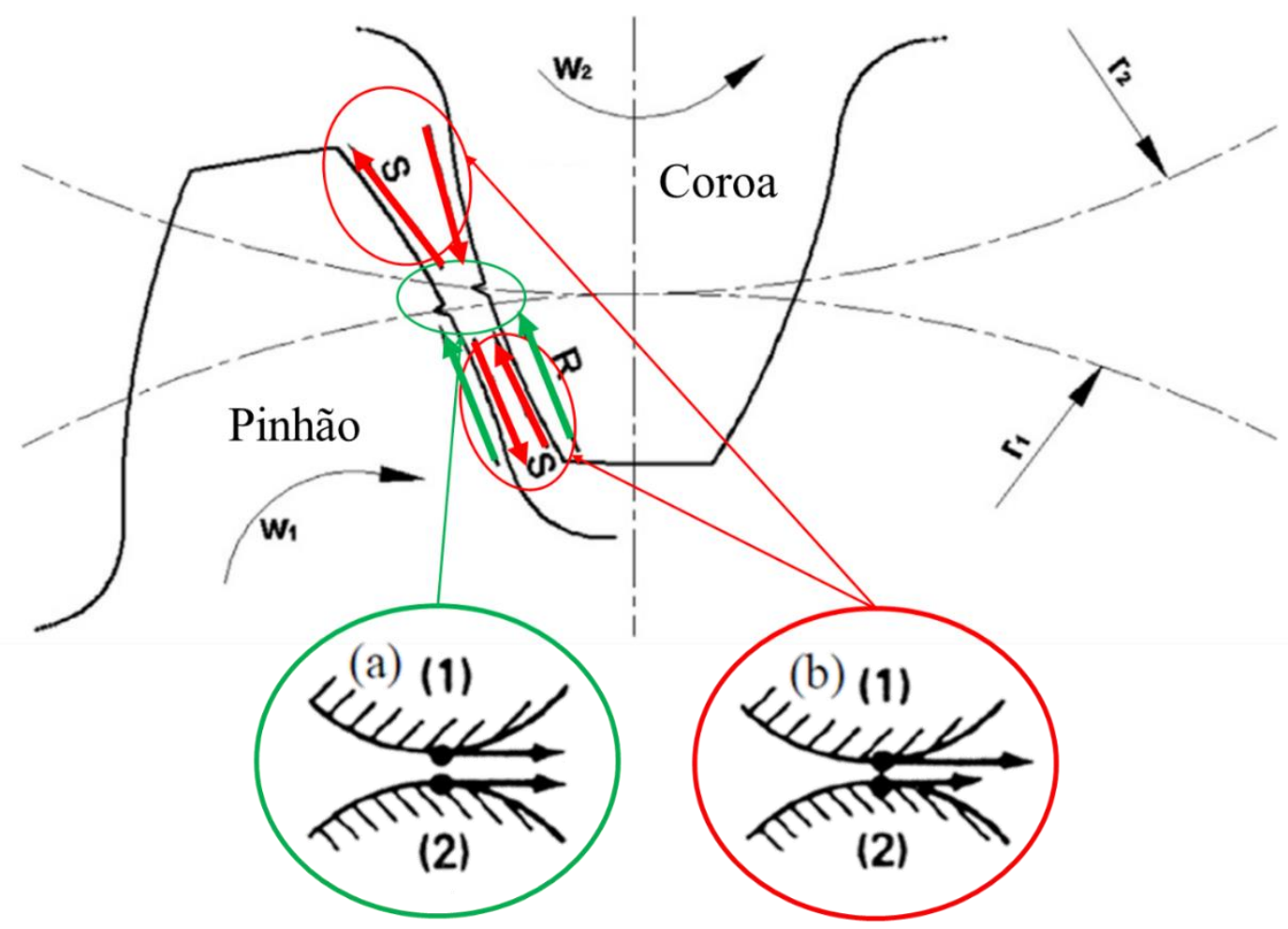

Figura 17 - Esquema das regiões de rolamento e deslizamento dos dentes das engrenagens adaptado com um esquema de movimento entre duas superfícies. (a) Rolamento puro, (b) combinação deslizamento e rolamento. Adaptado de Al-Tubi et al (2015) e (Matos, 2004).

A velocidade de rolamento é contínua durante todo o engrenamento (curva verde do gráfico na Figura 18), porém a velocidade de deslizamento muda de direção, iniciando em uma porcentagem de deslizamento máximo que diminui até zero no diâmetro primitivo. Na sequência do movimento, a velocidade de deslizamento aumenta até o valor máximo no final do engrenamento, como mostra a curva em vermelho da Figura 18. Este comportamento ocorre em todos os dentes das engrenagens acopladas. No caso das 
engrenagens helicoidais, o deslizamento não é perpendicular à linha de contato, o deslizamento também ocorre no perfil do dente, na sua largura.

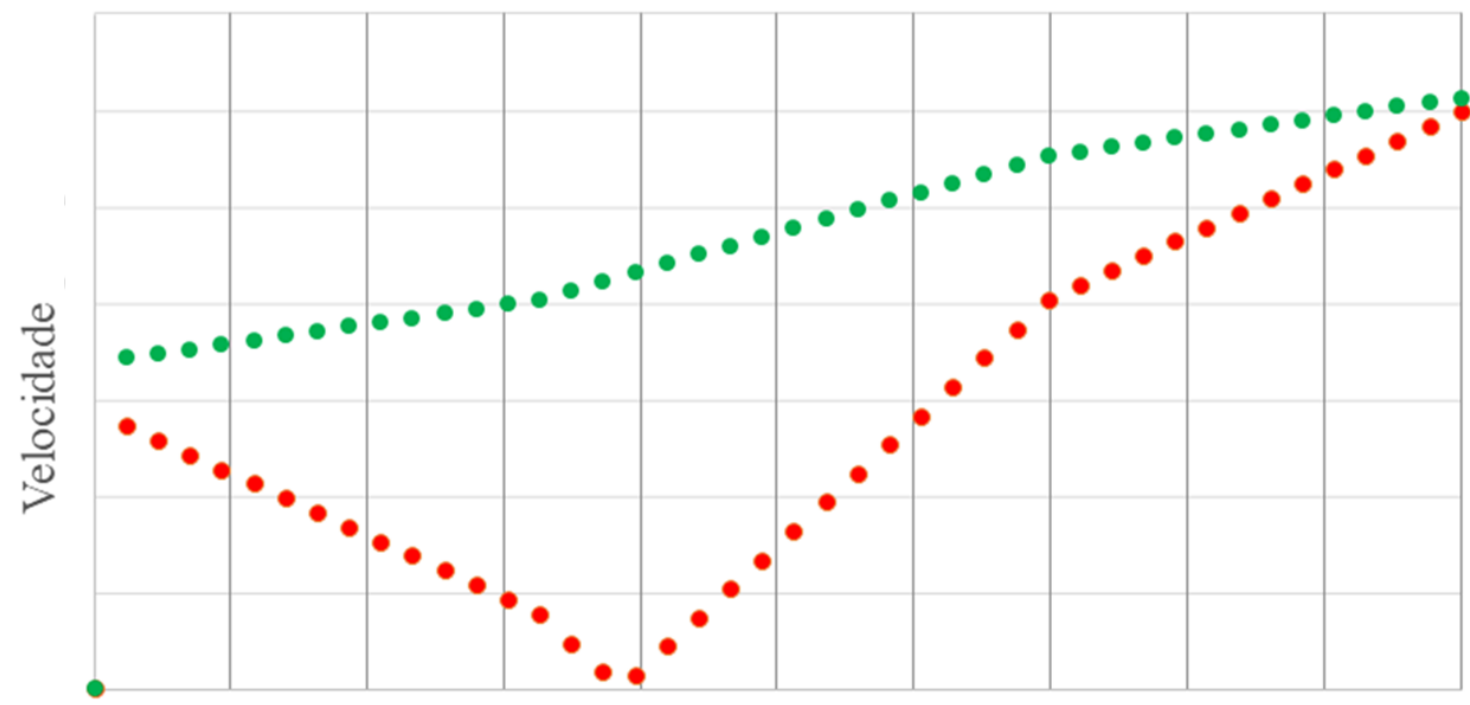

\section{Coordenada relativa do caminho do contao}

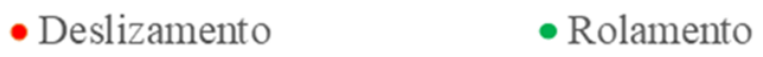

Figura 18 - Esquematização da velocidade de deslizamento e rolamento ao longo do contato. Adaptado de (KLUBER, 1998).

Uma maneira de relacionar a velocidade de deslizamento e rolamento é usando a razão de deslizamento e rolamento (SRR). O SRR varia com o engrenamento dos dentes. No início do contato, o SRR começa com valores máximos e diminui até zero, no diâmetro primitivo, depois aumenta até um SRR máximo, já no final do engrenamento, como ilustra a Figura 19. 


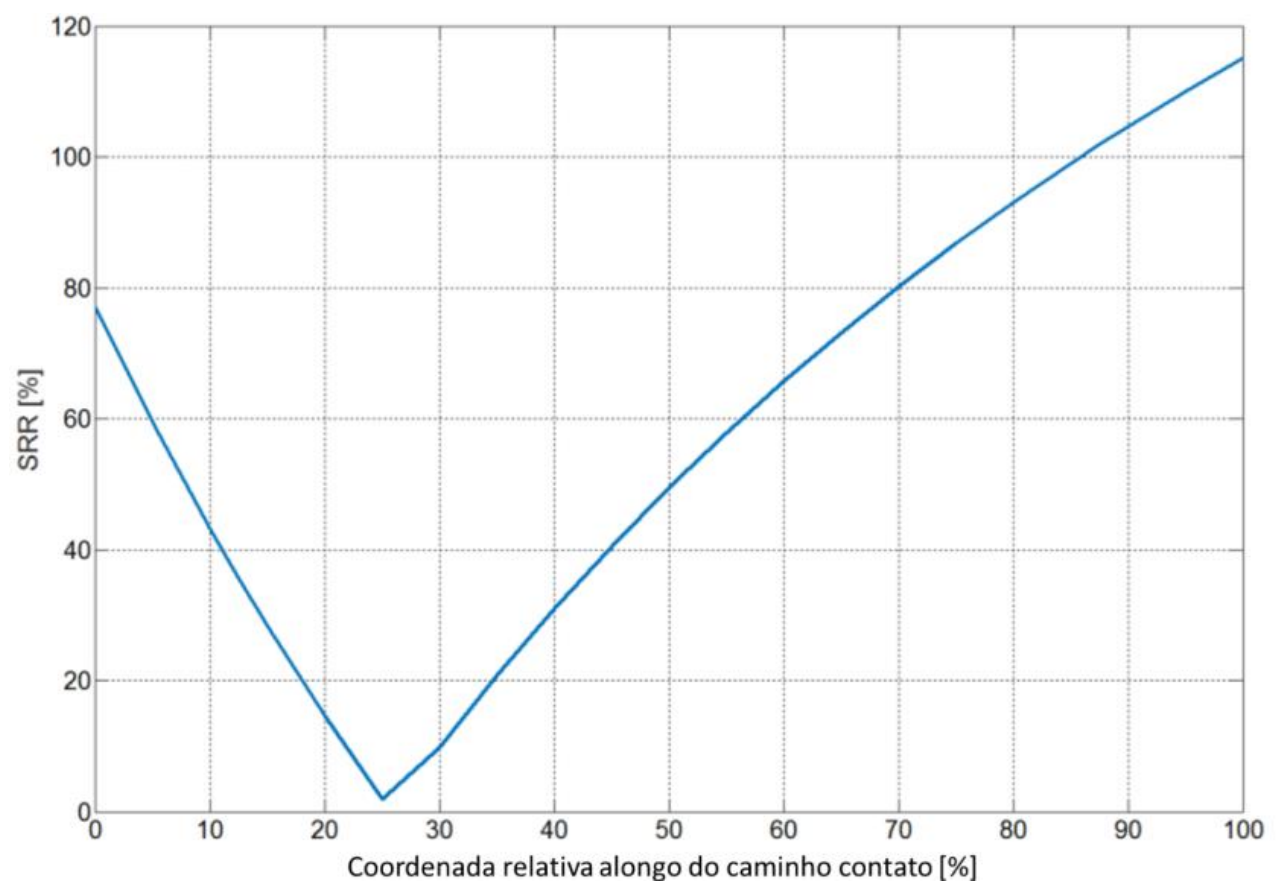

Figura 19 - Variação do SRR em dentes helicoidais. Adaptado de (FIGUEIREDO, 2017).

As equações (13)(14)(15) descrevem as velocidades de deslizamento e rolamento e o SRR, respectivamente:

$$
\begin{gathered}
U_{S}=U_{1}-U_{2} \\
U_{R}=\frac{\left|U_{1}-U_{2}\right|}{2} \\
S R R=\frac{U_{S}}{U_{R}}
\end{gathered}
$$

Sendo $U_{1}$ a velocidade tangencial do pinhão, $U_{2}$ a velocidade tangencial da coroa, Us a velocidade de deslizamento e $U_{R}$ a velocidade de rolamento. O SRR é afetado principalmente pela geometria do dente da engrenagem.

\subsubsection{Regimes de lubrificação em engrenamento}

Naunheimer et al (2011) resumiram, como apresentado na Figura 20, os principais regimes de lubrificação que ocorrem no dente da engrenagem. No topo e pé do dente os regimes de lubrificação podem variar entre limítrofe e misto, tendo nestas regiões um maior valor de coeficiente de atrito em comparação com a região do diâmetro primitivo, onde ocorrem regimes misto ou filme completo. 


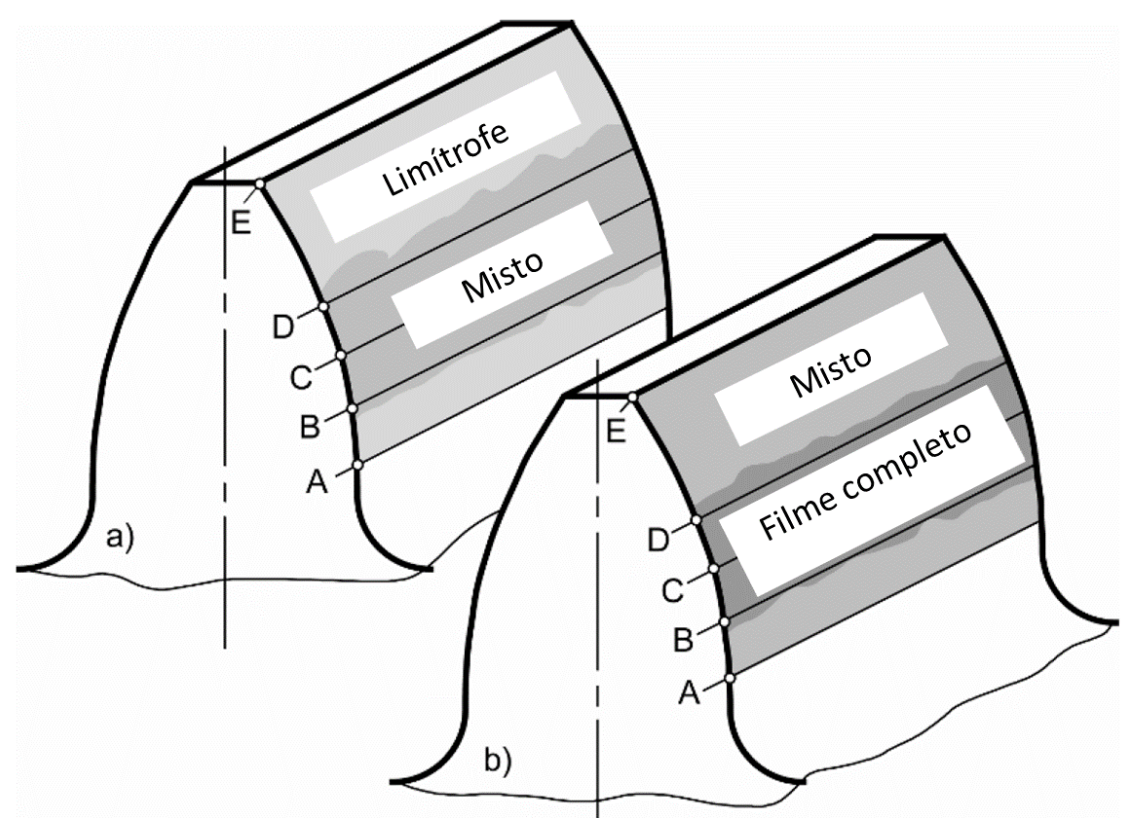

Figura 20 - Esquema dos regimes de lubrificação encontrados na superfície do dente de engrenagem. a) Para velocidade tangencial de até $5 \mathrm{~m} / \mathrm{s}$. b) Para velocidade tangencial acima de $5 \mathrm{~m} / \mathrm{s}$. Adaptado de (NAUNHEIMER et al., 2011)

Pirro; Webster; Daschner, (2016) recomendam a utilização de lubrificantes com baixa viscosidade para uso em sistemas com maiores velocidades, pois maior será a movimentação do lubrificante e mantendo assim um filme na área de contato. Porém, com o aumento da velocidade, a temperatura do lubrificante tende a aumentar devido ao efeito do atrito e do deslizamento ao longo da linha de contato, resultando em uma diminuição da viscosidade, conforme Figura 21 (AL-TUBI et al., 2015)

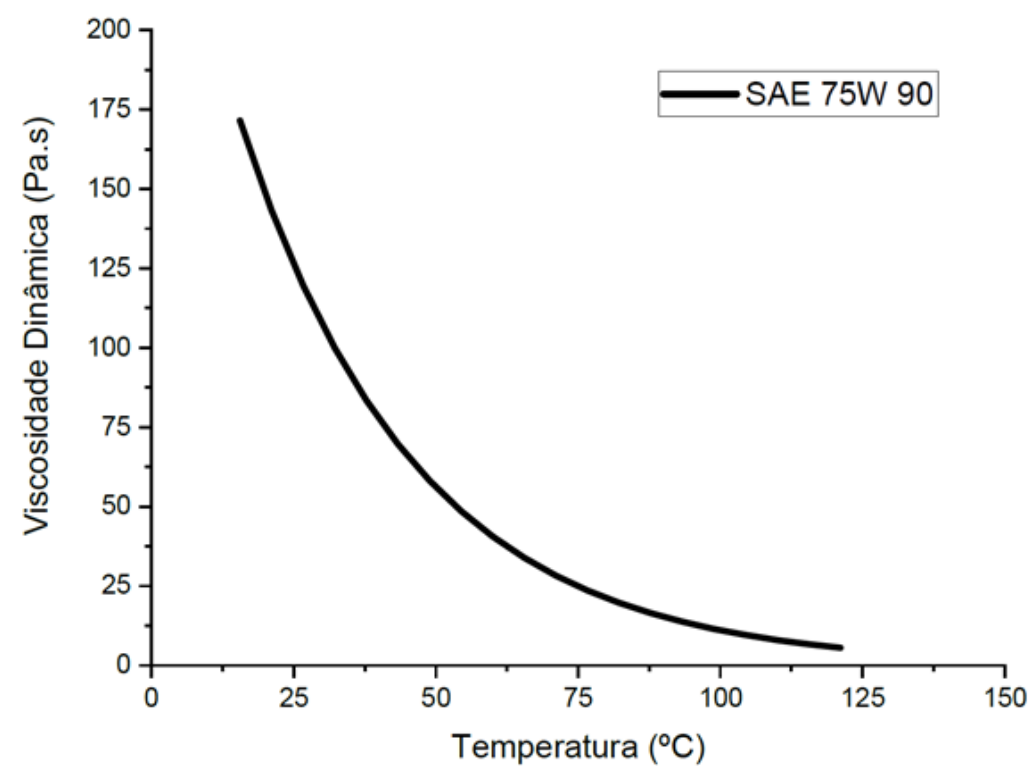

Figura 21 - Variação da viscosidade em função da temperatura para o óleo SAE75W-90. Adaptado de (XLROTOR, 2016). 
Especificamente, em um câmbio automotivo é normal obter variações entre regimes limítrofe e misto ao longo do contato (ABRAHAM, 2014), isto ocorre em função das condições de alta pressão e elevada velocidade de deslizamento das engrenagens. É importante também ressaltar que para engrenagens helicoidais, a geometria em hélice tende a remover o lubrificante na área frontal ao contato (Figura 22), empurrando lateralmente e assim dificultando a formação do filme lubrificante (PIRRO; WEBSTER; DASCHNER, 2016).

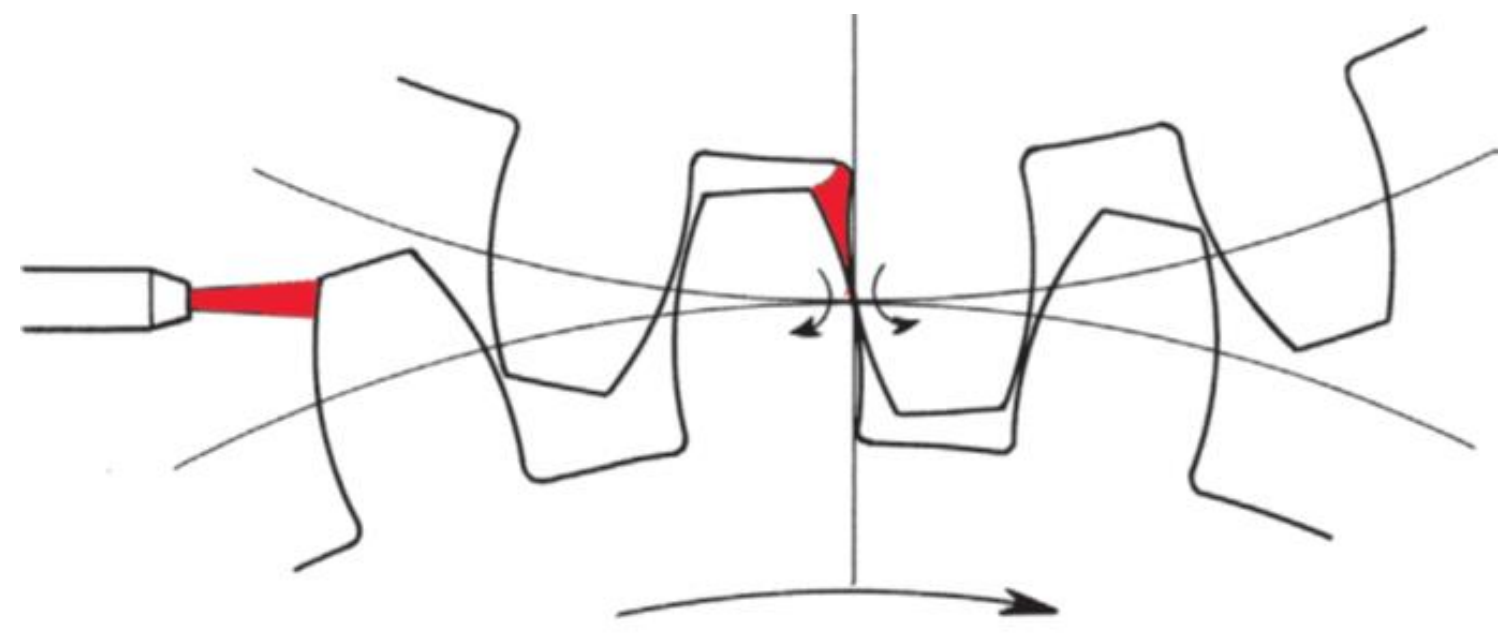

Figura 22 - Lubrificação na área frontal do contato. Adaptado de (PIRRO; WEBSTER; DASCHNER, 2016).

Aplicando os parâmetros de lubrificação, como viscosidade e cinemática do movimento, um esquema de um mapa do coeficiente de atrito em função do SRR é ilustrado na Figura 23 para um par de engrenagens em condições de lubrificação EHL. No ponto 0 , indicado pela região 2 , não ocorre deslizamento, portanto, o atrito é muito pequeno entre as superfícies e não ocorrendo de forma significativa o cisalhamento do filme. Com o acréscimo do deslizamento, ou seja, aumentando o SRR, na direção direita do eixo da abscissa, é gerado um aumento de atrito no contato e cisalhamento do filme, como mostram as regiões 1 e 3 . 


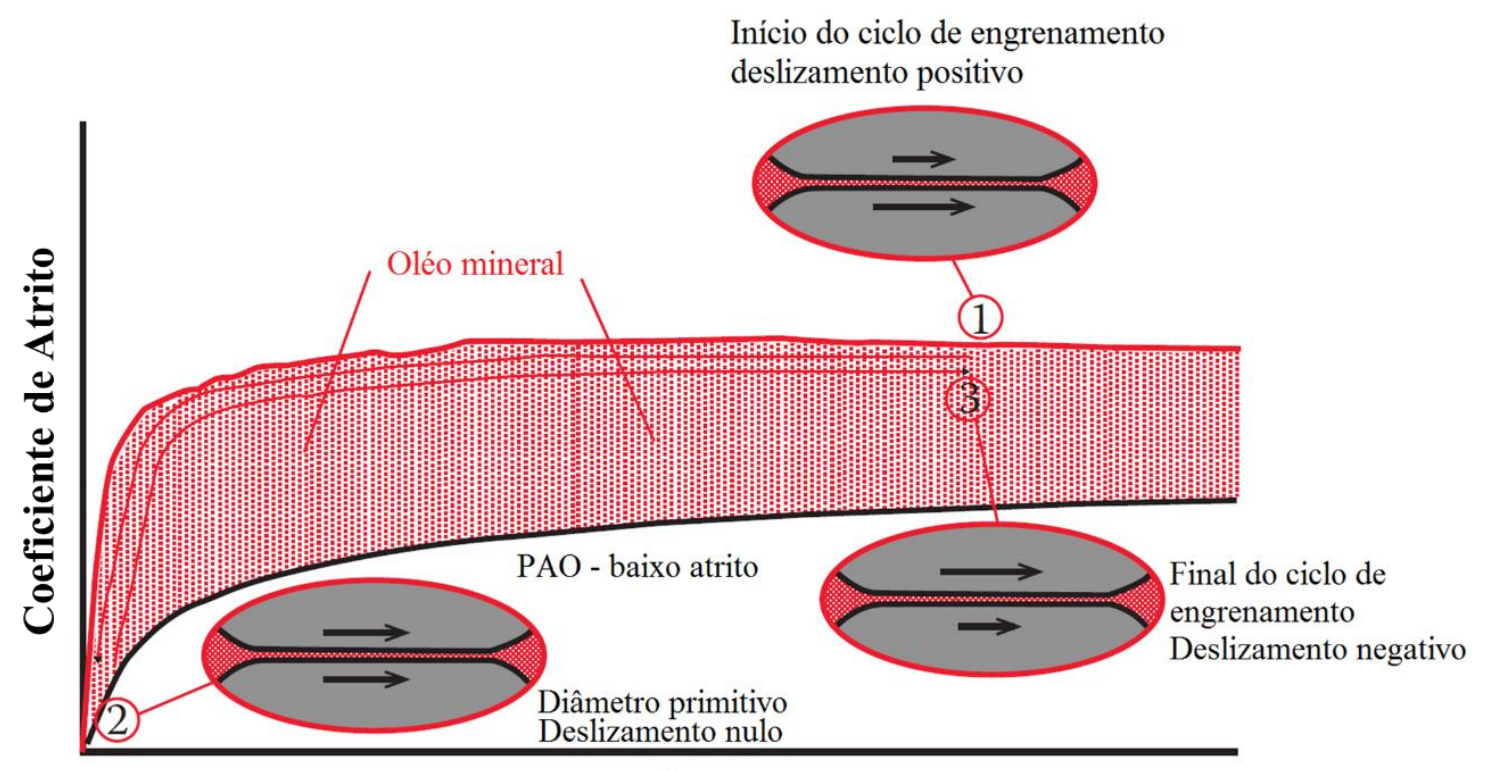

SRR

Figura 23 - Comportamento do coeficiente de atrito em função do SRR. Na região 1 e 3 maiores valores de $\mu$ devido ao deslizamento. Na região 2, indicado pelo deslizamento nulo, mínimos valores de $\mu$. Adaptado de (PIRRO; WEBSTER; DASCHNER, 2016).

Klein (2012) considerou que os regimes de lubrificação, em função do Rz, durante o engrenamento, variam para o $\lambda_{\text {Rz: }}$ maior que 1 é considerado regime elastohidrodinâmico e abaixo de 0,35 é considerado regime limítrofe, entre os dois está presente o regime misto.

\subsubsection{Eficiência mecânica de engrenagem helicoidal}

Foram apresentadas as variações de condições de contato e atrito ao logo do engrenamento, permitindo uma análise detalhada do sistema. Outras perdas de eficiência podem ser avaliadas de forma semelhante. A literatura (PIRRO; WEBSTER; DASCHNER, 2016) indica dois principais modos de perda de eficiência no contato em função do atrito (meshing losses) em meio lubrificado: o primeiro está relacionado com o cisalhamento do lubrificante e o segundo correspondente as asperezas que colidem e deslizam sobre as outras. Fora do contato existem as perdas devido o fluxo de óleo (churning losses) e de ar (windage losses) (STAVYTSKYY et al., 2010). Essas duas últimas, churning e windage losses, têm baixa influência em relação às meshing losses. A nomenclatura em inglês é muito utilizada e em função disso é destacada neste texto.

Por outro lado, o uso de sistemas complexos dificulta essas análises de componentes. A literatura (FISCHER et al., 2015; VAIDYANATHAN, 2009) apresenta 
algumas maneiras de quantificar e prever a eficiência da transmissão. Neste trabalho será usada uma das maneiras mais diretas para avaliação da eficiência $(\eta)$, sendo quantificada como apresentado na equação (16), onde a potência de saída $\left(\mathrm{P}_{\underline{s}}\right)$ e a potência de entrada $\left(\mathrm{P}_{\mathrm{e}}\right)$ são relacionadas.

$$
\eta=\frac{P s}{P e}
$$

A equação 16 consistirá em uma análise global e uma avaliação em função de aspectos topográficos e cinemáticos, que permitem avaliar atrito e ou perdas em função das características do par engrenado. 


\section{MATERIAIS E MÉTODOS}

Neste capítulo será apresentada uma descrição da metodologia e as propriedades dos materiais e do óleo lubrificante utilizados nas simulações.

\subsection{MODELO DE ATRITO}

O modelo aplicado, via subrotina no MEF, para obter o coeficiente de atrito usado nas simulações deste trabalho, foi desenvolvido analiticamente por Klein (2012) e calculado com base na teoria da lubrificação elastohidrodinâmica. Este modelo, equação (6), apresentado na revisão, foi escolhido devido à sua correlação para o contato real do engrenamento, por levar em consideração, no seu desenvolvimento, o deslocamento axial e o ângulo de hélice e por ser um dos modelos usados no programa da AVL Excite Power Unit.

$\lambda_{z}$ é calculado com a espessura específica de filme de lubrificante real dada pela equação (7). Neste modelo, a espessura de filme do lubrificante $\left(\mathrm{h}_{0}\right)$, é calculada de acordo com a formula criada por Grubin (1949) e aprimorada por Ertl (1984), na equação (17).

$$
h_{0}=1.95 .10^{3} \rho_{e r s} G^{0.73} U^{0.73} W^{-0.09}
$$

G, U e W são termos da equação, onde $\mathrm{G}$ é um parâmetro adimensional do material, calculado pela equação (18):

$$
G=\alpha E^{\prime}
$$

Nesse adimensional, $\alpha$ é o coeficiente de pressão-viscosidade $\left[\mathrm{Pa}^{-1}\right]$ e E' é o modulo de elasticidade reduzido (equação (19)):

$$
\frac{1}{E^{\prime}}=\left(\frac{1-v_{1}^{2}}{E_{1}}+\frac{1-v_{2}^{2}}{E_{2}}\right)
$$

Os números 1 e 2 indicam as propriedades dos materiais do pinhão e coroa, respectivamente. $\mathrm{O}$ parâmetro $\mathrm{U}$ é um adimensional de velocidade e calculado pela equação (20):

$$
U=\frac{2 \eta_{0} U_{R}}{E^{\prime} \rho_{e r s}}
$$


No qual $\eta_{0}$ [Pa.s] é a viscosidade dinâmica do lubrificante, $U_{R}[\mathrm{~m} / \mathrm{s}]$ é a velocidade de rolamento e $\rho_{\text {ers }}[\mathrm{m}]$ o raio de curvatura equivalente, dados pela equação (21), equação (22) e equação (23):

$$
\begin{gathered}
\rho_{1}=\frac{\omega_{1}}{U_{1}} \\
\rho_{2}=\frac{\omega_{2}}{U_{2}} \\
\rho_{\text {ers }}=\frac{\left(\frac{1}{\rho_{1}}+\frac{1}{\rho_{2}}\right)^{-1}}{2}
\end{gathered}
$$

Sendo que $\rho_{1}[\mathrm{~m}]$ o raio de curvatura do pinhão, $\rho_{2}[\mathrm{~m}]$ o raio de curvatura da coroa, $\omega_{1}[\mathrm{rad} / \mathrm{s}]$ a rotação angular do pinhão, $\omega_{2}[\mathrm{rad} / \mathrm{s}]$ a rotação angular da coroa, $\mathrm{U}_{1}$ $[\mathrm{m} / \mathrm{s}]$ a velocidade tangencial do pinhão e $U_{2}[\mathrm{~m} / \mathrm{s}]$ a velocidade tangencial da coroa. $\mathrm{O}$ parâmetro adimensional W é função da carga e é definido pela equação (24):

$$
W=\frac{F}{E^{\prime} \cdot \rho_{\text {ers }}}
$$

Onde $\mathrm{F}[\mathrm{N}]$ é a força normal aplicada no contato.

\subsection{GEOMETRIA E MATERIAL DO ENGRENAMENTO}

Para as simulações, foi utilizada uma geometria de perfil de dente helicoidal. Os parâmetros e características das engrenagens são apresentados na Tabela 2. Essa geometria de engrenagem helicoidal é usada em câmbio automotivo manual. Na Figura 24 está representado o modelo do par engrenado, sendo os dentes em azul, o pinhão e, em vermelho, a coroa. 
Tabela 2 - Dados geométricos do par engrenado

\begin{tabular}{|c|c|c|}
\hline & Pinhão & Coroa \\
\hline Número de Dentes & 11 & 47 \\
\hline Adendo [mm] & 33,8 & 117,3 \\
\hline Correção adendo & 0,595 & $-0,856$ \\
\hline Dedendo [mm] & 23,65 & 107,2 \\
\hline Módulo normal [mm] & \multicolumn{2}{|c|}{2,1} \\
\hline Distância entre eixo [mm] & \multicolumn{2}{|c|}{71} \\
\hline Ângulo de pressão normal [ ${ }^{\circ}$ ] & \multicolumn{2}{|c|}{17} \\
\hline Ângulo de hélice [ ${ }^{\circ}$ ] & \multicolumn{2}{|c|}{31} \\
\hline Largura [mm] & \multicolumn{2}{|c|}{16} \\
\hline
\end{tabular}

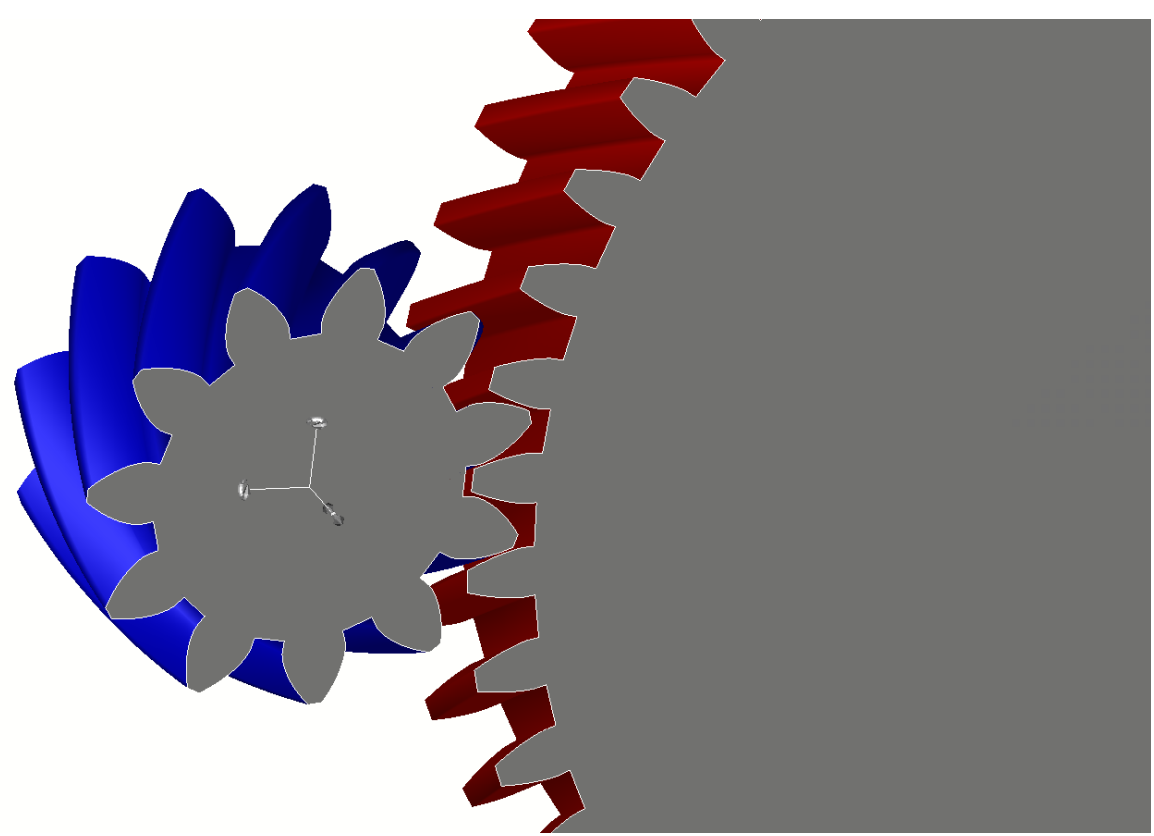

Figura 24 - Modelo do engrenamento utilizado no programa AVL Excite Power Unit. Em azul o pinhão e em vermelho a engrenagem

A Tabela 3 mostra as propriedades mecânicas dos materiais das engrenagens, que apresentam comportamento elásto-plástico, para a condição do par engrenado utilizado nas simulações.

Tabela 3 - Propriedades mecânicas do par de engrenagens

\begin{tabular}{|c|c|c|}
\hline & Pinhão & Engrenagem \\
\hline Módulo de Elasticidade & $210 \mathrm{GPa}$ & $210 \mathrm{GPa}$ \\
\hline Coeficiente de Poisson & 0,3 & 0,3 \\
\hline Densidade & $7,98 \mathrm{Kg} / \mathrm{m}^{3}$ & $7,98 \mathrm{Kg} / \mathrm{m}^{3}$ \\
\hline Limite de escoamento & $1,3 \mathrm{GPa}$ & $1,3 \mathrm{GPa}$ \\
\hline
\end{tabular}


Na avalição conduzida neste trabalho foi utilizado o parâmetro Rz para quantificar a rugosidade, pois as engrenagens trabalham com movimento de deslizamento entre as superfícies em contato. Este parâmetro, Rz, é geralmente mais sensível às mudanças de acabamento superficial do que Ra e Rq (HUTCHINGS; SHIPWAY, 2017; TAVARES; TAVARES, 2012).

\subsubsection{Topografia}

Neste trabalho foram utilizados 3 valores diferentes de rugosidades, que representam superfícies de processos de usinagem e acabamento para engrenagens. Os valores de $\mathrm{Rz}=0,5 \mu \mathrm{m}, 3 \mu \mathrm{m}$ e $7 \mu \mathrm{m}$ caracterizam, respectivamente, superfícies polidas, retificadas e fresadas. $\mathrm{O} R z$ de $0,5 \mu \mathrm{m}$ e $3 \mu \mathrm{m}$ foram retirados de tabelas de processos de usinagem da literatura (BLACK; KOHSER, 2012). O Rz de $7 \mu \mathrm{m}$ foi obtido das medições de análises topográficas de engrenagens da tese de Machado (2018), onde foram feitos ensaios em banco de prova com transmissões automotivas.

Para esta dissertação foram retiradas as engrenagens de primeira marcha, antes e depois dos ensaios de banco da tese de Machado (2018), para avaliar a rugosidade dos dentes. Esta análise da topografia dos dentes tem por objetivo obter valores reais de $\mathrm{Rz}$ para alimentar as simulações. Para isso foi utilizado o interferômetro Non-Contact Surface Profiler System e programa Talysurf CCI ambos de fabricação Mountains Technology®, com lente de 20x, gerando uma área de aproximadamente $800 \mu \mathrm{m} \mathrm{x}$ $800 \mu \mathrm{m}$. Este programa possui a ferramenta stitching para obter imagens de regiões extensas. As imagens foram feitas com espaçamento entre si de 2,1 $\mathrm{mm}$ e 2,5 $\mathrm{mm}$ da borda, conforme Figura 25. As regiões avaliadas iniciavam no pé do dente e terminavam no topo do dente, seguindo o ângulo de hélice, com uma área de 2,32 $\mathrm{mm}^{2}$, conforme região destacada em cinza na face do dente.

O processamento das imagens foi posteriormente analisado no programa TalyMap Gold v6.2.661, usando os seguintes filtros em sequência: leveling, non-measured point, gaussiano, com comprimento de amostragem de $800 \mu \mathrm{m}$, conforme norma ISO 4288 (2008) e removedor de forma com equação polinomial de ordem 4. A importância destas análises está em obter os valores de rugosidade encontradas em engrenagens fresadas comerciais para incluir nos modelos das simulações. 


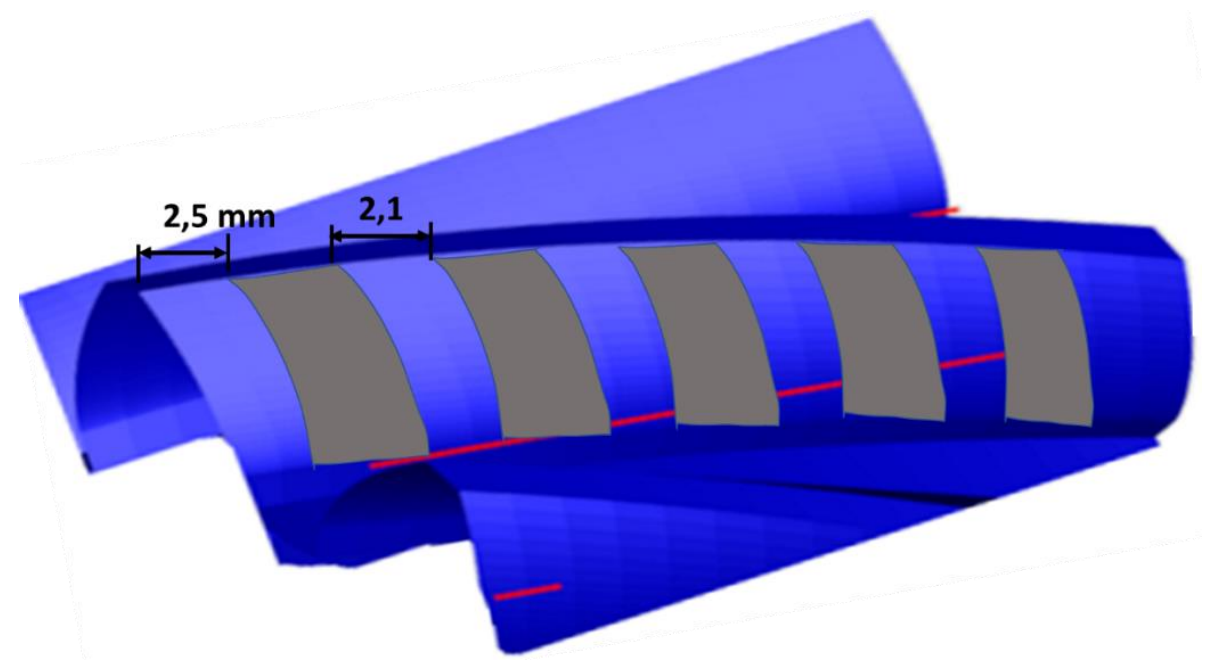

Figura 25 - Esquema das áreas selecionadas para avaliação topográfica, em cinza, da superfície do dente

\subsection{MODELO 1D}

O modelo 1D apresentado neste trabalho foi desenvolvido no programa AVL Excite Power Unit. Este programa permite a divisão do sistema mecânico em subsistemas e conectores não lineares entre os subsistemas. Os componentes (peças da transmissão) são representados por um modelo de elementos finitos condensados (as peças flexíveis são reduzidas a matrizes estruturais) e por dados de entrada como geometria, massa e rigidez dos corpos rígidos e flexíveis da transmissão. O modelo de simulação é criado em uma estrutura geométrica 2D para facilitar a visualização e compreensão, contudo a simulação é aplicada em um sistema 1D, com modelo de cálculo linear e solução no domínio do tempo ou da frequência, que permite analisar o comportamento não linear e transitório do sistema (KUIVANIEMI et al., 2017).

\subsubsection{Modelagem desenvolvida}

O sistema do câmbio simulado no AVL Excite Power Unit consiste de um motor, nomeado de $b$-pin, que fornece rotação e torque para o sistema, dois eixos (primário e secundário), um par de engrenagens, 5 rolamentos e um sistema de diferencial, conforme apresentado na Figura 26. Os dados geométricos das engrenagens e propriedades dos materiais, que estão listados no início deste capítulo, na Tabela 2 e na Tabela 3, foram inseridos no conector ACYG, representando o par engrenado, e tem o modelo de atrito desenvolvido por Klein (2012).

As velocidades angulares utilizadas no eixo de entrada foram de 1000 e $4000 \mathrm{rpm}$. É importante mencionar que foi mantido o mesmo torque de entrada com $140 \mathrm{Nm}$. Esses 
valores foram retirados de ensaios de banco de prova de transmissões automotivos avaliados na tese de Machado (2018).

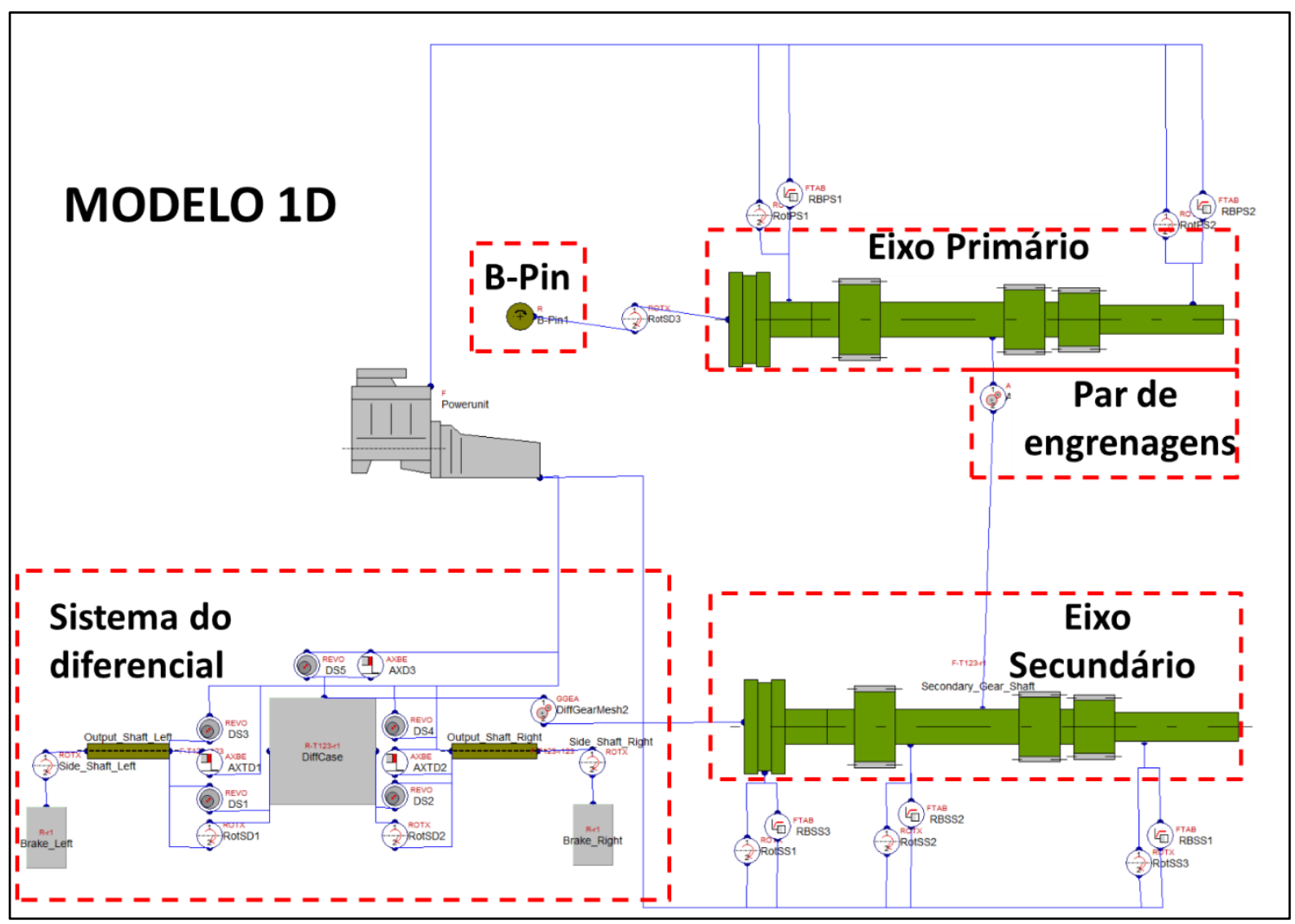

Figura 26 - Modelo 1D da transmissão utilizada nas simulações com o programa AVL Excite Power

Unit. Em destaque os principais elementos da transmissão, como, os eixos e o par de engrenagens.

A Tabela 4 apresenta as propriedades do óleo para transmissão SAE 75W-90 utilizadas nas simulações com a temperatura constante de $40^{\circ} \mathrm{C}$. Essa temperatura é utilizada em testes de banco de prova para transmissão manual automotiva em ensaios de eficiência (MACHADO, 2018).

Tabela 4 - Propriedades do óleo de transmissão comercial SAE 75W-90 (XLROTOR, 2016)

\begin{tabular}{|c|c|c|c|c|c|c|}
\hline \multicolumn{2}{|c|}{ Temperatura } & Densidade & $\begin{array}{c}\text { Viscosidade } \\
\text { Cinemática }\end{array}$ & $\begin{array}{c}\text { Viscosidade } \\
\text { Dinâmica }\end{array}$ & $\begin{array}{c}\text { Calor } \\
\text { Específico }\end{array}$ & $\begin{array}{c}\text { Condutividade } \\
\text { Térmica }\end{array}$ \\
\hline${ }^{\circ} \mathrm{C}$ & $\mathrm{F}$ & $\mathrm{kg} / \mathrm{m}^{3}$ & $\mathrm{cst}$ & Pa.s & $\mathrm{J} /(\mathrm{kg} \cdot \mathrm{C})$ & $\mathrm{W} / \mathrm{mK}$ \\
\hline 40 & 104 & 780,5 & 91,73 & $7,16 \mathrm{E}-02$ & $1,99 \mathrm{E}+03$ & $9,52 \mathrm{E}-04$ \\
\hline
\end{tabular}

\subsubsection{Fluxograma dos resultados obtidos no modelo 1D}

Dos muitos resultados que o programa AVL Excite Power Unit podem apresentar como saídas, foram selecionados os considerados principais, os quais são apresentados 
no fluxograma da Figura 27, para facilitar e simplificar o entendimento da sequência de resultados. Na entrada, conforme já mencionado, foi utilizado o valor de rugosidade e velocidade angular foram variados. Na saída, foram obtidos, para todos os casos, a eficiência do par engrenado, a pressão de contato, a força de atrito, a força normal e o raio de curvatura para o pinhão e a coroa.

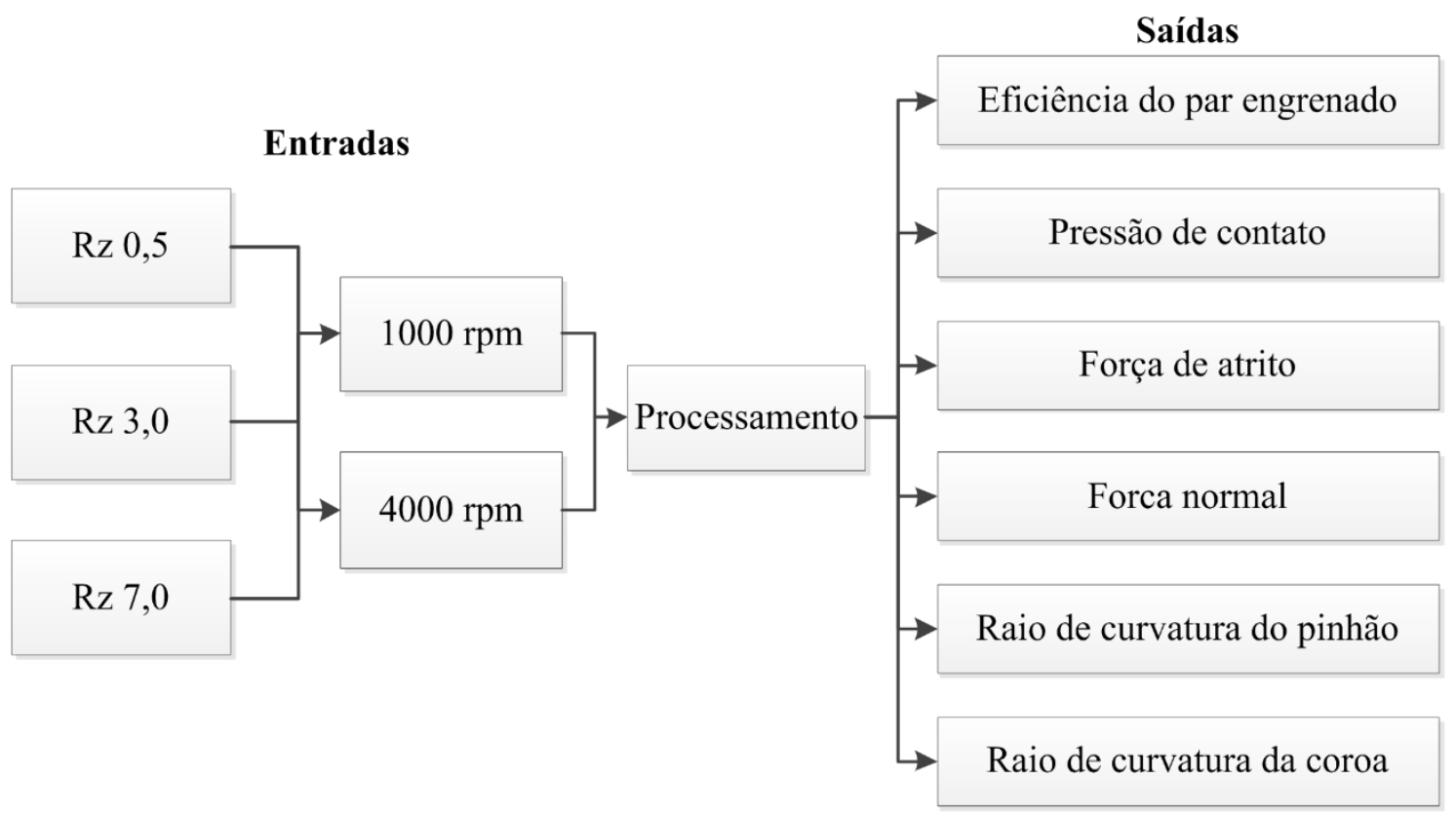

Figura 27 - Fluxograma dos resultados obtidos no modelo 1D

\subsection{MODELO 3D}

O modelo 3D foi desenvolvido utilizando o programa Abaqus® v.2017, para a simulação do contato entre duas engrenagens considerando as deformações elásticas e plásticas. Ao se utilizar o método de elementos finitos foi possível introduzir, além da geometria das engrenagens, suas propriedades mecânicas, apresentadas nas Tabela 2 e Tabela 3. Este modelo permite saídas como a variação do coeficiente de atrito no par engrenado e sua relação com a eficiência do engrenamento.

\subsubsection{Modelagem desenvolvida}

Para estas simulações foram mantidos os mesmos dados geométricos das engrenagens da simulação do modelo 1D. O contato, neste caso, foi reduzido para 5 dentes, a fim de reduzir o tempo de simulação. A Figura 28 apresenta o modelo e as simplificações utilizadas na simulação 3D. Para as condições de contorno, o ponto de referência PR1 foi considerado como ponto central do pinhão, onde teve o acoplamento 
com o movimento do pinhão, e aplicação da velocidade angular. $\mathrm{O}$ ponto de referência PR2 foi acoplado com o movimento da coroa, sendo localizado no centro da coroa e houve aplicação do torque na simulação.

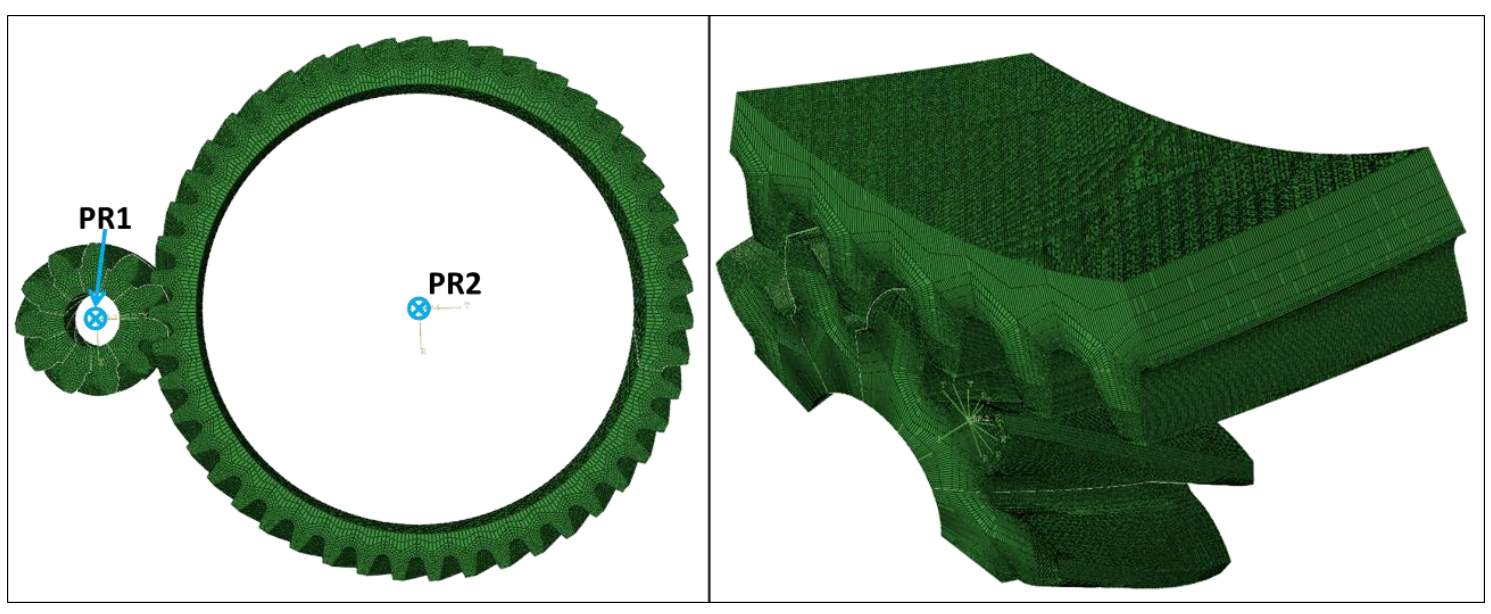

Figura 28 - Modelo 3D do par engrenado e a malha aplicada.

Foram criados sólidos deformáveis com a geometria apresentada na Tabela 2 e as propriedades mecânicas do material das engrenagens descritas na Tabela 3. A montagem foi feita respeitando a distância entre eixos de $71 \mathrm{~mm}$ e foi baseada na apresentada por Fukumasu, et al. (2016), porém com modificações, tais como a rotação e tempos totais diferentes de simulações, que estiveram entre 0,016 e 0,004 segundos, dependendo da velocidade angular, nas rotações de 1000 e $4000 \mathrm{rpm}$. As principais respostas foram força normal e força de atrito retiradas na linha de contato durante o engrenamento. Os parâmetros de rugosidade adotados $(\mathrm{Rz})$ foram de 7, 3 e 0,5 $\mu \mathrm{m}$, como indicado. Foi aplicado um torque constante de $140 \mathrm{Nm}$ na coroa. A malha de elementos utilizada tem o número total de 1.351.922 nós e 1.212.440 elementos hexaédricos lineares do tipo C3D8 (Contínuo, 3D e 8 pontos de integração) com tamanho de 146,23 $\mu \mathrm{m}$ x 97,37 $\mu \mathrm{m}$ x $60,24 \mu \mathrm{m}$, nas faces dos dentes que são as regiões de análises. Esta geometria foi escolhida devido a convergência da malha e a independência dos resultados em relação aos efeitos de malha, conforme Figura 29, na qual larguras inferiores a $300 \mu \mathrm{m}$ apresentam independência de malha nos resultados de coeficiente de atrito. 


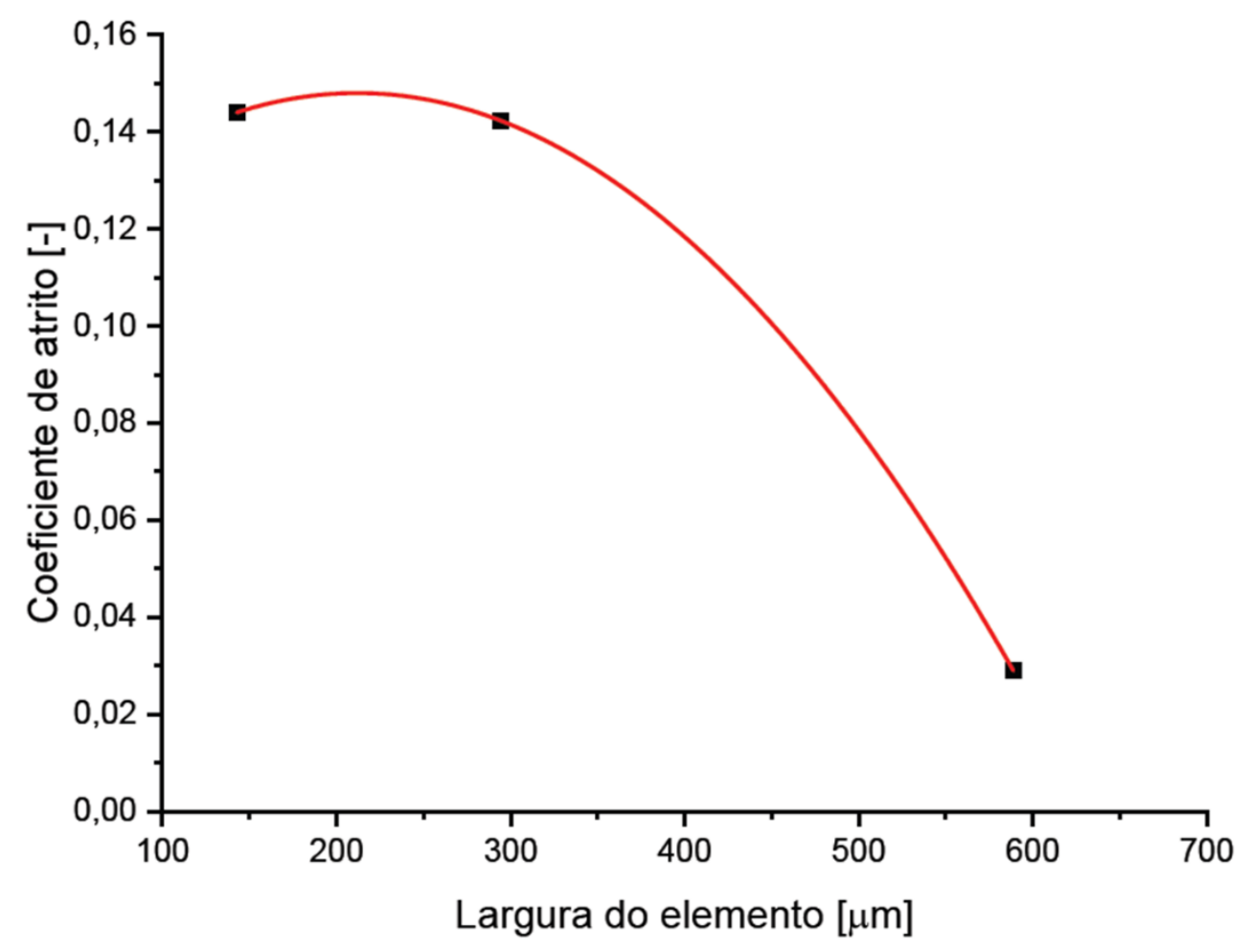

Figura 29 - Gráfico da variação do coeficiente de atrito pela largura do elemento. Análise realizada para verificação da convergência da malha aplicada no modelo 3D.

Simulações com o modelo de atrito de Coulomb, implementado no programa utilizado, foram realizadas impondo coeficientes de atrito de 0,$0 ; 0,05 ; 0,10 ; 0,15$ e 0,20 , que correspondem a uma faixa de variação para o caso estudado no modelo 1D. Estas simulações iniciais permitiram verificar o efeito do $\mu$ na eficiência no modelo 3D com aplicação de um modelo de atrito já oferecido dentro do programa Abaqus®.

Porém devido as simplificações do modelo de Coulomb, como não considerar uma espessura de filme lubrificante, sugeriu-se a implementação de uma subrotina com um modelo que levasse em consideração a teoria da lubrificação elastohidrodinâmica. Logo, desenvolveu-se e aplicou-se esta subrotina com o objetivo de definir a variação do coeficiente de atrito entre as superfícies em contato, para cada ponto de interação, ou ponto de contato, que é definido pela interação entre as superfícies dos dentes. Os resultados do modelo 3D serão apresentados apenas para o $4^{\circ}$ dente. Em função de o sistema entrar em um regime estável, e não haver oscilações entre as engrenagens, que ocorrem no início das simulações, quando o sistema muda de uma condição estática para dinâmica. 


\subsubsection{Subrotina desenvolvida}

A subrotina utilizada neste trabalho foi aprimorada a partir do trabalho de Fukumasu et. al. (2017), que analisou, com aplicação da simulação numérica, os danos em uma superfície em um ensaio lubrificado de movimento alternado (reciprocating). Neste trabalho, os autores criaram um código para a aplicação da curva de Stribeck considerando apenas o deslizamento puro no movimento. Para poder implementar o modelo desenvolvido por Klein (2012), foram necessárias algumas modificações, tais como adicionar as variáveis de entrada na simulação do efeito da rugosidade e a implementação do modelo de lubrificação criado por Klein. O código da subrotina é apresentado no Apêndice A.

\subsubsection{Fluxograma}

A Figura 30 mostra o fluxograma usado na simulação utilizando o programa Abaqus ${ }^{\circledR}$. Os dados de entrada do programa foram a geometria, as propriedades mecânicas, coordenadas para a montagem ideal, carga, condições de ensaio e as propriedades de interação, onde é especificado o uso da subrotina para calcular o coeficiente atrito local na interação entre as superfícies. Depois do processamento, as principais respostas analisadas foram as forças normal e de atrito.

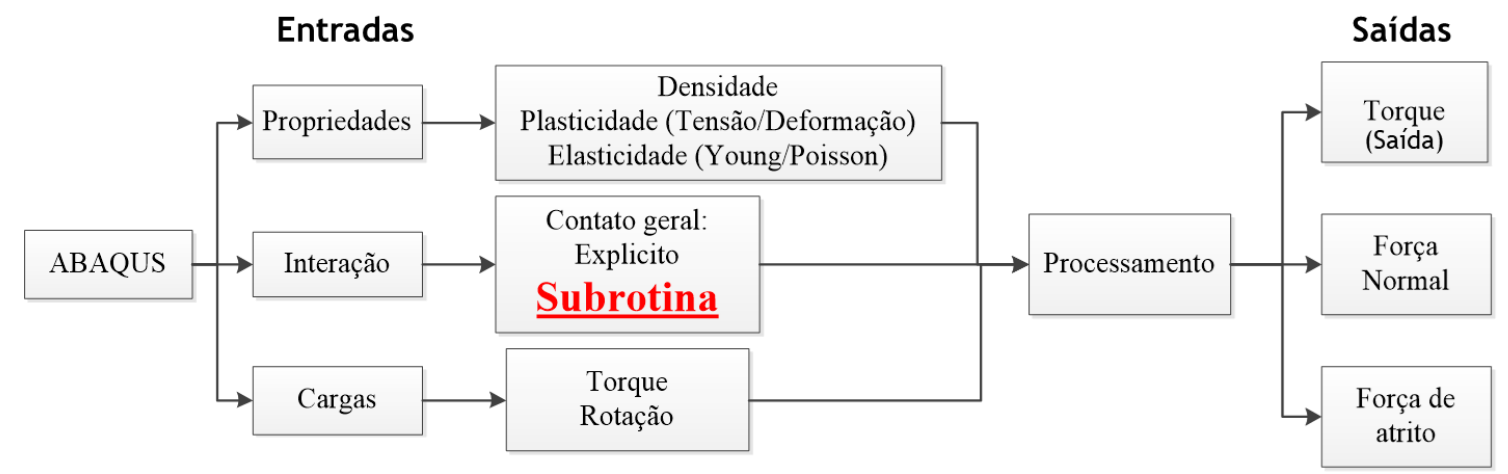

Figura 30 - Fluxograma do fluxo de processo usado na simulação com Abaqus® e subrotina.

\subsection{FLUXOGRAMA DA METODOLOGIA APLICADA}

A Figura 31 mostra o fluxograma da metodologia utilizada nesta dissertação. Foi realizado inicialmente um estudo dos parâmetros abordados na tese de Klein (2012) para o cálculo do coeficiente de atrito. Foi feito então, o desenvolvimento do modelo 1D no AVL Excite Power Unit, considerando apenas as deformações elásticas no contato 
elastohidrodinâmico (EHL) e obtidos resultados ao longo do engrenamento, como a variação do coeficiente de atrito e a eficiência. Utilizando o Abaqus®, que permitiu a construção do modelo 3D, que leva em consideração as deformações elásticas e plásticas e também permite a modelagem da engrenagem com suas características superficiais. Neste modelo 3D, foi necessário o acoplamento de uma subrotina com o modelo proposto por Klein (2012), tendo como resultado o coeficiente de atrito local que considera os efeitos de lubrificação ao longo do dente e na linha de contato. Por fim, foi realizado uma comparação entre os dois modelos, 1D e 3D.

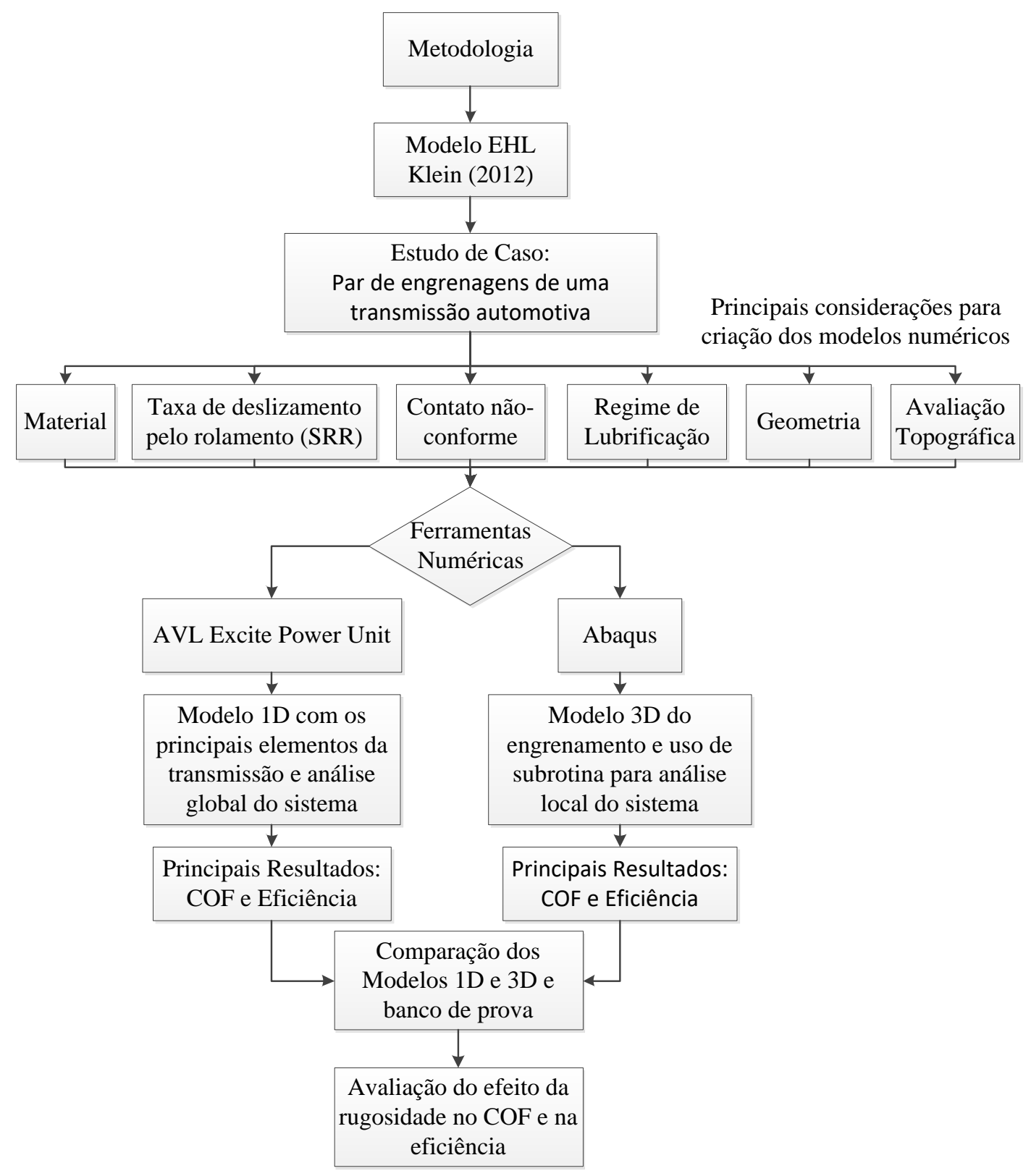

Figura 31 - Fluxograma da metodologia utilizada neste trabalho, levando em consideração os principais fatores que foram levados em consideração nas simulações. 


\section{RESULTADOS E DISCUSSÕES}

Os resultados foram divididos conforme a metodologia apresentada no capítulo 4, utilizando como critério os diferentes modelos criados: modelo 1D e modelo 3D. Em função da apresentação, foi conduzida uma análise comparativa entre os resultados dos diferentes modelos. A primeira parte deste capítulo mostra os resultados obtidos com aplicação do modelo desenvolvido por Klein (2012), utilizando o programa AVL Excite Power Unit. As análises apresentam a influência da rugosidade na eficiência, considerando as características já mencionadas deste modelo, tais como a dinâmica de multi-corpos. A segunda parte, mostra a variação do coeficiente de atrito, via subrotina, no modelo 3D na linha de contato durante o engrenamento. Os resultados dos modelos 1D e 3D mostram, além da influência da rugosidade, as principais regiões do dente que apresentam máximo valor de coeficiente de atrito. Por fim, é feita análise dos modelos para melhor compreensão e avaliação do coeficiente de atrito e eficiência do sistema de transmissão.

Conforme mencionado no capítulo 4.2.1, foram feitas imagens da topografia do dente para se obter valores próximos dos reais de Rz para alimentar as simulações. A Figura 32 mostra a topografia do dentado da coroa de primeira marcha antes de ensaio de banco de prova e foi obtido valor de $\mathrm{Rz}$ de $6,7 \mu \mathrm{m}$. É possível observar as marcas de usinagem devido ao processo de fresamento. 


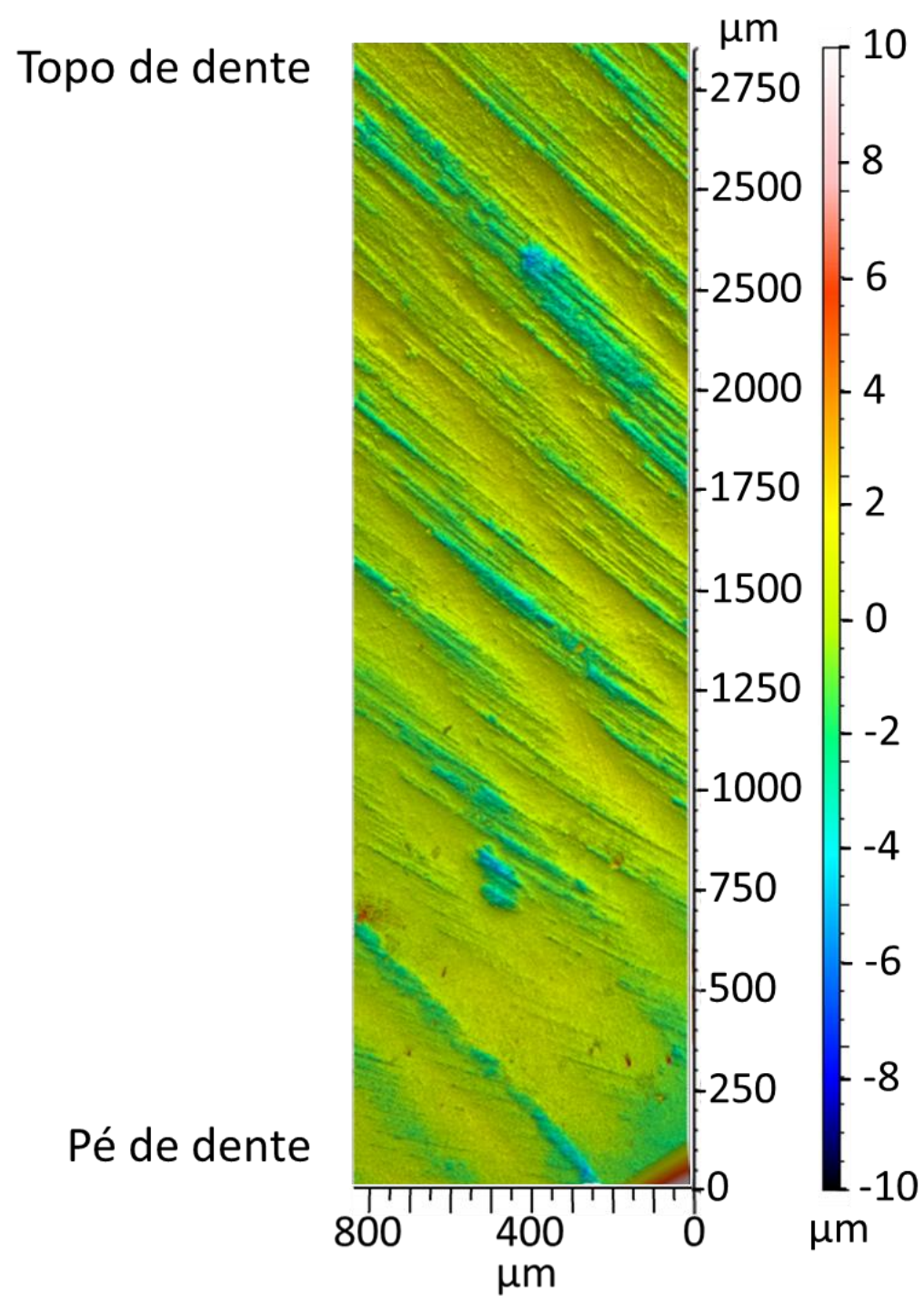

Figura 32 - Imagem topográfica da coroa antes do ensaio da transmissão

A Figura 33a mostra as imagens da topografia do dente da coroa após o ensaio de banco de transmissão automotiva. Conforme estabelecido no capitulo 4.2.1, foram feitas medições ao longo do dente com área de $2,32 \mathrm{~mm}^{2}$ e espaçamento entre si de $2,1 \mathrm{~mm}$. Essas áreas estão numeradas de 1 a 5 e organizadas em sequência conforme esquema da Figura 33b. O Rz obtido foi de $6,4 \pm 0,5 \mu \mathrm{m}$, não havendo uma mudança significativa na rugosidade em comparação com a análise feita antes do ensaio. Este resultado é importante, pois colaborou para a definição do máximo valor de Rz utilizado nas simulações. Não foram avaliados os motivos para a mudança de rugosidade dos dentes das engrenagens em ensaio de banco de prova. 


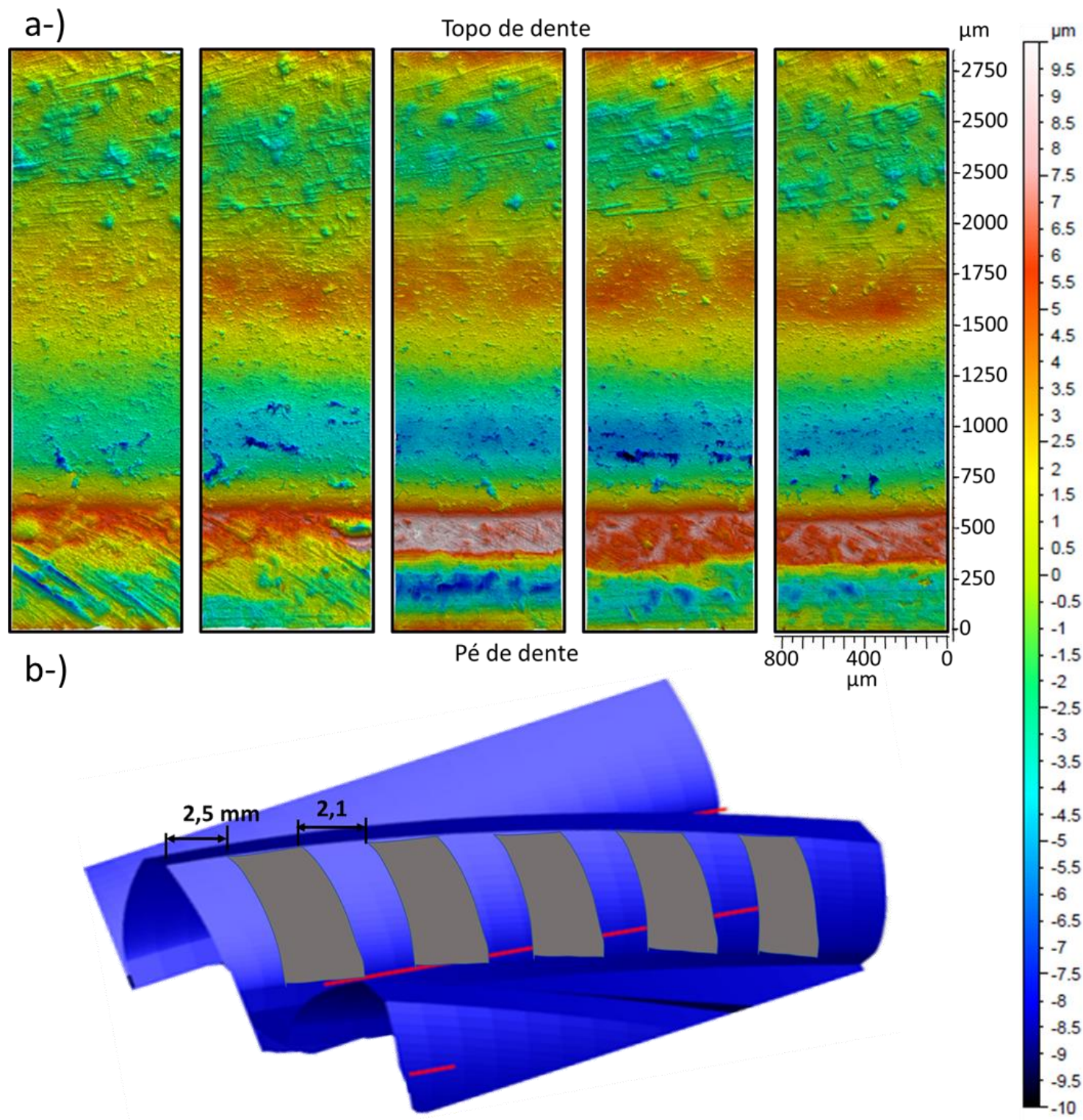

Figura 33 - a-) Imagem da topografia da coroa depois do ensaio da transmissão. A primeira imagem está a 2,5 mm da borda e as demais estão com espaçamento entre si de 2,1 mm, as áreas analisadas vão do pé do dente até o topo. b-) Esquema da face do dente da coroa onde foram analisadas as áreas das imagens.

\subsection{RESULTADOS - MODELO 1D}

Para o entendimento dos resultados obtidos nas simulações, foram padronizadas as regiões e condições avaliadas, como mostra a Figura 34. Nessa figura, a linha amarela está localizada ao longo do perfil no centro longitudinal do dente e varia de $0 \%$, representando a posição de contato no topo do dente, até $100 \%$, localizado no pé do dente. Já a linha vermelha da Figura 34, representa a linha de contato em um determinado 
instante de tempo. A seta verde representa o sentido em que está girando o engrenamento e os lados de entrada e saída do engrenamento.

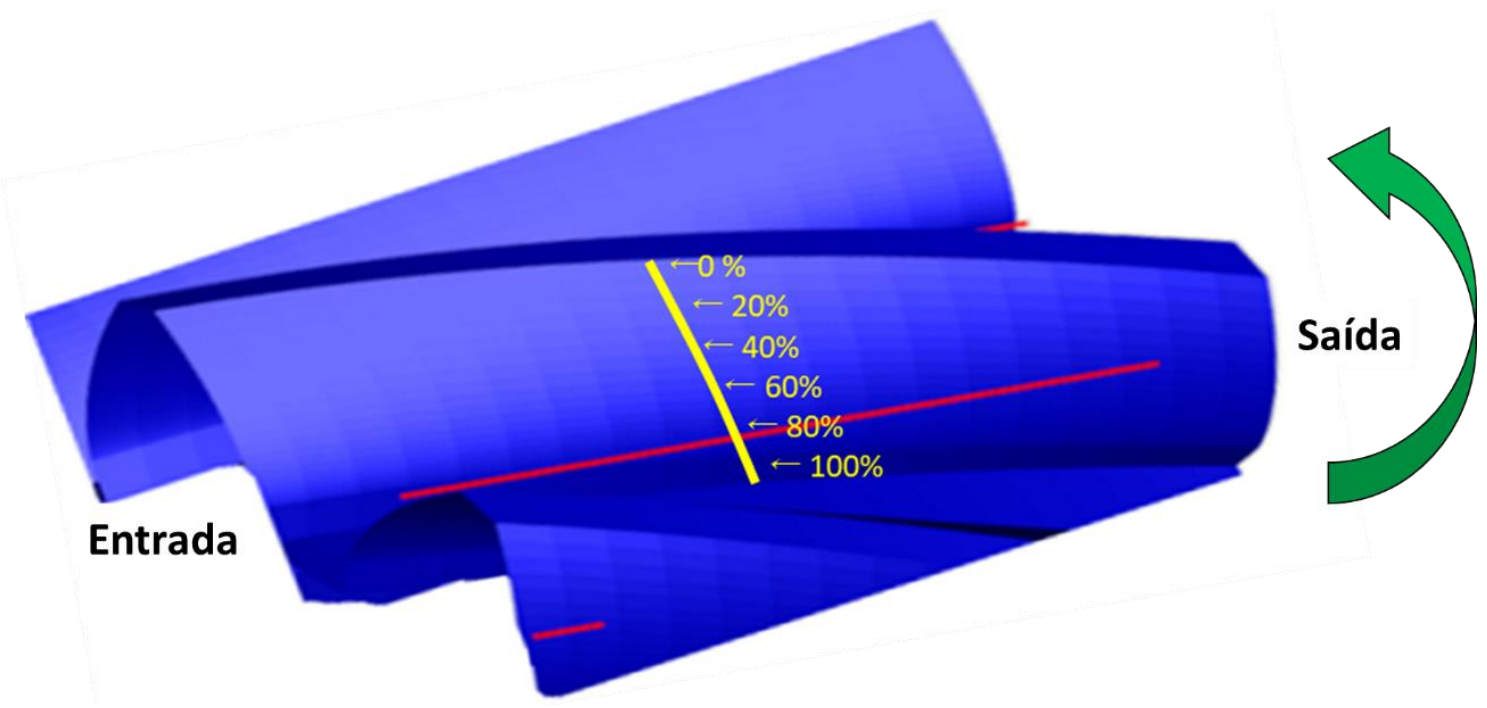

Figura 34 - Linha de contato (linha vermelha) e linha de análise (linha amarela) dos resultados no centro do dente helicoidal.

A Figura 35 mostra a variação da pressão de contato ao longo da linha amarela (Figura 34) no perfil do dente. Foi observada a diminuição da pressão de contato com o movimento do engrenamento, comportamento similar apresentado no trabalho de Amaro (2001). Nestas simulações, o modelo não mostrou variação de pressão de contato devido à variação de rugosidade, pois a rugosidade não é levada em consideração no cálculo da pressão de contato no modelo 1D, como verificado na equação (11) (AVL LIST GMBH, 2016). Também foi possível verificar uma oscilação na variação da pressão de contato, quando ocorre a mudança no contato de dois para três pares de dentes em contato (na posição de $40 \%$ do perfil de engrenamento) e de três para dois pares de dentes em contato (na posição de $60 \%$ do perfil de engrenamento). Isto ocorre devido às mudanças na distribuição de carga entre os dentes. A diferença de pressão de contato em relação à rotação angular está relacionada com a influência do torque resistivo do diferencial, onde aumentando a velocidade também aumenta a potência de saída do engrenamento. Para rotação de 4000 rpm, foi obtido uma maior resistência do diferencial e maiores valores da pressão de contato. 


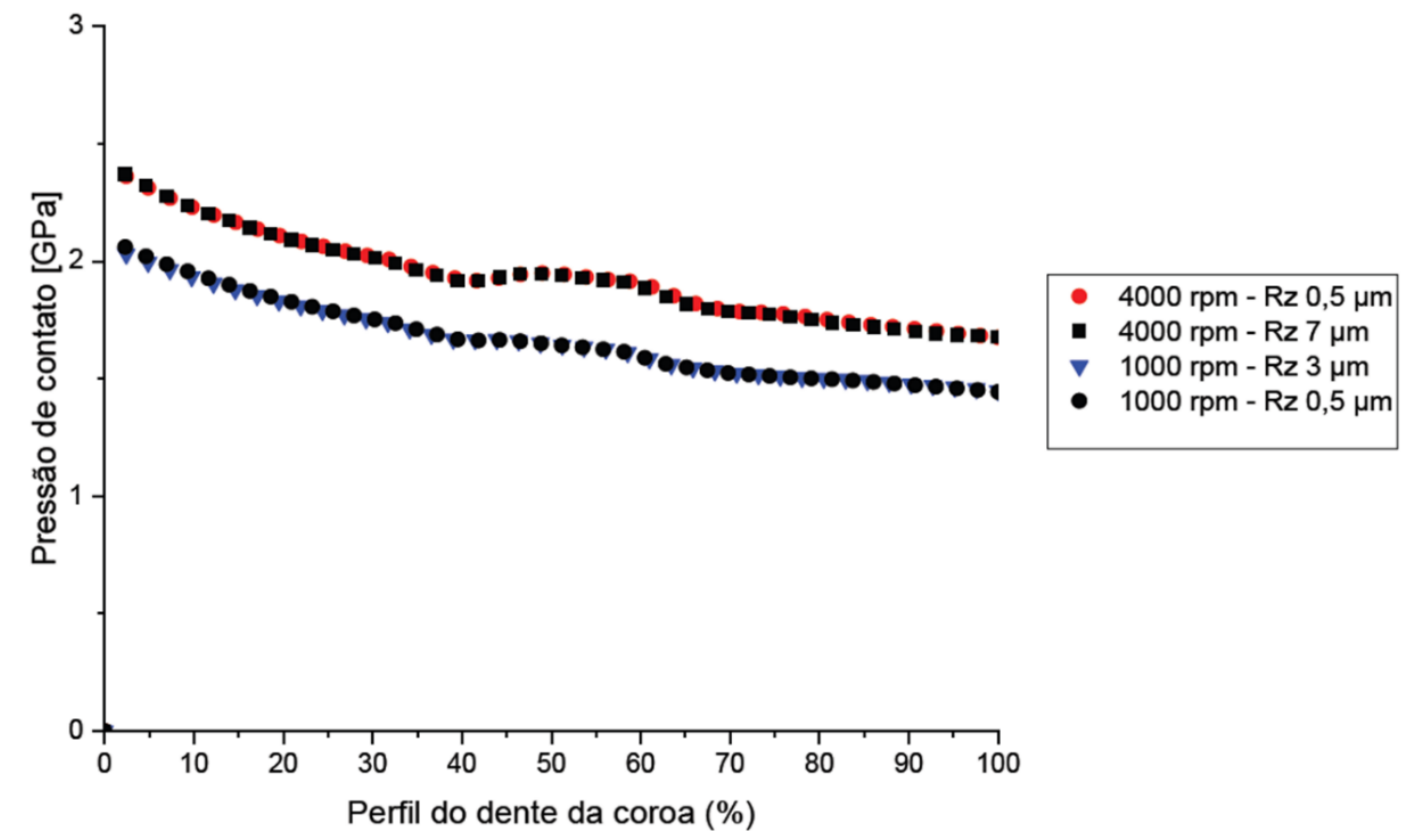

Figura 35 - Variação da pressão de contato ao longo do engrenamento para as simulações com modelo

$1 \mathrm{D}$.

A Figura 36 mostra o gráfico das velocidades tangenciais do pinhão $\left(\mathrm{U}_{1}\right)$ e da coroa $\left(\mathrm{U}_{2}\right)$ para $1000 \mathrm{rpm}$ e $4000 \mathrm{rpm}$ na região central do dente conforme a linha de análise em amarelo da Figura 34 durante o engrenamento. $\mathrm{O}$ ponto onde ocorre a intersecção das curvas, próximo aos $40 \%$ do perfil de engrenamento do dente (Figura 34), corresponde ao momento em que a linha de contato passa pelo diâmetro primitivo. A região de $0 \%$ a $40 \%$ corresponde à região do adendo e dos $40 \%$ até $100 \%$ à região do dedendo A velocidade tangencial do pinhão aumenta ao longo do engrenamento, enquanto a velocidade tangencial da coroa diminui, isto está relacionado diretamente com o raio de curvatura, pois o raio de curvatura diminui para a coroa e cresce para o pinhão. 


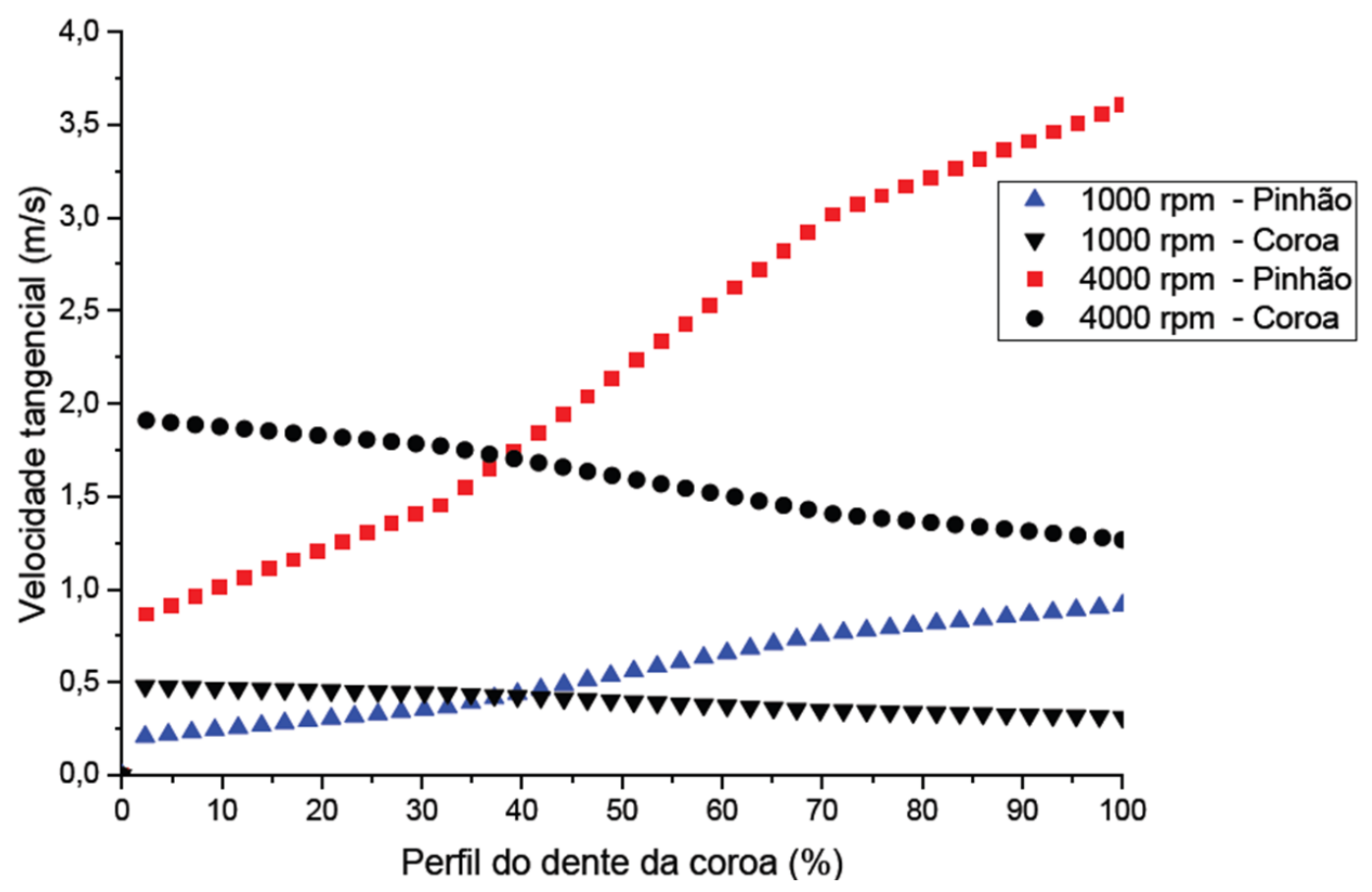

Figura 36 - Gráfico das velocidades tangenciais do pinhão e engrenagem

A Figura 37 mostra o gráfico das velocidades de rolamento e deslizamento ao longo da porcentagem do perfil do dente. A velocidade de deslizamento é o módulo da diferença entre as velocidades tangenciais do pinhão e coroa (Equação 11). Já a velocidade de rolamento é a média entre as velocidades tangenciais do pinhão e coroa (Equação 12). A velocidade de deslizamento será zero no diâmetro primitivo indicando, nessa posição, a ocorrência de um movimento de rolamento puro. A relação entre essas velocidades foi calculada de acordo com a equação (13) e o resultado é mostrado na Figura 38, onde é apresentado um gráfico de SRR. Mesmo para diferentes velocidades angulares, a taxa de deslizamento por rolamento não teve variação. Sendo mais influenciada pela deformação e geometria do dente, como apresentado na literatura (FRANÇOSO, 2009). 


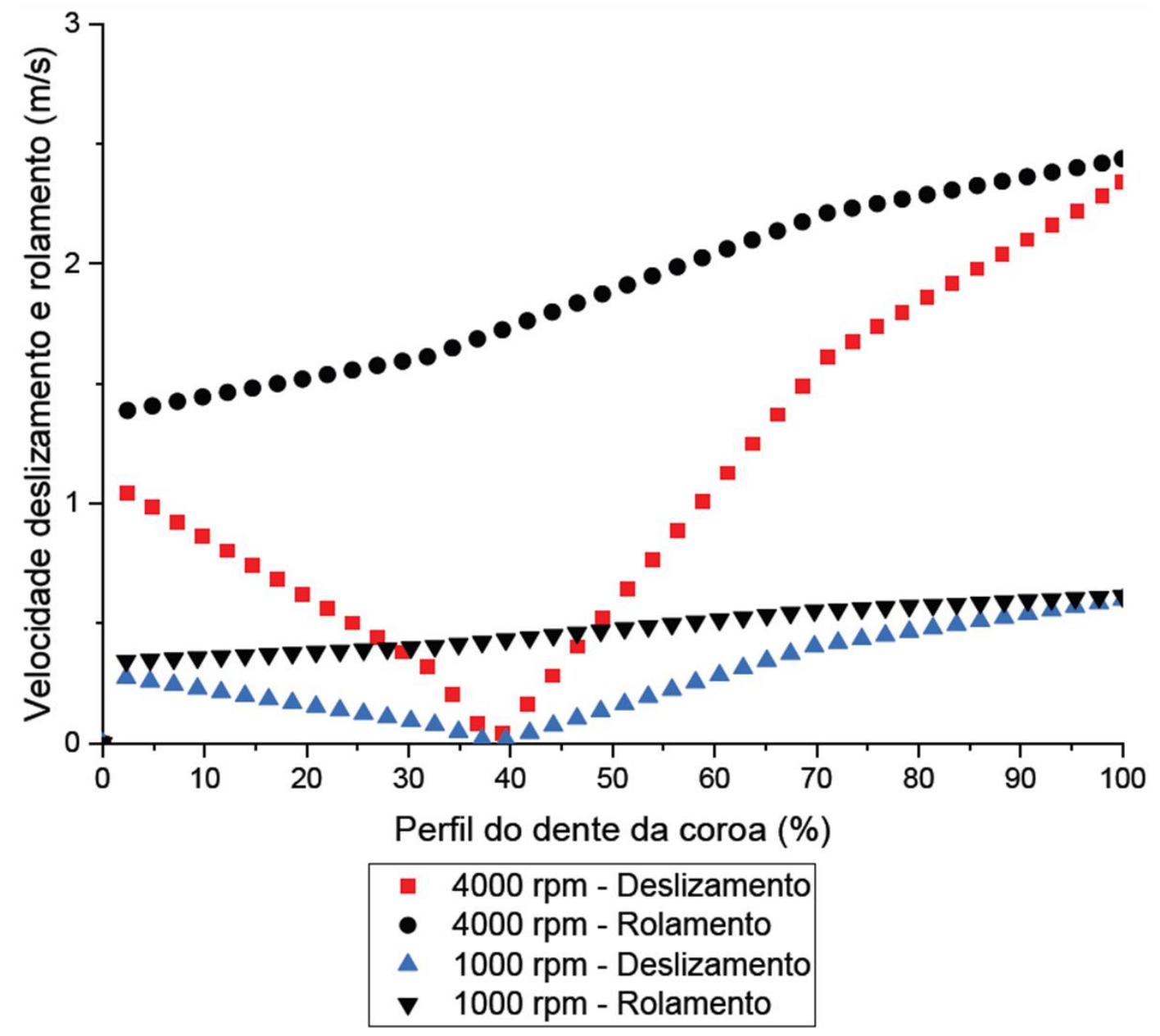

Figura 37 - Gráfico das velocidades de deslizamento e rolamento ao longo da porcentagem do contato

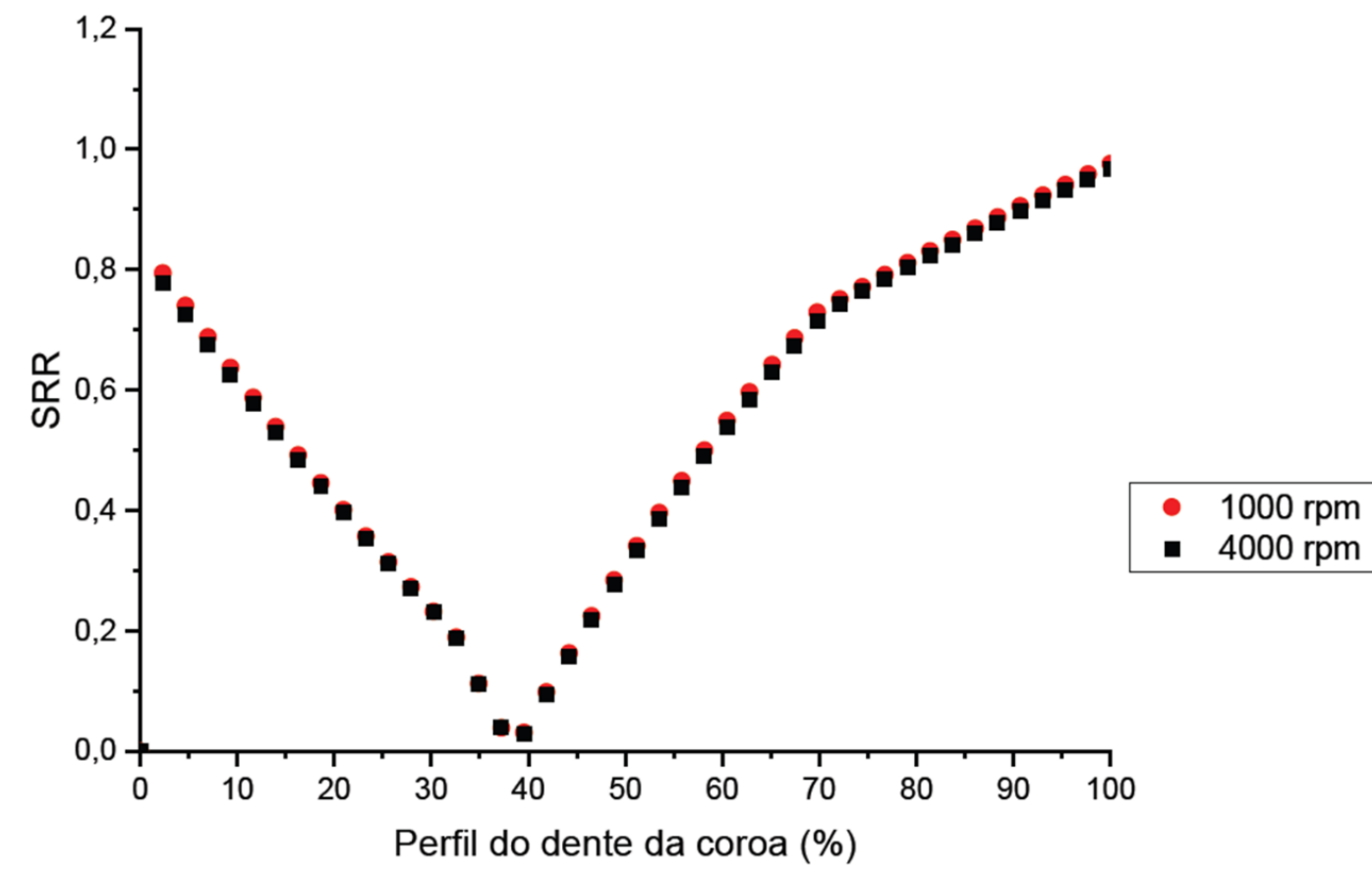

Figura 38 - Taxa de deslizamento para o rolamento pela porcentagem de perfil de dente engrenado 
A Figura 39 mostram a variação da espessura específica de filme $(\lambda)$ ao longo do engrenamento. Em destaque um segundo gráfico onde tem um melhor detalhamento para $\mathrm{Rz}$ de 7,0 $\mu \mathrm{m}$ e 3,0 $\mu \mathrm{m}$. Esses gráficos são regidos pelas velocidades de rolamento para cada simulação. A rugosidade influencia na espessura específica de filme, sendo que para maiores valores de $\mathrm{Rz}$, foram obtidos menores valores de espessura específica de filme. Estes gráficos mostram o mesmo comportamento da espessura específica de filme apresentado na literatura por Amaro (2001), Figura 15. No diâmetro primitivo observase um aumento de espessura específica de filme, devido ao movimento de rolamento puro nesta região.

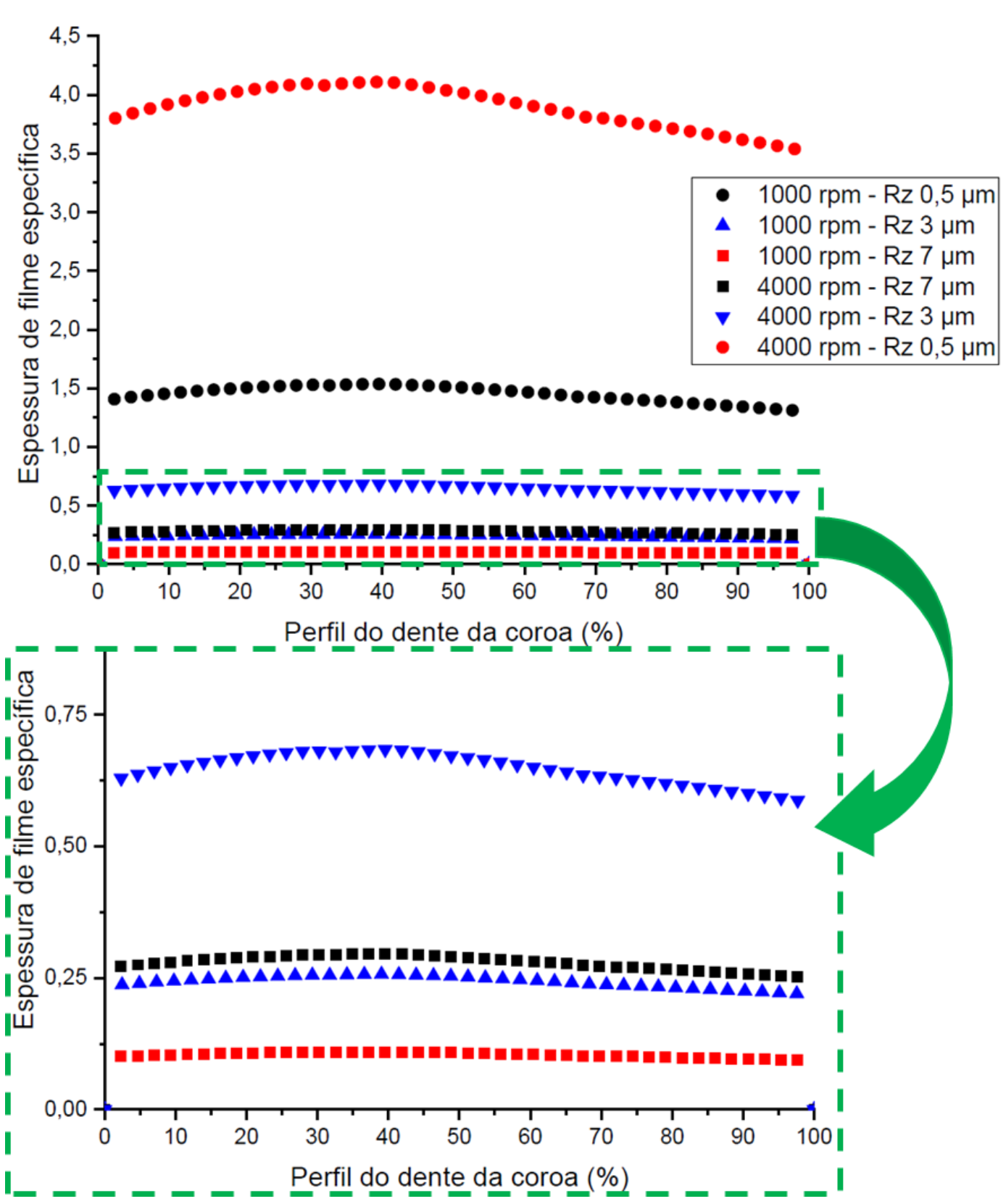

Figura 39 - Gráfico da espessura específica de filme ao longo da porcentagem do perfil do dente. 
A Figura 40 mostra o gráfico dos coeficientes de atrito obtidos durante o engrenamento entre dois dentes. O coeficiente de atrito é influenciado pela rugosidade e pela velocidade angular. Para velocidades angulares maiores, foram obtidos menores coeficientes de atrito, pois há um aumento da espessura de filme, como mostra a Figura 39. Nesta análise não foi considerada a variação de temperatura como em outros modelos da literatura (CASTRO; SEABRA, 2007; MUMINOVIC; REPCIC; COLIC, 2014), que apresentaram que quanto maior a temperatura do lubrificante, maior será o coeficiente de atrito. Os resultados correlacionados com o efeito da rugosidade mostraram que os valores de rugosidade menores levaram a menores coeficientes de atrito. Este resultado pode ser relacionado com a maior espessura específica de filme no contato, como está relacionado pela equação 6 .

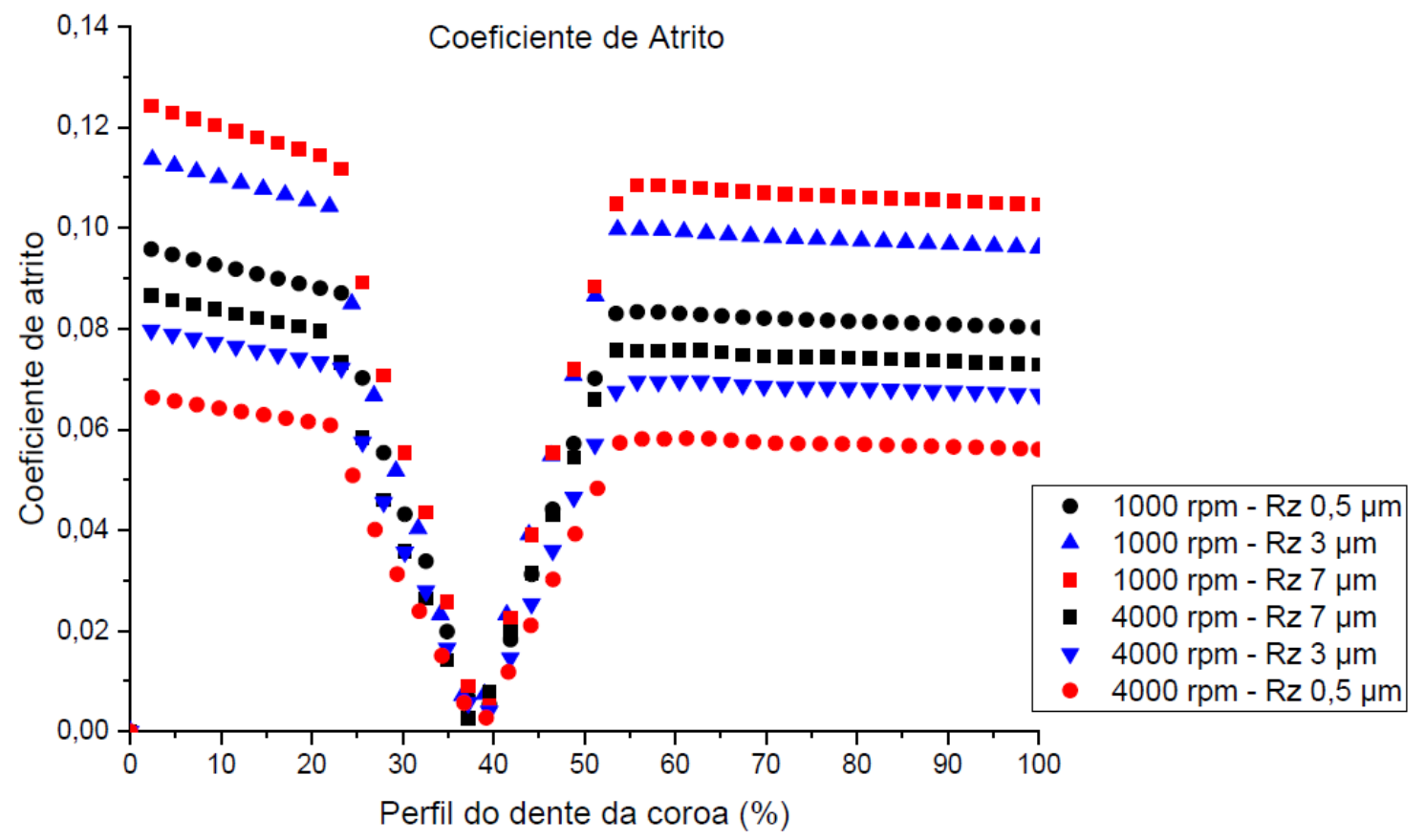

Figura 40 - Gráfico do coeficiente de atrito ao longo da porcentagem de engrenamento

A Figura 40 mostra, que no diâmetro primitivo, o coeficiente de atrito é próximo a zero, conforme mostrado por Beilicke, Bobach, Bartel, (2016), o que era esperado devido ao movimento de rolamento puro desta região. Nas regiões do pé e topo do dente foram obtidos os maiores valores de coeficiente de atrito, sendo assim as regiões mais críticas. A Figura 33 mostra uma diferença na topografia destas regiões, corroborando estes resultados. Na Figura 41, foi isolada a taxa de deslizamento pelo rolamento. Isto permite estudar as alterações no coeficiente de atrito em relação ao apresentado na literatura, como apresentado na Figura 23. 


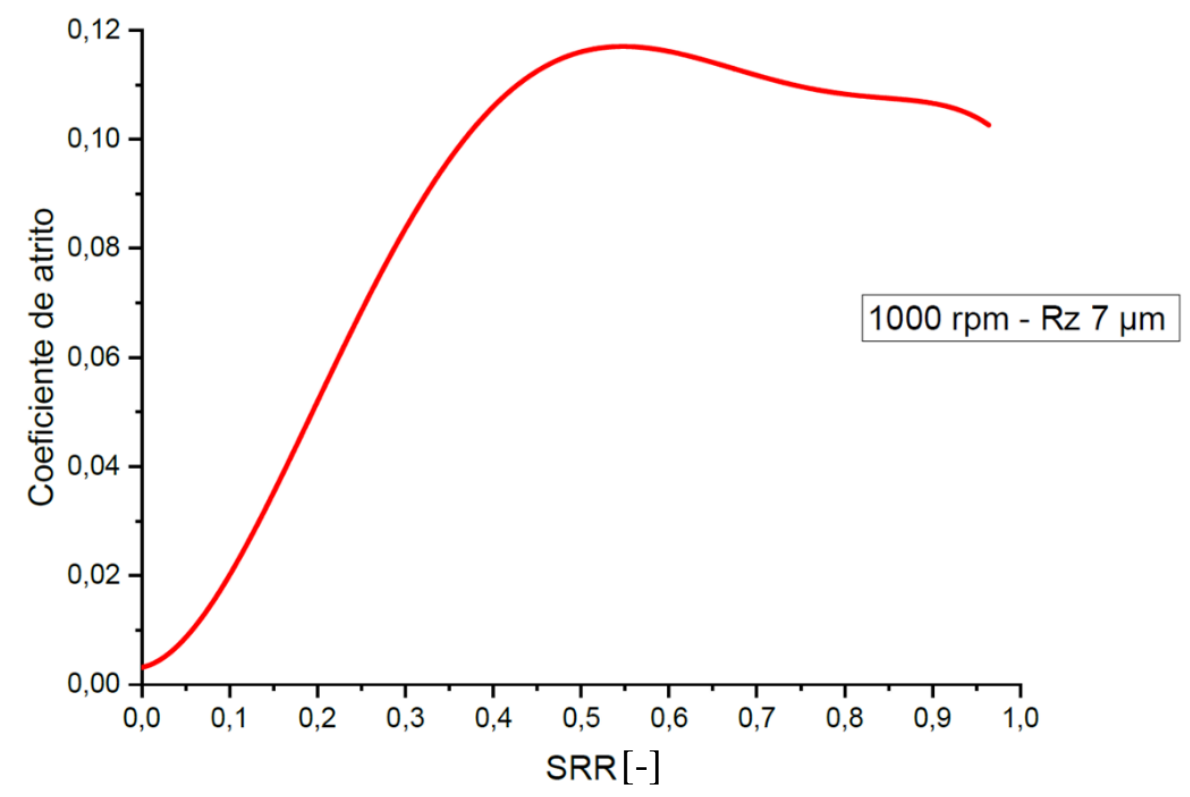

Figura 41 - Gráfico da variação do coeficiente pela taxa de deslizamento pelo rolamento.

Na Figura 42 pode-se analisar o comportamento da eficiência no par engrenado. A rugosidade e a velocidade angular influenciam diretamente na eficiência da transmissão. Rugosidades menores e velocidades de deslizamento maiores promovem menor coeficiente de atrito e maior espessura específica de filme lubrificante, o que resulta numa maior eficiência de transmissão. É possível observar também, que o ganho de eficiência relacionado com a velocidade angular é maior do que com a redução de rugosidade. Este comportamento pode ser explicado pela influência que a rugosidade tem na espessura específica de filme apresentada na Figura 39. Onde, a maior velocidade angular tem-se um maior valor de velocidade de rolamento, aumentando assim a espessura de filme lubrificante. 


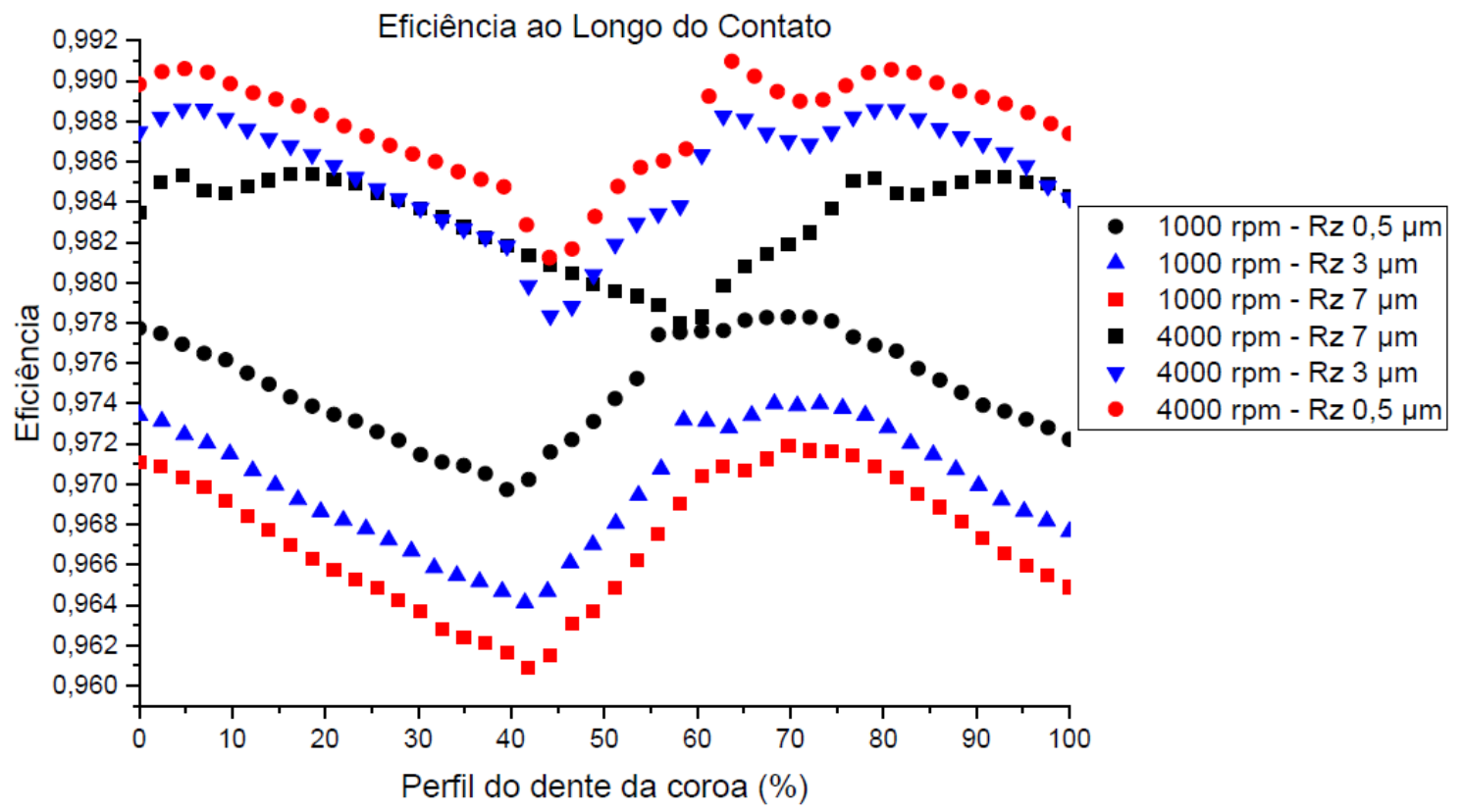

Figura 42 - Eficiência do par engrenado ao longo do perfil do dente em porcentagem para o modelo 1D.

\subsection{RESULTADOS - MODELO 3D}

Os resultados obtidos utilizando o programa Abaqus ${ }^{\circledR}$ foram divididos em duas etapas: em uma foi utilizada um valor de coeficiente de atrito constante e, posteriormente, foi aplicada uma subrotina par avaliar o coeficiente de atrito no perfil do dente da engrenagem.

\subsubsection{Simulação com coeficiente de atrito constante}

Conforme descrito na metodologia de simulação estabelecida, é utilizado o modelo de Coulomb de atrito, com coeficiente de atrito constante. Nestas condições de simulação foi possível construir o gráfico da Figura 43. Para uma redução de $50 \%$ de coeficiente de atrito, entre 0,05 e 0,1 , é possível obter um ganho de $2 \%$ no torque. $\mathrm{Na}$ Figura 43 observa-se que para uma diminuição de 0,15 para 0,12 no coeficiente de atrito, é obtido um ganho de $1,3 \%$ do torque. Esse ganho de torque está diretamente correlacionado com a eficiência do modelo 3D. 


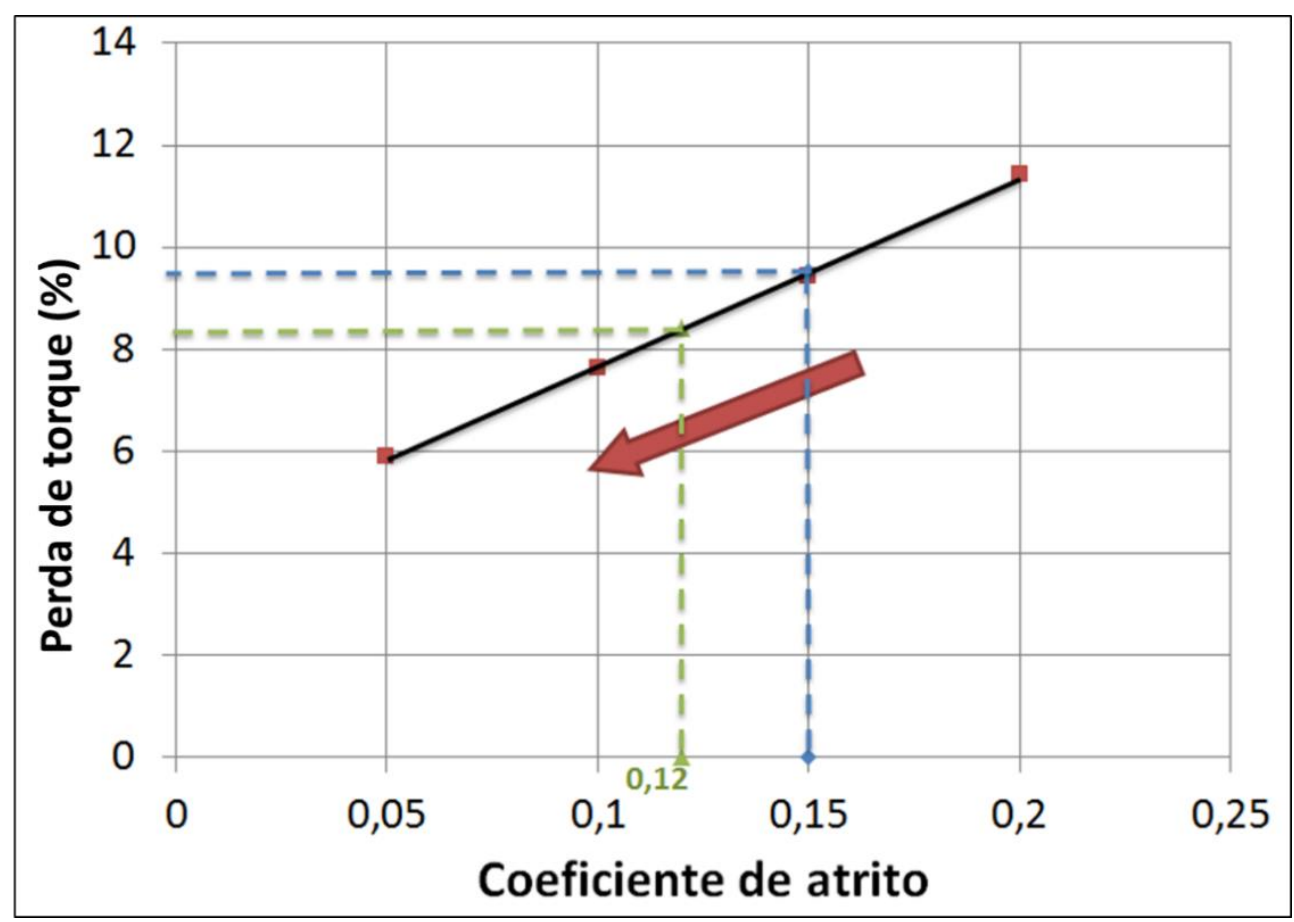

Figura 43 - Gráfico de perda de torque em relação ao coeficiente de atrito

Esta simulação mostra o efeito da redução do atrito, em condições de atrito constante, e também permitiu uma análise preliminar dos resultados antes da introdução da subrotina. Em outras palavras, fica evidenciado na Figura 43 uma das motivações para a redução do coeficiente de atrito e obtenção de melhoria da eficiência.

\subsubsection{Simulação com aplicação da subrotina}

A partir dos resultados apresentados no capítulo 5.2.1, foi possível evidenciar a influência do coeficiente de atrito na eficiência do sistema mecânico. Para a análise subsequente foi considerada a subrotina implementada no modelo 3D, desprezando assim o modelo de atrito de Coulomb presente no programa Abaqus®. Inicialmente, a Figura 44 mostra a variação do coeficiente de atrito na região de contato para o pinhão, em um engrenamento com a existência de lubrificação, sendo avaliadas as condições de $4000 \mathrm{rpm}$ e Rz de 0,5 $\mu \mathrm{m}$. O máximo valor encontrado para o coeficiente de atrito ficou em torno de 0,14, indicando uma região com contato limítrofe. Essas regiões de maiores valores de coeficiente de atrito estão localizadas no topo e no pé do dente, sendo consideradas as regiões críticas. Foi ser observada uma mudança de topografia (Figura 33), corroborando esses resultados. 


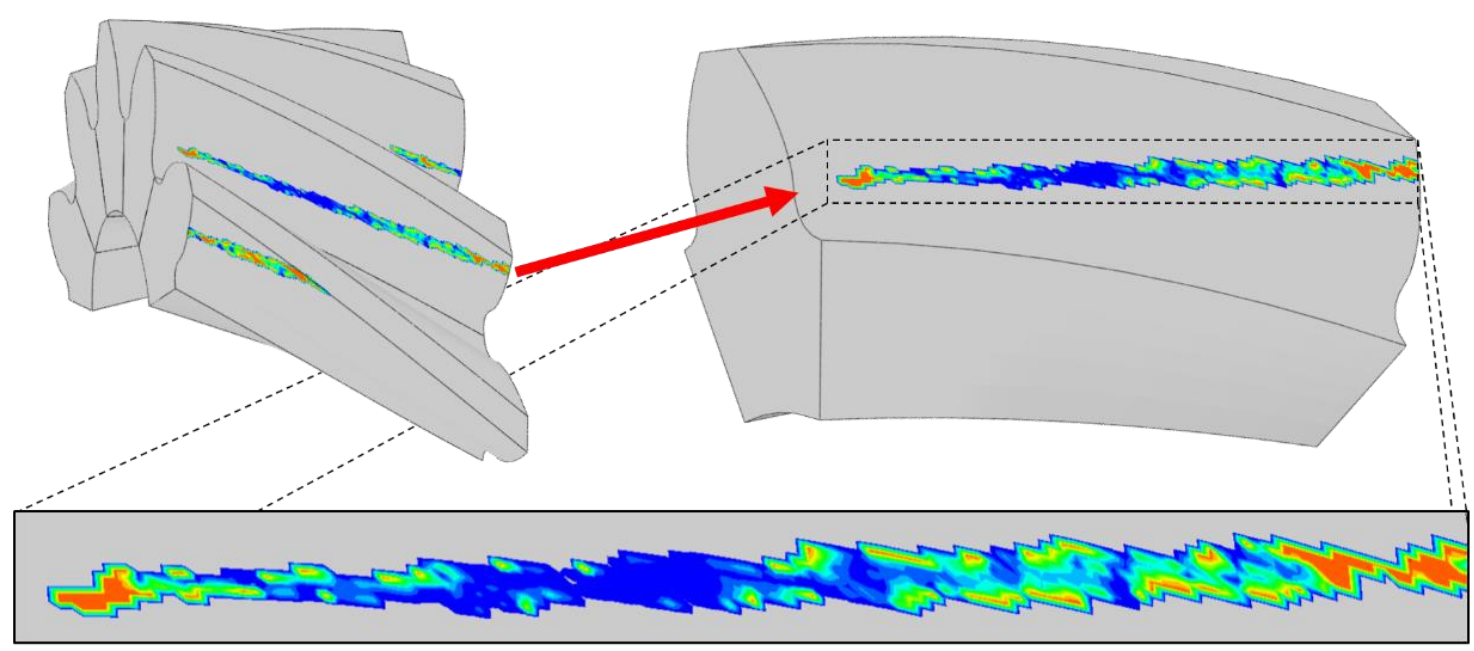

Coeficiente de atrito

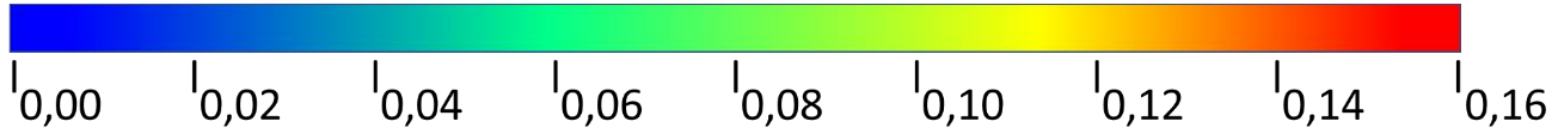

Figura 44 - Variação do coeficiente de atrito na linha de contato do pinhão para 4000 rpm e Rz de $0,5 \mu \mathrm{m}$.

Na Figura 44 é possível observar que o coeficiente de atrito varia ao longo da região de contato, isto ocorre porque o atrito muda ao longo da geometria do dente, com a velocidade angular e pressão de contato, sendo uma das avaliações mais importantes neste trabalho O máximo do coeficiente de atrito está nas regiões próximas ao topo e ao pé do dente, sendo que uns dos principais fatores, que influenciam este resultado, é a alta velocidade de deslizamento nestas regiões. Por outro lado, na região do diâmetro primitivo, o coeficiente é praticamente nulo, devido ao baixo SRR, onde praticamente só existe rolamento, e a uma maior espessura específica de filme. É importante mencionar, que este modelo apresenta uma contribuição em relação ao modelo de Coulomb, onde não existe esta variação no coeficiente de atrito. O modelo de atrito de Coulomb não é considera as características do lubrificante e a variação de velocidade. Os regimes encontrados em cada região do dente estão correlacionados com resultados apresentados na literatura (NAUNHEIMER et al., 2011).

A Figura 45 mostra o resultado obtido para simulações com rotações de 1000 rpm e Rz de $0,5 \mu \mathrm{m}$. As regiões de maior valor de coeficiente de atrito estão no pé e no topo do dente, e na região do diâmetro primitivo os menores valores de coeficiente de atrito, como já mencionado anteriormente. No entanto, com a velocidade mais baixa, $1000 \mathrm{rpm}$, são esperadas menores espessuras específica de filme lubrificante onde obtém-se os 
maiores valores de coeficiente de atrito, quando comparada à condição de velocidade (veja Figura 44).

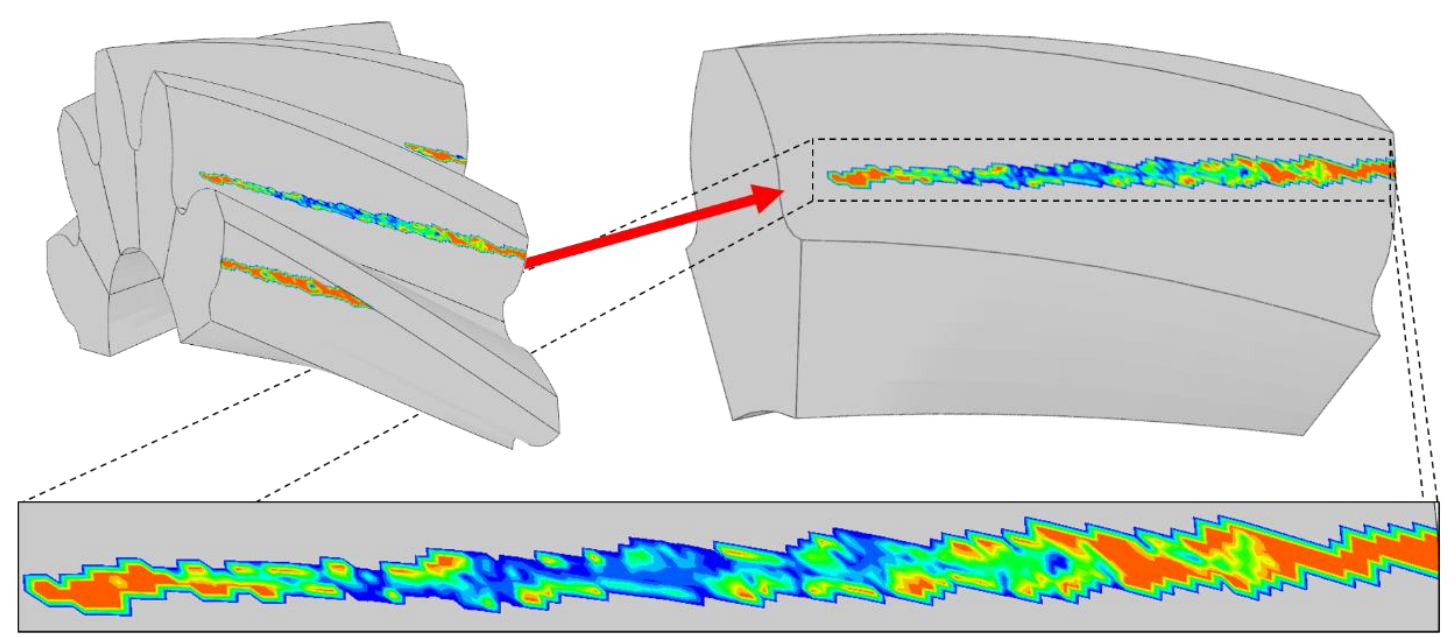

Coeficiente de atrito

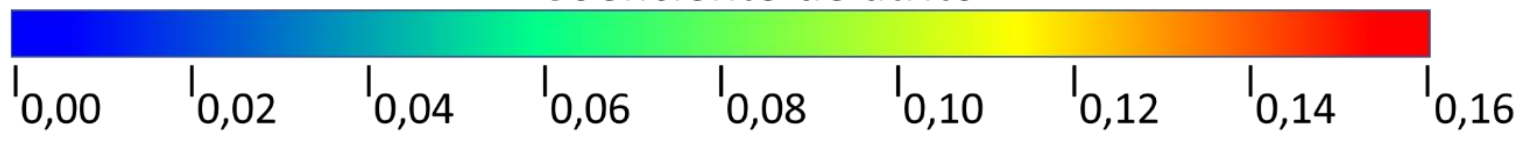

Figura 45 - Variação do coeficiente de atrito na linha de contato do pinhão para $1000 \mathrm{rpm}$ e Rz de $0,5 \mu \mathrm{m}$.

A Figura 46 mostra a variação do coeficiente de atrito ao longo da região de contato para as condições de $4000 \mathrm{rpm}$ e Rz de $7 \mu \mathrm{m}$, isto é, a rugosidade mais elevada e próxima dos valores medidos, conforme detalhado no início deste capítulo. É possível notar que houve um aumento do coeficiente de atrito em relação a rugosidade menor $-\mathrm{Rz}$ de $0,5 \mu \mathrm{m}$ (Figura 44), principalmente no topo e pé do dente, onde o deslizamento é mais acentuado. 


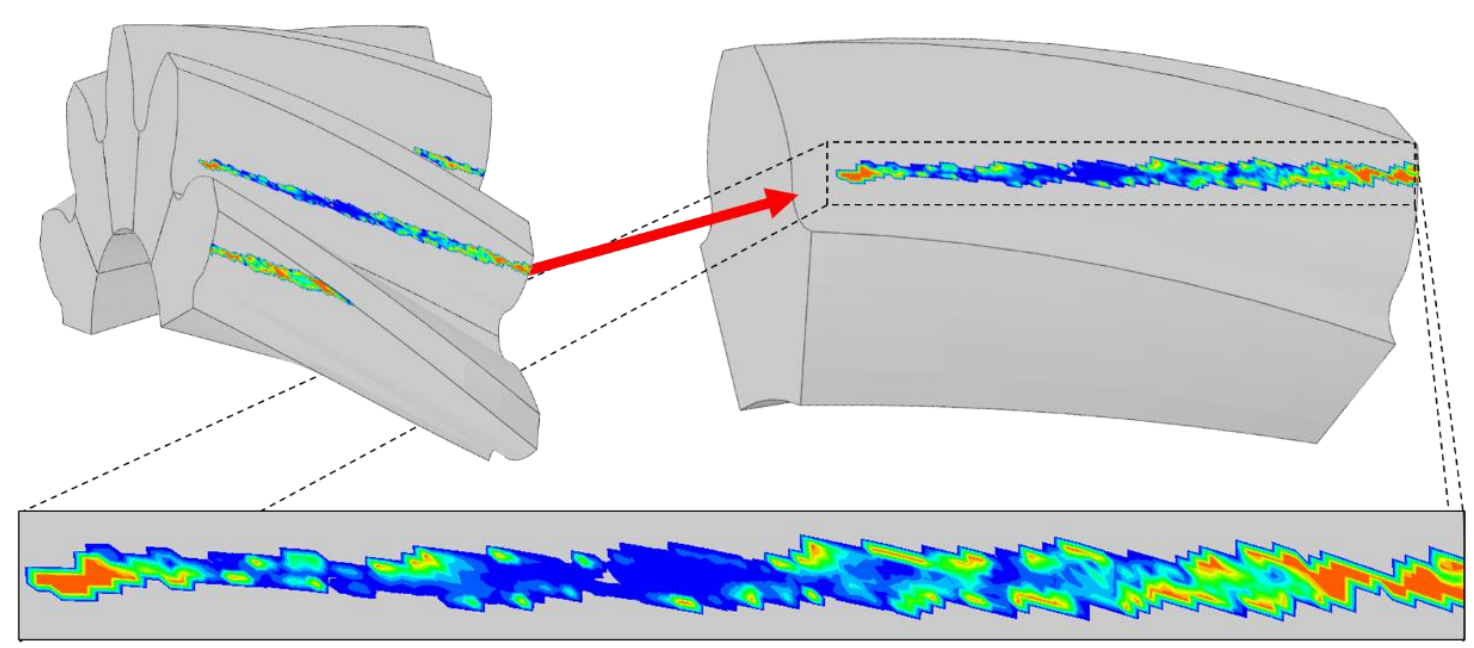

\section{Coeficiente de atrito}

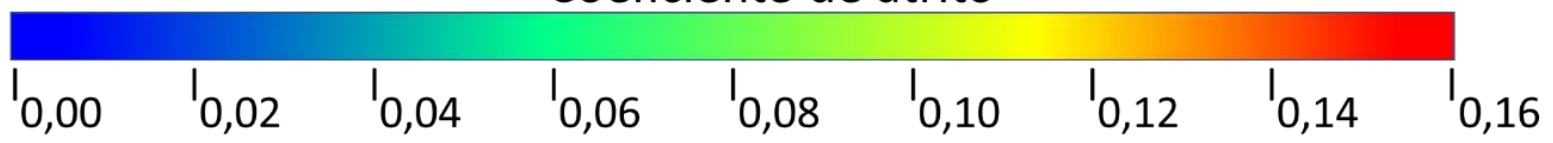

Figura 46 - Variação do coeficiente de atrito na linha de contato do pinhão para 4000 rpm e Rz de $7 \mu \mathrm{m}$.

\subsection{COMPARAÇÃO ENTRE OS MODELOS 1D E 3D}

É importante mencionar na comparação entre os modelos e programas utilizados, que os dois modelos são distintos no aspecto de cálculo e poder computacional. O AVL Excite Power Unit (modelo 1D) considera todos os elementos do sistema da transmissão, porém não considera alguns aspectos como as propriedades mecânicas elastoplásticas das engrenagens. Por outro lado, o Abaqus ${ }^{\circledR}$ permite um grande detalhamento das engrenagens, mas apresenta uma elevada exigência de capacidade computacional (modelo 3D).

A Figura 47 mostra a comparação da variação do coeficiente de atrito para ambas as simulações propostas, com modelo 1D e modelo 3D. Para o resultado do modelo 3D, foi aplicado um filtro do tipo threshold com coeficiente de 0,15 no programa Origin v2019, da OriginLab Comporation, e foi feita uma média dos valores de coeficiente de atrito na região da linha de contato para comparar estes resultados com a simulação 1D. Observa-se que os resultados dos dois modelos são diferentes. Outro detalhe, também importante, é o valor mínimo do coeficiente de atrito no diâmetro primitivo. Pode ser observado um valor praticamente nulo para o modelo $1 \mathrm{D}$, porém para o modelo $3 \mathrm{D}$, este valor está em entorno de 0,04. Analisando o modelo de Klein (2012), que foi aplicado na subrotina, era esperado alcançar valores de coeficiente de atrito nulos nessa região, mas como foi necessário fazer um filtro dos resultados do modelo $3 \mathrm{D}$, o valor obtido de 
coeficiente de atrito não foi nulo no diâmetro primitivo. Outro aspecto a ser mencionado, é que a região de dedendo apresenta um valor máximo coeficiente de atrito para a simulação no modelo 3D, conforme encontrado na literatura (NAUNHEIMER et al., 2011). Uma hipótese que pode justificar esse aumento do coeficiente de atrito na saída do engrenamento, é a variação da área de contato devido a deformação elástica no contato do dente no modelo 3D.

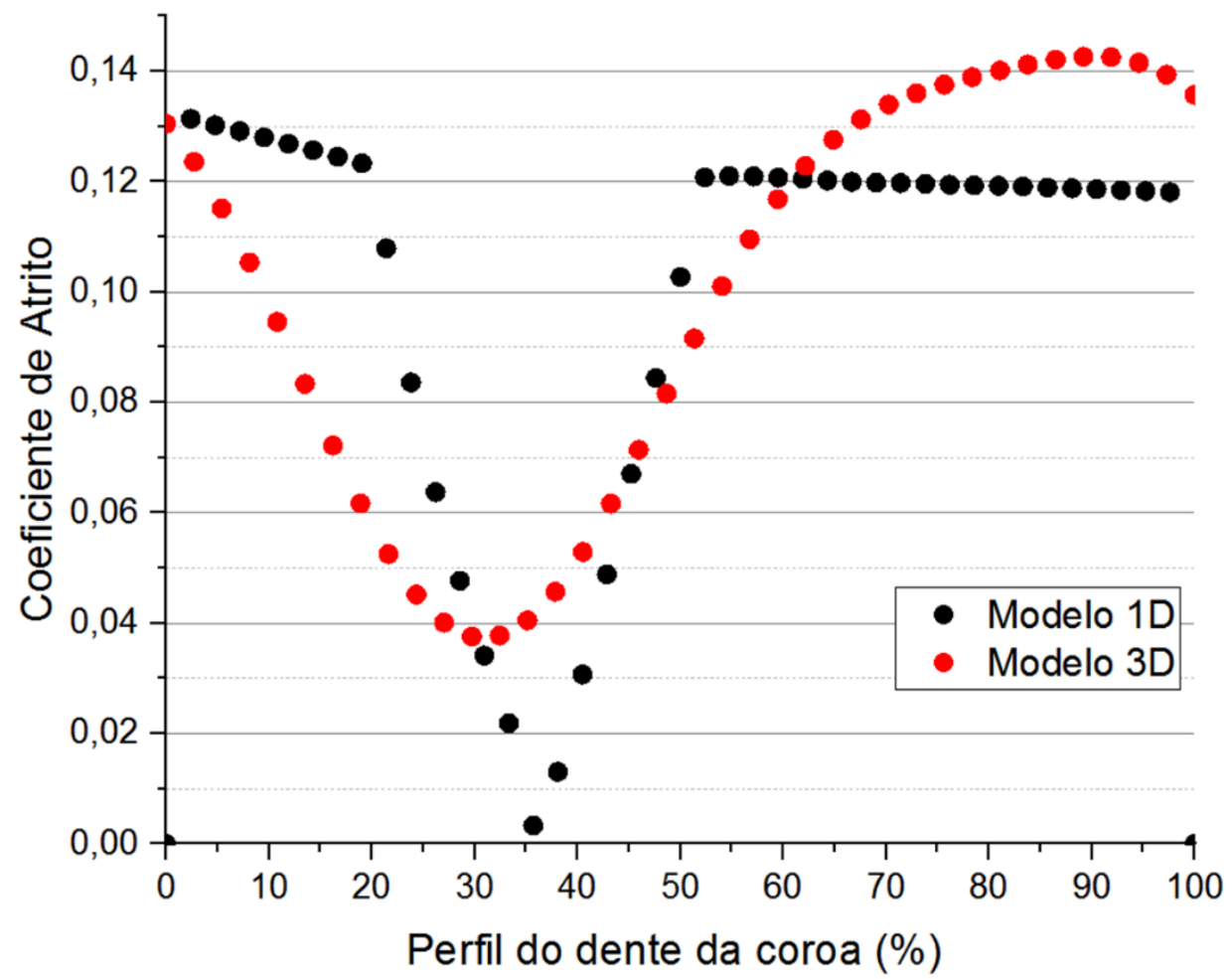

Figura 47 - Comparação do comportamento do coeficiente de atrito para a simulação no modelo $1 \mathrm{D}$ e modelo 3D.

A Figura 48 mostra a comparação entre as eficiências calculadas utilizando o modelo 1D, o modelo 3D e obtida experimentalmente em banco de prova (MACHADO, 2018) em função do ciclo de engrenamento, ou seja, levando em consideração a influência de todos os dentes em contato. No modelo 1D a eficiência oscilou entre os 96 97\%, porém no modelo 3D a eficiência ficou em torno de 93\%. Mesmo não levando em consideração os outros elementos da transmissão, pois foi avaliado apenas o coeficiente de atrito no engrenamento, os resultados das simulações foram bastante próximos em comparação com a eficiência encontrada em ensaios de dinamômetro em transmissão automotiva. Uma hipótese para as diferenças entre os modelos e o banco de prova pode estar relacionada com a variação de temperatura no contato do engrenamento. Outra hipótese é que modelo 1D simula vários ciclos do engrenamento e após estabilização da 
dinâmica de multi-corpos é obtido os resultados, porém o modelo 3D apenas considera um único ciclo, sendo observado oscilações nos resultados do modelo 3D.

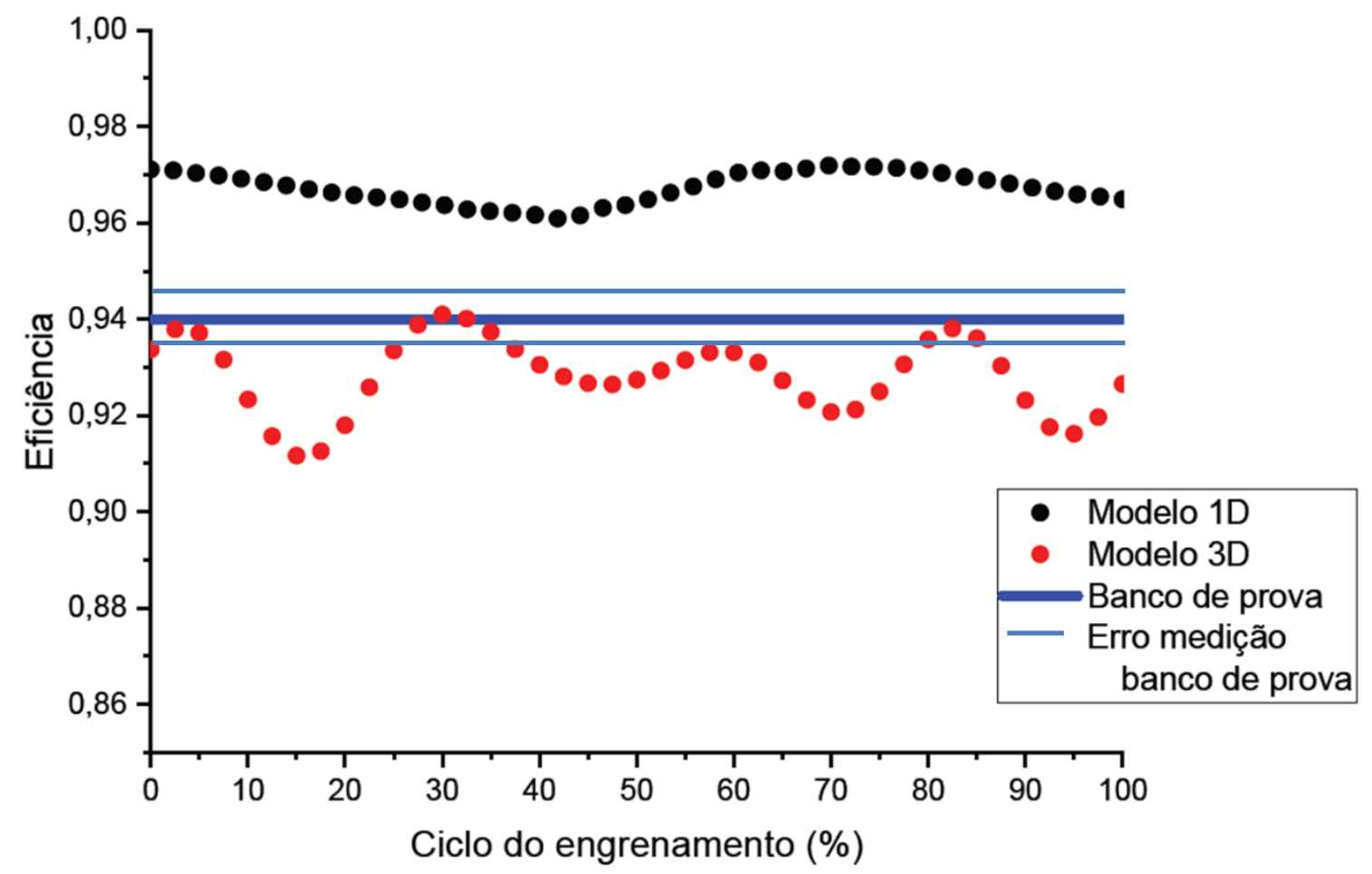

Figura 48 - Comparação da eficiência obtida nos modelos 1D, 3D e de banco de prova para $1000 \mathrm{rpm}$.

A comparação realizada entre os modelos 1D e 3D permitiu analisar os modelos de atrito e eficiência em uma transmissão automotiva com os seus principais elementos e, validar uma metodologia, utilizando o MEF acoplado com modelo de lubrificação, via subrotina, para o detalhamento e determinação do atrito durante o contato lubrificado entre os dentes das engrenagens. Foi possível analisar a influência da rugosidade e da velocidade no coeficiente de atrito e na eficiência durante o engrenamento para ambos os modelos.

A Tabela 5 mostra, de forma resumida, a influência dos parâmetros analisados no modelo 1D. A pressão de contato e as velocidades de deslizamento e rolamento foram menores para a velocidade de $1000 \mathrm{rpm}$ do que para a velocidade de $4000 \mathrm{rpm}$, já em relação a variação de rugosidade não foi observado nenhum efeito significativo e o modelo 1D acaba tendo uma limitação do cálculo da pressão de contato não ser influenciado pela rugosidade. A taxa de deslizamento pelo rolamento não apresentou nenhuma influência em relação a variação de velocidade e de rugosidade. A espessura específica de filme e a eficiência tiveram um comportamento similar, ambos diminuíram 
para a velocidade de $1000 \mathrm{rpm}$ e aumentaram para a velocidade de $4000 \mathrm{rpm}$. Com relação à rugosidade, o uso de $\mathrm{Rz} 0,5 \mu \mathrm{m}$ levou a um aumento de eficiência em relação ao $\mathrm{Rz} 7 \mu \mathrm{m}$. O coeficiente de atrito aumentou para a velocidade de $1000 \mathrm{rpm}$ e $\mathrm{Rz} 7 \mu \mathrm{m}$, porém diminuiu para $4000 \mathrm{rpm}$ e Rz $0,5 \mu \mathrm{m}$, sendo o oposto em relação à espessura de específica de filme, validando o modelo, de acordo com o apresentado na literatura (AMARO, 2001; BEILICKE; BOBACH; BARTEL, 2016).

Tabela 5 - Resumo dos resultados do modelo 1D obtidos com a pressão de contato, velocidade de deslizamento e rolamento, taxa de deslizamento pelo rolamento, espessura específica de filme lubrificante, coeficiente de atrito e eficiência em relação a variação da velocidade e rugosidade.

\begin{tabular}{|c|c|c|c|c|}
\hline & \multicolumn{2}{|c|}{ Velocidade [rpm] } & \multicolumn{2}{|c|}{ Rugosidade- Rz $[\mu \mathrm{m}]$} \\
\hline & 1000 & 4000 & 0,5 & 7 \\
\hline Pressão de contato & & & & \\
\hline $\begin{array}{l}\text { Velocidade de } \\
\text { deslizamento e } \\
\text { rolamento }\end{array}$ & & & & \\
\hline $\begin{array}{c}\text { Taxa de deslizamento } \\
\text { pelo rolamento }\end{array}$ & & & & \\
\hline $\begin{array}{l}\text { Espessura específica } \\
\text { de filme lubrificante }\end{array}$ & & & & \\
\hline Coeficiente de atrito & & & & \\
\hline Eficiência & & & & \\
\hline
\end{tabular}

A Tabela 6 e a Figura 49 resumem os resultados obtidos nas simulações do modelo 3D. Para velocidade de $1000 \mathrm{rpm}$ ocorre um aumento do coeficiente de atrito em relação a velocidade de $4000 \mathrm{rpm}$, já para a rugosidade, com Rz de 0,5 $\mu \mathrm{m}$ observam-se menores valores de coeficiente de atrito em relação a $\mathrm{Rz}$ de $7 \mu \mathrm{m}$. Sendo, a variação na velocidade angular, o parâmetro que teve uma influência mais significativa, maior que o aumento de rugosidade superficial. 
Os modelos 1D e 3D mostraram ser promissores como métodos numéricos para análise do coeficiente de atrito em uma região de contato lubrificado. Apesar do modelo 1D ser mais restrito para uso em transmissão veicular, o modelo 3D é de aplicação mais ampla podendo ser usado em outros tipos de contatos lubrificados, por exemplo, cames e rolamentos. $\mathrm{O}$ modelo 3D pode ser aplicado a diversos tipos de superfícies, como porosas e ou com defeitos, e diferentes tipos de lubrificantes. $\mathrm{O}$ modelo 3D também permite aplicação de outros modelos de lubrificação da literatura para determinação do coeficiente de atrito e realização de comparações entre eles.

Tabela 6 - Resumo do efeito da velocidade angular e a rugosidade na variação do coeficiente de atrito para o modelo 3D.

\begin{tabular}{|c|c|c|c|c|}
\hline \multirow{2}{*}{ Coeficiente de atrito } & \multicolumn{2}{|c|}{ Velocidade [rpm] } & \multicolumn{2}{c|}{ Rugosidade- Rz [ $\mu \mathrm{m}]$} \\
\cline { 2 - 5 } & 1000 & 4000 & 0,5 & 7 \\
\hline & & & & \\
\hline
\end{tabular}

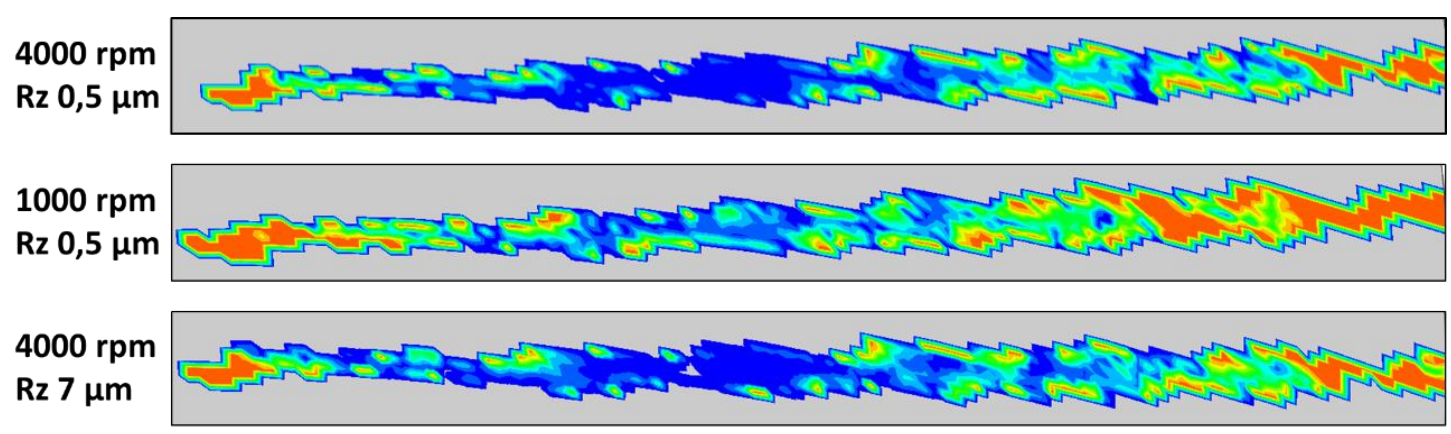

Figura 49 - Variação do coeficiente de atrito na linha de contato do pinhão para 1000 rpm e Rz de $0,5 \mu \mathrm{m}$; $4000 \mathrm{rpm}$ e Rz de $0,5 \mu \mathrm{m}$ e $7 \mu \mathrm{m}$ 


\section{CONCLUSÕES}

O uso de diferentes programas e o desenvolvimento de uma subrotina, para o cálculo do coeficiente de atrito, permitiram modelar e analisar a eficiência de uma transmissão automotiva, considerando as perdas devido ao atrito no contato utilizando modelos 1D e 3D, onde o modelo 1D consistia em uma transmissão automotiva e o modelo 3D, considerou um par de engrenagens em contato lubrificado. O modelo 3D mostra as principais características locais do contato em um engrenamento. Foi aplicado o mesmo modelo de lubrificação elastohidrodinâmica para ambos os programas. As análises realizadas mostram a limitação do modelo $1 \mathrm{D}$, que só pode ser utilizado em um sistema de transmissão automotiva. O modelo 3D, por outro lado, pode ser aplicado em outros sistemas mecânicos com outras configurações de contato não conforme lubrificado. $\mathrm{O}$ modelo $3 \mathrm{D}$ foi comparado e validado com o modelo $1 \mathrm{D}$ e com resultados de eficiência de bancos de prova.

Os modelos 1D e 3D utilizados permitiram avaliar e concluir que:

- na simulação numérica desenvolvida nesta dissertação, aplicando o modelo de lubrificação desenvolvido por Klein (2012), reproduziu a variação do coeficiente de atrito local, em engrenagens cilíndricas helicoidais de eixos paralelos, ao longo da linha de contato na face dos dentes.

- os resultados mostraram as regiões mais críticas, onde o coeficiente de atrito é mais elevado, sendo correlacionadas com a literatura.

- a velocidade angular teve maior influência nos resultados do que a rugosidade, nas condições estudadas. Verificou-se que para velocidades angulares maiores produziu um aumento das espessuras específicas de filme resultando em menores valores de coeficiente de atrito.

- os resultados de eficiência foram superestimados pelo modelo $1 \mathrm{D}$, enquanto o modelo 3D estimou a eficiência comparável com a do banco de prova. 


\section{TRABALHOS FUTUROS}

Com o uso da subrotina no Abaqus ${ }^{\circledR}$, as diferentes maneiras de aplicação do programa da AVL e os modelos de lubrificação EHL apresentados na literatura, são feitas algumas sugestões de continuidade deste trabalho:

- Aplicação ou desenvolvimento de novos modelos de EHL com o modelo 3D para diferentes sistemas lubrificados e validação com a literatura e ensaios experimentais.

- Novo projeto de dente de engrenagem, variando a geometria para uma melhoria na eficiência no modelo 3D.

- Aplicação dos demais pares de engrenagem do câmbio como, $2^{\circ}, 3^{\circ}, 4^{\circ}$ e última marcha para o estudo da eficiência da transmissão.

- Aplicação de modelo analítico na subrotina levando em consideração a variação térmica do sistema lubrificado e efeito no lubrificante e aditivos.

- Uso do modelo 3D com diferentes características superficiais (texturas, trincas e defeitos, recobrimentos) para estudar a influência no coeficiente de atrito do contato lubrificado. 


\section{REFERÊNCIAS}

ABRAHAM, R. M. An Experimental Study of Scuffing Performance of a Helical Gear Pair Subjected to Different Lubrication Methods. Tese. Engenharia Mecânica. Universidade do Estado de Ohio, 2014.

ACERO, J. S. R. Influência do Acabamento Superficial no Desempenho de Lubrificantes de Motos Novos e Usados em Automovéis Abastecidos com E22 e E100. Dissertação apresentada à Escola Politécnica da Universidade de São Paulo para obtenção do título de Mestre em Ciências., 2015.

AL-TUBI, I. S. et al. Experimental and analytical study of gear micropitting initiation and propagation under varying loading conditions. Wear, v. 328-329, p. 8-16, 2015.

ALI, Y. H. et al. Artificial neural network model for monitoring oil film regime in spur gear based on acoustic emission data. Shock and Vibration, 2015.

AMARO, R. P. I. I. Comportamento Tribológico de Revestimentos AutoLubrificantes para Engrenagens. Dissertação. Pos-Graduação em Engenharia Mecânica. Universidade do Porto, 2001.

ANDERSON, N. E.; LOEWENTHAL, S. H. Spur-Gear-System Efficiency at Part and Full Load. NASA Technical Paper 1622. AVRADCOM Technical Report 79-46., n. February, 1980.

APONTE, C. F. C. Utilização do Método dos Elementos Finitos no Desenvolvimento de Modelos de Corte de Material. Dissertação - Programa de Pós- Graduação em Engenharia Civil da PUC-Rio., 2011.

ASM HANDBOOK, V. 18. v. 18. Friction, lubrication, and wear technology. 1992. v. 2

AVL LIST GMBH. AVL EXCITE PowerUnit Theory Overview, 2016.

BEILICKE, R.; BOBACH, L.; BARTEL, D. Transient thermal elastohydrodynamic simulation of a DLC coated helical gear pair considering limiting shear stress behavior of the lubricant. Tribology International, v. 97, p. 136-150, 2016.

BJÖRLING, M. Friction in elasto-hydrodynamic lubrication. Lulea University of Technology, 2014.

BLACK, J. T.; KOHSER, R. A. DeGarmo's and Processes Materials in Manufacturing. 11. ed. John Wiley \& Sons, Inc., 2012.

CASTRO, J.; SEABRA, J. Coefficient of friction in mixed film lubrication: Gears versus twin-discs. Proceedings of the Institution of Mechanical Engineers, Part J: Journal of Engineering Tribology, v. 221, n. 3, p. 399-411, 2007.

CASTRO, R. M. D. E. Critério de Projeto para Engrenagens Helicoidais Aplicadas em Transmissões Mecânicas Veiculares. Dissertação. Escola Politécnica. Universidade de São Paulo, 2005.

DOWSON, D. Thin Films in Tribology. Tribology Series, v. 25, n. C, p. 3-12, 1993. 
DUNNE, F.; PETRINIC, N. Introduction to Computational Plasticity. Oxford: Oxford University Press, 2005.

FERNANDES, C. M. C. G.; MARTINS, R. C.; SEABRA, J. H. O. Tribology International Torque loss of type C40 FZG gears lubricated with wind turbine gear oils. Tribiology International, v. 70, p. 83-93, 2014.

FERNANDES, C. M. C. G.; MARTINS, R. C.; SEABRA, J. H. O. Coefficient of friction equation for gears based on a modified Hersey parameter. Tribology International, v. 101, p. 204-217, 2016.

FERREIRA FILHO, V. S. et al. Inovar-Auto \& Alianças Estratégicas : Um novo cenário de cooperação para Montadoras e Fornecedores de Auto-peças. 2013.

FIGUEIREDO, T. P. Effect of Lubricant Properties on the Friction Coefficient under Different Temperatures, Speeds and Loads Using a Ball-on-Disc Test. Dissertação. Escola Politécnica. Universidade de São Paulo, 2017.

FISCHER, R. et al. The Automotive Transmission Book. Springer International Publishing Switzerland, 2015.

FRANÇOSO, J. H. R. Análise de Modelos de Rendimento de Engrenagens e Aplicação em Câmbios Manuais Automotivo. Escola Politécnica. Universidade de São Paulo, 2009.

FUKUMASU, N. K. et al. Stress Analysis to Improve Pitting Resistance in Gear Teeth. Procedia CIRP, v. 45, p. 255-258, 2016.

HAMMAMI, M. Efficiency and Wear in Automotive Gear Transmissions. Tese. Faculdade de Engenharia. Universidade do Porto, 2017.

HAMROCK, J. Fundamentals of Fluid Film Lubrication. Columbus, Ohio: The Ohio State University, 1991.

HEINGARTNER, P.; MBA, D. Determining Power Losses in Helical Gear Mesh: Case Study. Volume 4: 9th International Power Transmission and Gearing Conference, Parts A and B, v. 2003, n. June, p. 965-970, 2003.

HÖHN, B.-R.; MICHAELIS, K.; KREIL, O. Ã. Influence of surface roughness on pressure distribution and film thickness in EHL-contacts. Tribology International, $v$. 39, n. 12, p. 1719-1725, 2006.

HOLMBERG, K.; ANDERSSON, P.; ERDEMIR, A. Global energy consumption due to friction in passenger cars. Tribology International, v. 47, p. 221-234, 2012.

HUTCHINGS, I. M. Tribology Friction and wear of engineering materials. Cambridge: Departament of Materials Science and Metallurgy, University of Cambridge, 1992.

HUTCHINGS, I.; SHIPWAY, P. Tribology: Friction and Wear of Engineering Materials. Cambridge-Kidlington: Elsevier Ltd, 2017.

INOVAR-AUTO. Conheça o INOVAR-AUTO, 2012.

ISO 4288. Especificações geométricas de produto (GPS) - Rugosidade: Método do 
perfil - Regras e procedimentos para avaliação de rugosidade, 2012.

ISO INTERNATIONAL STANDARD. ISO 6336-1 : Calculation of load capacity of spur and helical gears. v. 2006, p. 1-8, 2006.

JACOBSON, B. The Stribeck memorial lecture. Tribology International, v. 36, n. 11, p. 781-789, 2003.

KLEIN, M. M. Zur Fresstragfähigkeit von Kegelrad- und Hypoidgetrieben. PhD Thesis, TU München, 2012.

KLUBER, K. L. M. K. Lubrication of Gear Systems, 1998.

KREIL, O. Einfluss der Oberflächenstruktur auf Druckverteilung und Schmierfilmdicke im EHD-Kontakt. Tese. Departamento de Elementos de Máquinas. Technischen Universität München, 2008.

KRUPKA, I.; SPERKA, P.; HARTL, M. Effect of surface roughness on lubricant film breakdown and transition from EHL to mixed lubrication. Tribology International, $v$. 100, p. 116-125, 2016.

KUIVANIEMI, T. et al. Dynamic Gear Wheel Simulations using Multibody Dynamics. Rakenteiden Mekaniikka, v. 50, n. 3, p. 287, 2017.

LI, S. et al. Influence of Design Parameters on Mechanical Power Losses of Helical Gear Pairs. Journal of Advanced Mechanical Design, Systems, and Manufacturing, v. 3, n. 2, p. 146-158, 2009.

LIN, L. Assessment of Effects of Surface Roughness and Oil Viscosity on Friction Coefficient under Lubricated Rolling-sliding Conditions (Analysis of Lubrication Modes Based on EHL Theory). v. 59, n. 166, p. 1-7, 2013.

LOTTI, R. S. et al. Aplicabilidade científica do método dos elementos finitos. Dental Press de Ortodontia e Ortopedia Facial, p. 35-43, 2006.

MACHADO, G. A. A. Eficiência de uma transmissão automotiva e do comportamento tribológico em regimes de lubrificação aplicados à engrenagens automotivas. Escola Politécnica. Universidade de São Paulo, 2018.

MUMINOVIC, A.; REPCIC, N.; COLIC, M. Thermo elasto hydrodynamic lubrication model of mixed friction. Procedia Engineering, v. 69, p. 49-56, 2014.

NAUNHEIMER, H. et al. Automotive Transmissions Fundamentals, Selection, Design and Application, 2011.

NBR ISO 4287. Especificações geométricas do produto (GPS) - Rugosidade: Método do perfil - Termos, definições e parâmetros da rugosidade. ABNT - Associação Brasileira de Normas Técnicas, p. 18, 2002.

NORTON, R. L. Projeto de máquinas: uma abordagem integrada, 2013.

PARKER, R. G.; VIJAYAKAR, S. M.; IMAJO, T. Non-Linear Dynamic Response of a Spur Gear Pair: Modelling and Experimental Compariosons. Journal of Sound and <ibration, v. 237, n. 3, p. 435-455, 2000. 
PIRRO, D. M.; WEBSTER, M.; DASCHNER, E. Lubrication Fundamentals. Igarss 2014, n. 1, p. 1-515, 2016.

QIN, W. J.; GUAN, C. Y. An investigation of contact stresses and crack initiation in spur gears based on finite element dynamics analysis. International Journal of Mechanical Sciences, v. 83, p. 96-103, 2014.

SAMPAIO, M. A. B. Mecânica do Contato com o Método dos Elementos de Contorno para Modelagem de Máquinas Tuneladoras. Dissertação. Engenharia de Estruturas. Universidade de São Paulo, 2009.

SÁNCHEZ, M. B.; PEDRERO, J. I.; PLEGUEZUELOS, M. Critical stress and load conditions for bending calculations of involute spur and helical gears. International Journal of Fatigue, v. 48, p. 28-38, 2013.

SCHLENK, L. Unterscuchungen zur Fresstragfähigkeit von Grozahnrädern. Tese. T.U.München, 1994.

SEABRA, J. Engrenagens: Lubrificação, Rendimento e Avarias. Faculdade de Engenharia do Porto, 2005.

SERIACOPI, V. Simulação numérica do campo de tensões na microestrutura do aço ferramenta aisi h13 durante o forjamento a quente. Dissertação. Engenharia Mecânica de Projeto de Fabricação, 2013.

SOPOUCH, M.; RESCH, T.; HERSTER, P. Analysis of Gearbox Acoustics with AVL EXCITE Analysis of Gearbox Acoustics with AVL EXCITE. AVL List GmbH, A-8020 Graz, Hans-List-Platz 1, n. June, 2016.

SOUSA, R. A. DE. Adaptatividade geométrica e numérica na geração de malhas de elementos finitos em 2D e 3D. Dissertação. Engenharia Civil. PUC-Rio, 2007.

SOUZA, G. L. DE; BRACARENSE, A. Q.; MASSARANI, M. Residência tecnológica para engenheiros. p. 620-625, 2016.

STAVYTSKYY, V. et al. Load-Independent Power Losses of Gear Systems: A Review. TEKA Kom. Mot. i Energ. Roln, p. 205-213, 2010.

TAVARES, M. R. S.; TAVARES, J. M. R. S. CFAC: Indicação dos Estados de Superfície, 2012.

TERTULIANO, I. DA S. Textura superficial: Efeito sobre o desempenho de óleos aditivados e não aditivados em ensaios alternados. Dissertação. Engenharia Mecânica de Projetos e Fabricação. Universidade de São Paulo, 2017.

TURNER, M. J. et al. Stiffness and Deflection Analysis of Complex Structures. JOURNAL OF THE AERONAUTICAL SCIENCES, v. 23, n. 9, p. 805-823, 1956.

VAIDYANATHAN, A. An Experimental Investigation of Helical Gear Efficiency. PhD Thesis, Ohio State University, p. 1-122, 2009.

VILLALVA, S. G. Análise de virabrequins automotivos utilizando modelos analíticos e flexíveis. p. 268, 2013.

WANG, D. S.; LIN, J. F. Effect of surface roughness on elastohydrodynamic lubrication 
of line contacts. Tribology International, v. 24, n. 1, p. 51-62, 1991.

WEI, J.; ZHANG, A.; GAO, P. A study of spur gear pitting under EHL conditions: Theoretical analysis and experiments. Tribology International, v. 94, p. 146-154, 2016.

XLROTOR. Lubricant Data Base and Properties Calculator. Disponível em: <https://www.xlrotor.com/index.php/solutions/data-sheet>. Acesso em: 10 mar. 2019. 


\section{APÊNDICE A}

\subsection{SUBROTINA}

C

c User subroutine VFRICTION to define friction forces

C

subroutine vfriction (

c Write only -

* fTangential,

c Read/Write -

* state,

c Read only -

* nBlock, nBlockAnal, nBlockEdge,

* nNodState, nNodSlv, nNodMst,

* nFricDir, nDir,

* nstates, nProps, nTemp, nFields,

* jFlags, rData,

* surfint, surfSlv, surfMst,

* jConslvUid, jConMstUid, props,

* dSlipFric, fStickForce, fTangPrev, fNormal,

* dircosN, dircossl,

* shapeSlv, shapeMst,

* coordSlv, coordMst,

* velslv, velMst,

* tempslv, tempMst,

* fieldSlv, fieldMst,

* pressure )

C

include 'vaba_param.inc'

dimension fTangential(nFricDir, nBlock),

* state(nstates, nNodState, nBlock),

* jConslvUid(nNodSlv, nBlock),

* jConMstUid(nNodMst, nBlockAnal),

* props(nProps),

* dSlipFric(nDir,nBlock),

* fStickForce(nBlock),

* fTangPrev(nDir, nBlock),

* fNormal(nBlock),

* $\operatorname{areaSlv}(\mathrm{nBlock})$,

* $\operatorname{dir} \cos N(n D i r, n B l o c k)$,

* dircossl(nDir, nBlock),

* ShapeSlv(nNodSlv, nBlockEdge),

* shapeMst (nNodMst, nBlockAnal),

* coordSlv(nDir, nNodSlv, nBlock),

* coordMst (nDir, nNodMst, nBlockAnal),

* velSlv(nDir, nNodSlv, nBlock),

* velMst(nDir, nNodMst, nBlockAnal),

* tempSlv(nBlock),

* tempMst (nBlockAnal),

* fieldSlv(nFields, nBlock),

* fieldMst(nFields, nBlockAnal),

* pressure (nBlock)

\begin{tabular}{|c|c|c|}
\hline parameter & iKStep & $=1$, \\
\hline$*$ & iKInc & $=2$, \\
\hline$*$ & iLConType & $=3$, \\
\hline$*$ & nFlags & $=3$ ) \\
\hline parameter & iTimstep & \\
\hline$*$ & iTimGlb & \\
\hline
\end{tabular}




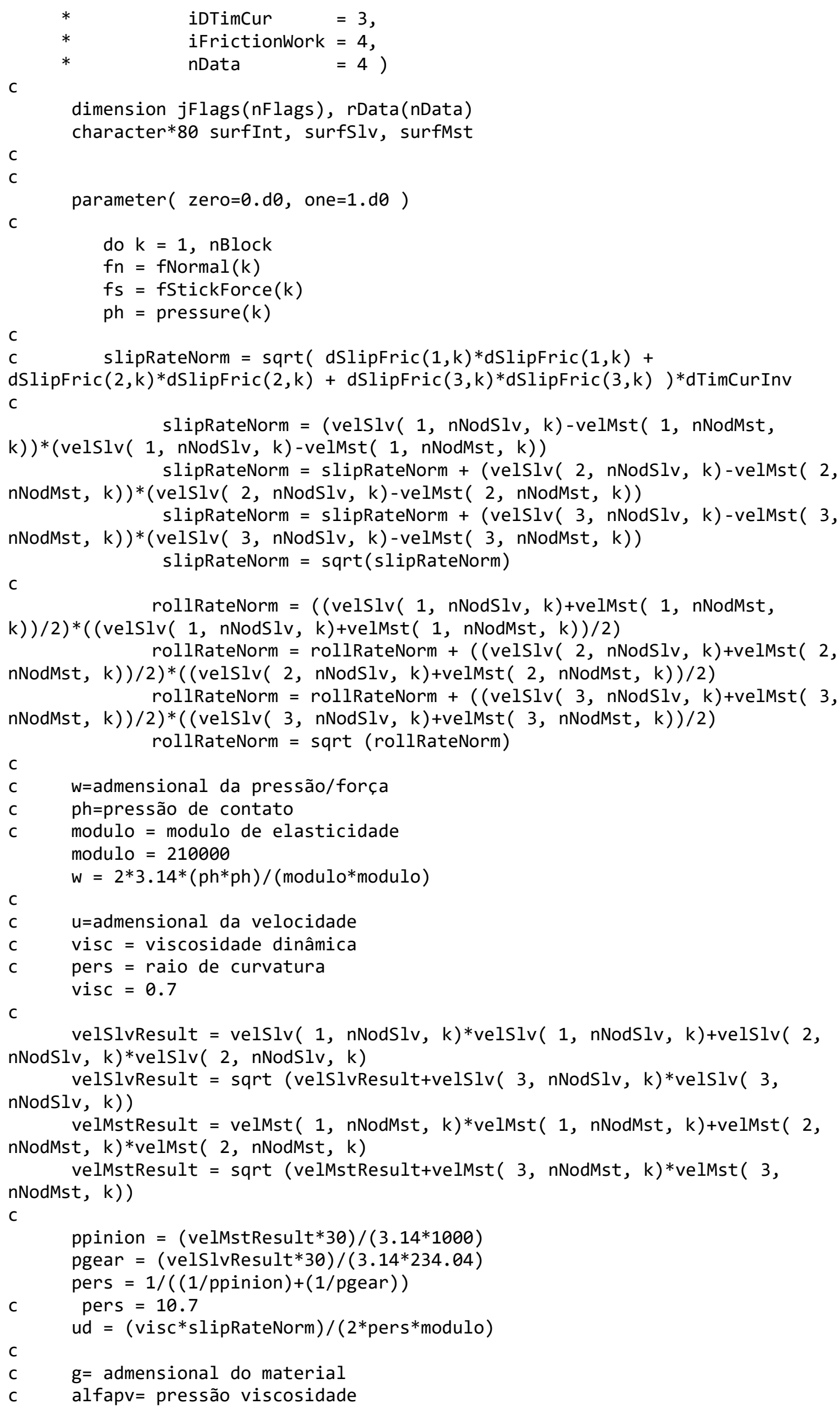




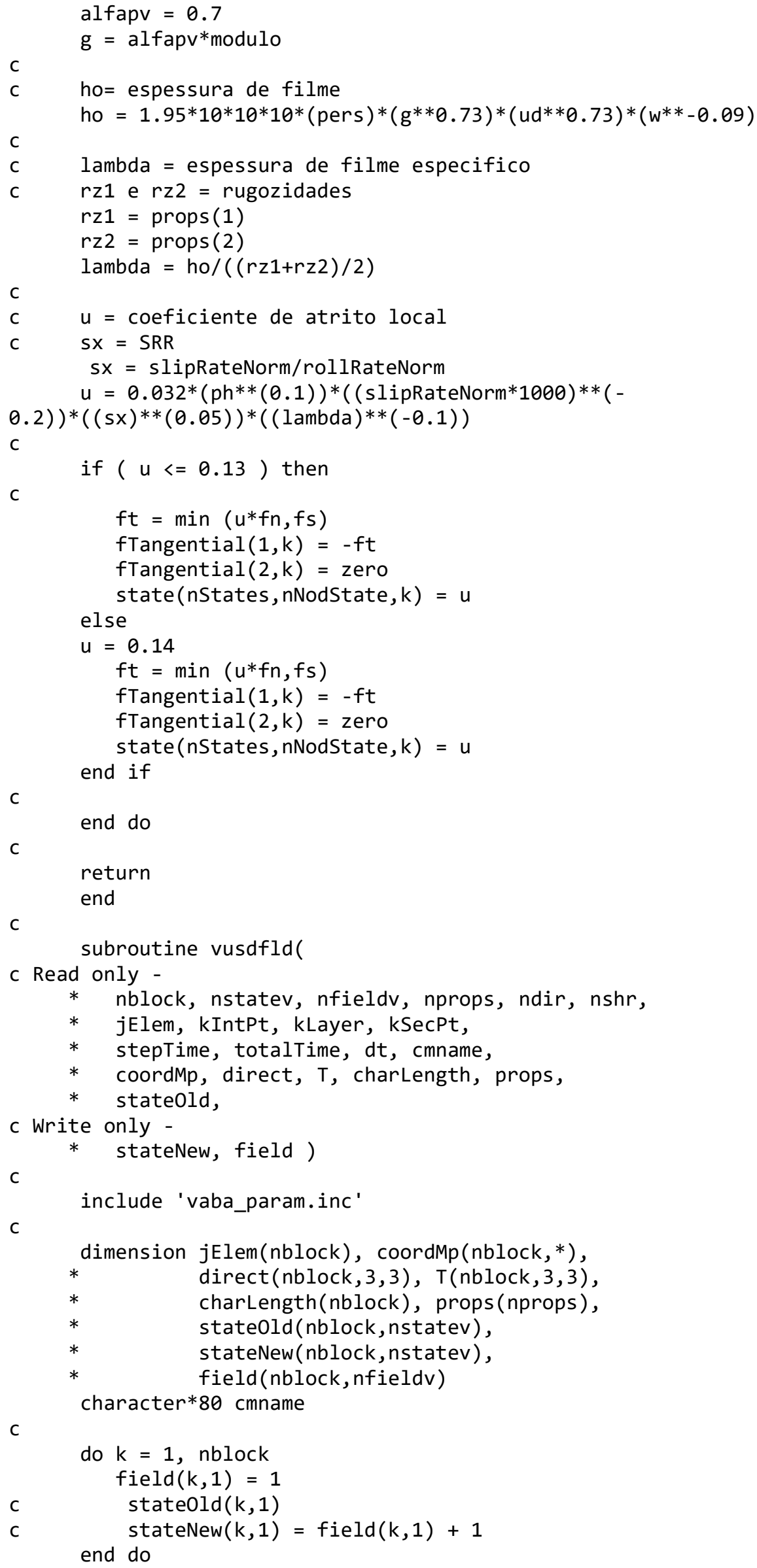




\section{C}

return

end 